\title{
Intensified green production of astaxanthin from
}

Haematococcus pluvialis.

\author{
by \\ Fatima Nasrin Haque
}

A Thesis
presented to
The University of Guelph

In partial fulfilment of requirements

for the degree of

Masters of Applied Science

in Biological Engineering

Guelph, Ontario, Canada

(c) Fatima N. Haque, August, 2016 


\section{ABSTRACT \\ Intensified green production of astaxanthin from}

\section{Haematococcus pluvialis.}

Fatima Nasrin Haque

University of Guelph

2016

\author{
Advisor: Dr. Yi Wai Chiang \\ Co - Advisor: Dr. Animesh Dutta \\ Committee Member: Dr. Mahendra Thimmanagari
}

The work presented in this study demonstrated the use of the wastewater generated by a bioethanol production plant as a potential growth media for the microalgae, Haematococcus pluvialis, growth, as well as astaxanthin production. A high density (4.37 $\pm 0.007 \mathrm{~g} / \mathrm{l}$ ) biomass culture was obtained by culturing $H$. pluvialis in an air - lift photobioreactor, supplemented with $5 \%$ carbon dioxide gas.

This study evaluated the effectiveness of ultrasound in microalgal cell disruption and astaxanthin extraction. Total astaxanthin extracted (TAE) was $38 \pm 2.55 \mathrm{mg} / \mathrm{g}$, by pretreating the astaxanthin rich cells with ultrasound with $2 \mathrm{M}$ sodium hydroxide for 25 min, followed by solvent extraction using methanol.

The residual Haematococcus biomass, obtained after astaxanthin extraction, was characterized as a potential biofuel feedstock. Hence, H. pluvialis helps in wastewater utilization, carbon dioxide uptake, production of high-value astaxanthin, as well as it has a potential to be used as a biofuel feedstock. 


\section{DEDICATION}

This thesis is dedicated to my

Parents: Dr. Md. Noorul Haque and Nasrin Haque. 


\section{ACKNOWLEDGEMENTS}

I would like to thank my advisor, Dr. Emily Chiang, without her this thesis would not have been possible. It was because of her support I was honored with the prestigious OMAFRA HQP scholarship. I would like to extend my appreciation towards Dr. Animesh Dutta (University of Guelph) and Dr. Mahendra Thimmanagari (OMAFRA), for their guidance throughout the duration of my research.

I am also thankful to Ryan Smith, Joanne Ryks, Mike Speagle, Harpreet, Arefeh, Zainab, Manar, and Sharif. I would like to thank Regis Benech and Hisham Hafez for giving me the opportunity to complete my summer work term at Greenfield Specialty Alcohols. My work term would not have been a successful one without the guidance of Mohammad and Nicole, and all the lab technicians and analysts: Simon, Jenny, Adam and Mike.

Finally, I would like to thank my friends Sunil, Vidya, Sekhar, Hitesh, Kazi, Abhishek, Anu, Ramneek, Cyndhya, Simranjit, Adarsh, Kushan, and Nishant, for their encouragement, and for being there as a family. 


\section{TABLE OF CONTENT}

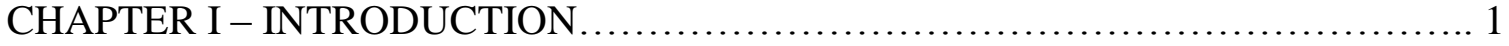

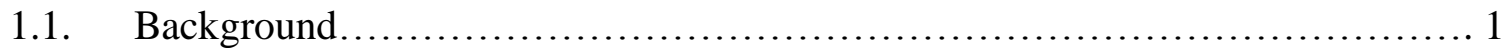

1.2. Scope and objectives........................................................ 5

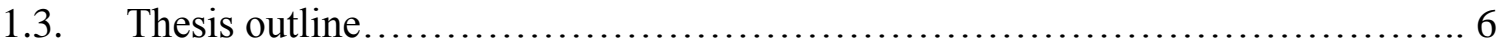

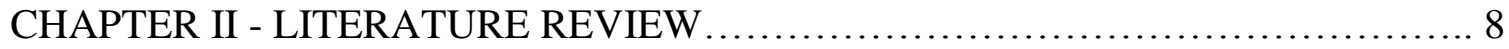

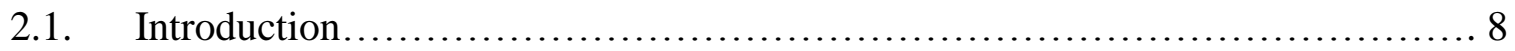

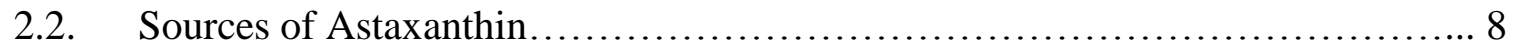

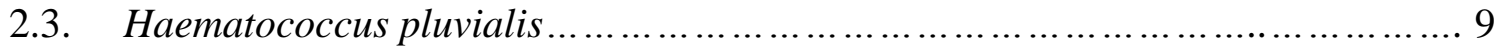

2.4. Growth Media.............................................................. 10

2.5. Cultivation system.................................................. 13

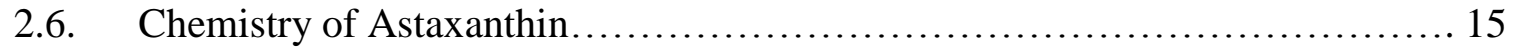

2.7. Extraction of Astaxanthin.................................................... 16

2.7.1. Ultrasound Assisted Extraction (UAE) ............................ 18

2.7.2. Microwave Assisted Extraction (MAE) .............................. 19

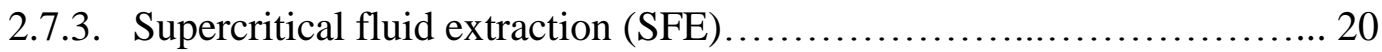

2.8. Application of Astaxanthin.............................................. 21

2.8.1. Aquaculture..................................................... 21

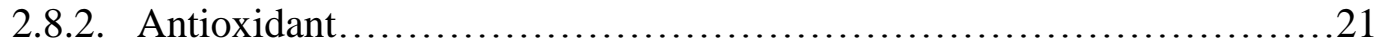

2.8.3. Human Health.........................................................22

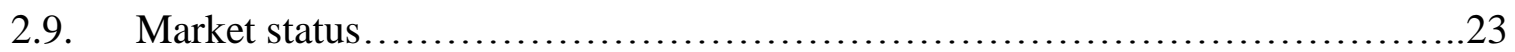

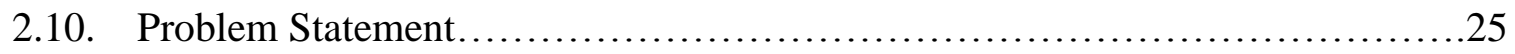

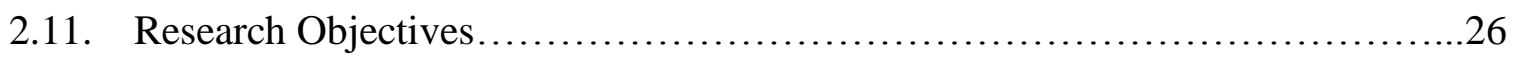




\section{CHAPTER III - INTENSIFIED GREEN PRODUCTION OF ASTAXANTHIN FROM}

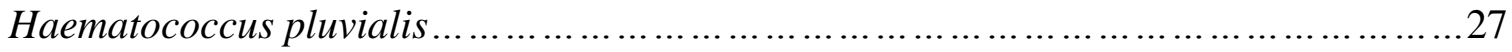

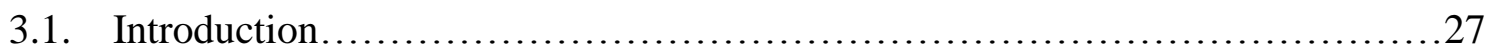

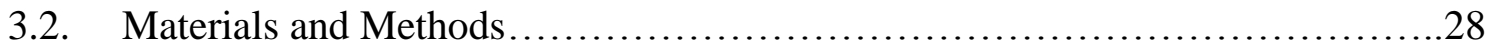

3.2.1. Wastewater Sampling and Characterization...........................28

3.2.2. Microalgal Stock and Cultivation..................................28

3.2.3. Microalgal Growth and Astaxanthin Accumulation in Bioethanol

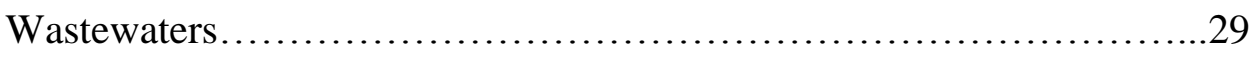

3.2.4. Astaxanthin Extraction..................................................

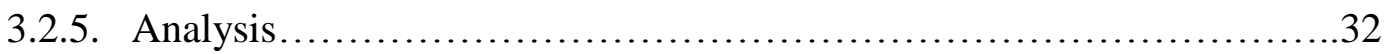

3.2.5.1. Cell and Cyst Density Determination.............................32

3.2.5.2. Astaxanthin Extraction Yield Determination.....................32

3.2.5.2. Extractability Calculation.....................................33

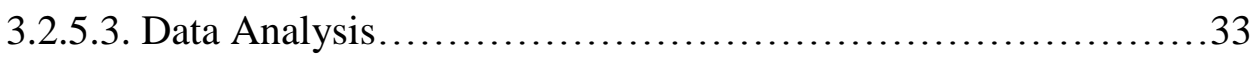

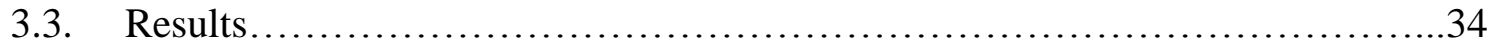

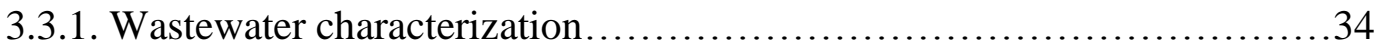

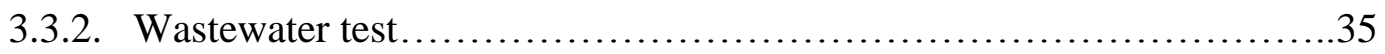

3.3.2.1. Effect of wastewater dilutions.................................. 35

3.3.2.2. Effect of different wastewater samples and formulations..........36

3.3.3. Screening of effective medium for cell disruption......................39

3.3.3.1. Effect of cell-disrupting chemicals.............................39

3.3.3.2. Effect of sodium hydroxide concentration and extraction time...43

3.3.3.3. Effect of solvents coupled with ultrasonication..................44

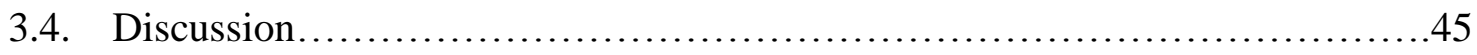

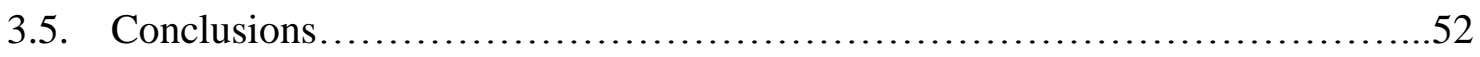


CHAPTER IV - CHARACTERIZATION OF THE Haematococcus pluvialis RESIDUAL BIOMASS, OBTAINED AFTER ASTAXANTHIN EXTRACTION, AS A POTENTIAL

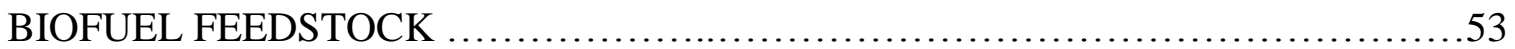

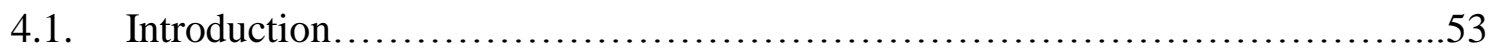

4.2. Materials and Methods..................................................... 56

4.2.1. Microorganism, media, and cultivation condition.....................56

4.2.2. Enhanced Biomass Production of H. pluvialis............................57

4.2.2.1. Effect of $\mathrm{CO}_{2}$ on algal growth in an air-lift batch photobioreactor.......................................57

4.2.2.2. Astaxanthin extraction..................................... 59

4.2.3. Analysis..................................................6 60

4.2.3.1. Growth and astaxanthin accumulation curve estimation........6 60

4.2.3.2. Initial and Final Wastewater characterization..................6 60

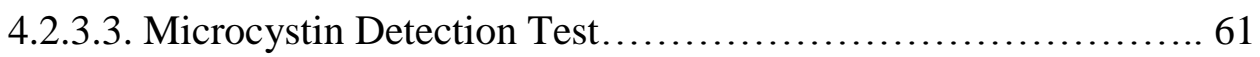

4.2.3.4. Residual algal biomass characterization.................... 62

4.2.3.4.1. Proximate and Ultimate Analysis, and High Heating

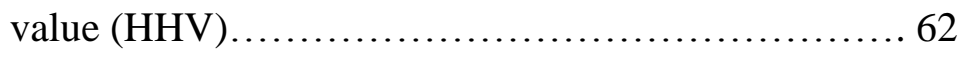

4.2.3.4.2. FTIR Analysis................................ 63

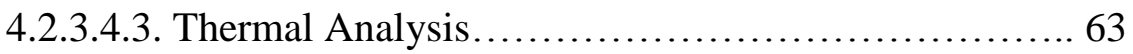

4.2.3.5. Data Analysis............................................. 63

4.3. Results ....................................................... 64

4.3.1. Effect of $\mathrm{CO}_{2}$ on $H$. pluvialis growth............................ 64

4.3.2. Comparison of initial and final characteristics of the wastewater media...67

4.3.3. Microcystin Detection Test...................................6 68

4.3.4. Characterization of residual $H$. pluvialis biomass.....................69 
4.3.4.1. Proximate and Ultimate Analysis

4.3.4.2. FTIR Spectra........................................71

4.3.4.3. Thermal Analysis.....................................73

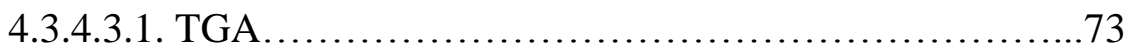

4.3.4.3.2. Analysis of the gas evolved during TGA process......75

4.4. Discussion...................................................... 77

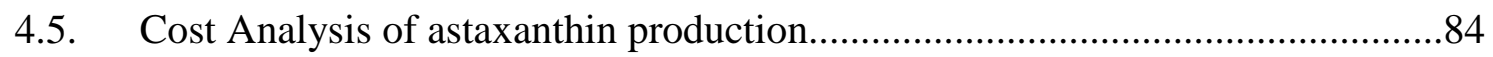

4.6. Conclusion..................................................... 88

CHAPTER V - OVERALL CONCLUSIONS AND RECOMMENDATIONS..........89

5.1. Conclusions........................................................ 89

5.1.1. H. pluvialis growth and astaxanthin accumulation in wastewater........89

5.1.2. High-density cultivation of $H$. pluvialis in Air-Lift

Photobioreactor............................................90

5.1.3. Intensified Recovery of Astaxanthin using ultrasonication..............90

5.1.4. Nutrient removal from the wastewater............................91

5.1.5. Residual Haematococcus biomass is a potential biofuel feedstock........91

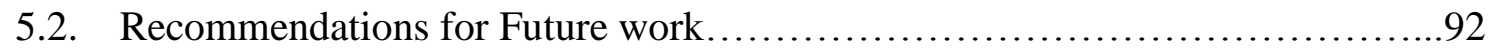

References..........................................................93 


\section{LIST OF FIGURES}

Figure 2.1: Two life phases of $H$. pluvialis ............................................................ 10

Figure 2.2: Paddle wheel Raceway pond used by Cyanotech Corporation, Hawaii .........14

Figure 2.3: Closed Photobioreactor used at Algecan Biotech Ltd, Canada .....................15

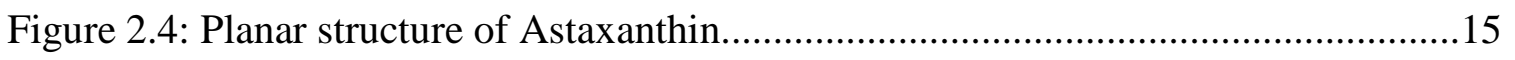

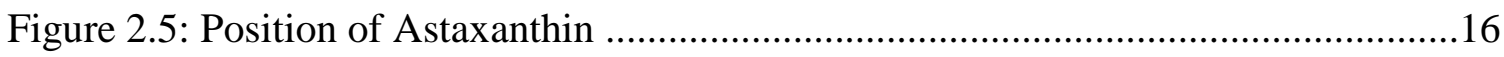

Figure 2.6: Principle of ultrasonication .................................................................. 18

Figure 2.7: Schematic diagram of microwave extraction unit .....................................19

Figure 2.8: Phase Diagram showing the supercritical fluid region ...............................20

Figure 2.9: Different forms of astaxanthin available in the market: algal biomass (left)

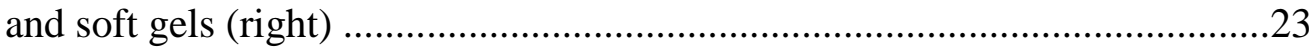

Figure 3.1: (a) Thin Stillage, (b) Process Condensate, (c) Scrubber/Dryer Sample .........28

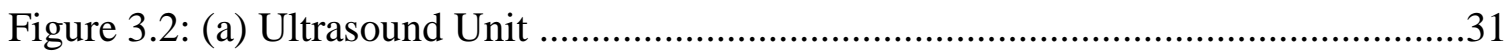

(b) Schematic outline of the ultrasound set up used in the study ..................31

Figure 3.3: Growth curve of $H$. pluvialis in $\mathrm{S} 1$ wastewater dilutions, expressed as total cell density measured by OD $(670 \mathrm{~nm})$................................................. 36

Figure 3.4: (a) Growth curve of $H$. pluvialis in culture medium formulated from wastewater, expressed as total cell density measured by OD $(670 \mathrm{~nm})$......38

(b) Cyst accumulation curve in culture medium formulated from wastewater, expressed as cyst density measured by OD (450 nm) 38

Figure 3.5: H. pluvialis growth and astaxanthin accumulation in GroAst Media ............39

Figure 3.6: Microscopic observation of $H$. pluvialis cells in (a) vegetative stage ...........40

(b) cyst stage (without pretreatment) ….............................................. 40

(c) after pretreatment with sodium hydroxide (2M) .................................40 
(d) after pretreatment with hydrogen peroxide (2M) ..................................40

(e) after pretreatment with acetic acid $(5 \mathrm{M})$................................................40

(f) after pretreatment with citric acid $(5 \mathrm{M})$...............................................40

Figure 3.7: (a) Effect of pretreatment chemicals and pretreatment time on cell disruption, expressed as OD after solvent (methanol) extraction .....................................42

(b) Effect of sodium hydroxide concentration and pretreatment time on cell disruption, expressed as OD after solvent (methanol) extraction ..................42

Figure 3.8: Astaxanthin extraction amounts using different intensified approaches compared to controls; in order of increasing TAC .45

Figure 3.9: Schematic diagram of bioethanol production, wastewater generation, and proposed microalgal culture and astaxanthin production

Figure 3.10: Mechanism of sodium hydroxide action .49

Figure 4.1: Schematic diagram of bioethanol production, wastewater generation, and proposed microalgal culture with $\mathrm{CO}_{2}$, astaxanthin production, and residual biomass utilization .54

Figure 4.2: (a) Experimental Set up for H. pluvialis culture .58

(b) The photobioreactor used for the study .58

Figure 4.3: Growth and astaxanthin accumulation curve at different concentration of $\mathrm{CO}_{2}$ gas supply .65

Figure 4.4: Biomass density at different $\mathrm{CO}_{2}$ gas supply ............................................66

Figure 4.5: Dried astaxanthin rich H. pluvialis biomass ................................................66

Figure 4.6: Microcystin calibration Curve …………………......................................69

Figure 4.7: FTIR Spectrum of astaxanthin-rich algae and residual biomass ....................71

Figure 4.8: The TGA-DTG curve of residual biomass at $10{ }^{\circ} \mathrm{C} / \mathrm{min}$ heating flow rate.. .75

Figure 4.9: FTIR Spectrum of the gasses evolved during the TGA process .....................76

Figure 4.10: Variation of the Total dissolved carbonate concentration $\left(\mathrm{C}_{\mathrm{T}}\right)$ relative to $\mathrm{pH}$. .79 


\section{LIST OF TABLES}

Table 2.1: Sources of Astaxanthin...................................................... 9

Table 2.2: Nutrient composition of different growth media............................11

Table 2.3: TN and TP content in different wastewater sources....................................... 13

Table 2.4: Different astaxanthin extraction method.................................17

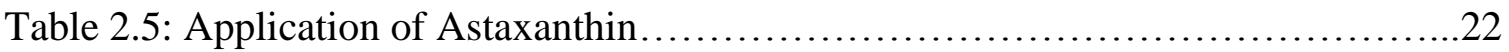

Table 2.6: Manufacturers of Natural Astaxanthin ..................................24

Table 3.1: Wastewater characteristics and nutrient composition of the culture media ......35

Table 3.2: Astaxanthin Content, Extractability, and RACI Estimation ...................43

Table 3.3: Comparison of astaxanthin content extracted from ultrasonicated (25 min) microalgal cells (a) not pretreated and (b) pretreated with $2 \mathrm{M}$ sodium hydroxide ....................................................... 44

Table 4.1: $\mathrm{pH}$ change and specific growth rate at different $\mathrm{CO}_{2}$ concentrations ...........67

Table 4.2: Wastewater characterization and percentage nutrient removal ................68

Table 4.3: Microcystin concentration in the H. pluvialis sample ..........................69

Table 4.4: Characterization of residual Haematococcus Biomass .......................70

Table 4.5: Characteristic bands observed in the biomass ..............................73

Table 4.6: Characteristic bands observed in the evolved gas ...........................76

Table 4.7: Ultimate Analysis of different biomass sources .............................................82

Table 4.8: Selection of a suitable biofuel conversion technology .......................83

Table 4.9: Cost analysis of astaxanthin production in bioethanol waste stream .................87 


\section{LIST OF ABBREVIATONS}

$\begin{array}{ll}\text { A } & \text { Absorbance } \\ \text { AL }- \text { PBR } & \text { Air-lift photobioreactor } \\ \text { AMD } & \text { Age related macular degeneration } \\ \text { ASTM } & \text { American Society for Testing and Materials } \\ \text { BG11 } & \text { Blue Green 11 } \\ \text { BOD } & \text { Biological Oxygen Demand } \\ \text { BM } & \text { Basal Media } \\ \text { CEPA } & \text { Canadian Environment Protection Agency } \\ \text { CO } & \text { Carbon dioxide } \\ \text { DMSO } & \text { Dimethyl Sulphoxide } \\ \text { DO } & \text { Dissolved Oxygen } \\ \text { FTIR } & \text { Fourier transform infrared spectroscopy } \\ \text { DTG } & \text { Derivative thermogravimetric graph } \\ \text { DW } & \text { Dry weight } \\ \text { EC } & \text { Environment Canada } \\ \text { EFSA } & \text { European Food and Safety Authority } \\ \text { EDA } & \text { Food and Drug Administration } \\ \text { DW } & \end{array}$




\begin{tabular}{|c|c|}
\hline GHG & Greenhouse gas \\
\hline GRAS & Generally Regarded as Safe \\
\hline $\mathrm{H} / \mathrm{C}$ & Hydrogen: Carbon ratio \\
\hline HHV & High heating value \\
\hline $\mathrm{HCl}-\mathrm{ACE}$ & Hydrochloric acid - Acetone \\
\hline LDL & Low density lipoprotein \\
\hline MAE & Microwave assisted extraction \\
\hline $\mathrm{MC}$ & Microcystin \\
\hline MCM & Marine Culture Media \\
\hline $\mathrm{N}$ & Nitrogen \\
\hline $\mathrm{NaOH}$ & Sodium Hydroxide \\
\hline NAABB & National Alliance for Advanced Biofuels and Bioproducts \\
\hline NREL & National renewable Energy Laboratory \\
\hline NTU & Nephelometric Turbidity Units \\
\hline $\mathrm{O} / \mathrm{C}$ & Oxygen: Carbon ratio \\
\hline OD & Optical Density \\
\hline $\mathrm{P}$ & Phosphorous \\
\hline PBR & Photobioreactor \\
\hline RACI & Relative Astaxanthin Content Increase \\
\hline
\end{tabular}




$\begin{array}{ll}\text { S1 } & \text { Thin stillage sample } \\ \text { S2 } & \text { Process condensate sample } \\ \text { SFE } & \text { Scrubber / Dryer Wastewater sample } \\ \text { TAC } & \text { Supercritical Fluid extraction } \\ \text { TAE } & \text { Total Astaxanthin Content } \\ \text { TAG } & \text { Triacylglycerides } \\ \text { TGA } & \text { Thermogravimetric Analysis } \\ \text { TN } & \text { Total Nitrogen } \\ \text { TOC } & \text { Total Organic Carbon } \\ \text { TP } & \text { Total Phosphorous } \\ \text { UAE } & \text { Ultrasound Assisted Extraction } \\ \text { US } & \text { Ultrasonication } \\ \text { UV } & \text { Ultraviolet } \\ \text { V } & \text { Volume of sample (ml) } \\ \text { Volatile matter } \\ \text { Dry Weight of microalgal cells (g) }\end{array}$




\section{ACCOMPLISHMENTS}

- Fatima Haque, Animesh Dutta, Mahendra Thimmanagari, and Yi Wai Chiang, 2016. "Intensified green production of astaxanthin from Haematococcus pluvialis". Food and Bioproducts Processing. 99, 1-11. doi:10.1016/j.fbp.2016.03.002.

- "Intensified green production of microalgal astaxanthin from ethanol production waste streams", presented at "Microalgae Research \& Commercialization Forum", Guelph, Canada, 20th July 2016.

- "Studying the effect of dilution, mixing ratio and light on production of high value microalgal astaxanthin in bioethanol waste stream", presented at "World Congress on Industrial Biotechnology”, Montreal, Canada, 20-22 $2^{\text {nd }}$ July, 2015.

- "Producing high-value microalgal astaxanthin using wastewater from bioethanol industry" presented at "Ag Biomass Day", Guelph, Ontario, Canada, 27 $7^{\text {th }}$ Mar, 2015. 


\section{CHAPTER I - INTRODUCTION}

\subsection{Background}

Astaxanthin $\quad\left(3,3^{\prime}\right.$-dihydroxy- $\beta, \beta$-carotene-4,4'-dione $), \quad$ a $\quad$ xanthophyll ketocarotenoid that possesses stronger antioxidant property than beta-carotene and Vitamin E, has been of notable recent interest for pharmaceutical applications that include anti-ageing protection due to UV light photo-oxidation and inflammation (Sarada et al., 2006; Zou et al., 2013). Owing to its anticarcinogenic properties, this carotenoid also finds application for immune response enhancement and amelioration of tissue damage, in addition to treatment of cardiovascular diseases, diabetes, gastric ulcers and hypertension (Dong et al., 2014; Mendes-Pinto et al., 2001).

The two most common methods of astaxanthin production include chemical synthesis and biological synthesis from microalgae, yeast and crustaceans by-products. Synthetic astaxanthin is produced by dienolether condensation of alkyl ethers with acetals (Ruttimann, 1999), or by hydroxylation of canthaxanthin (Bernhard et al. 1984), and the synthetically produced astaxanthin consists of (3S, 3'S), (3R, 3'S), (3S, 3'R), (3R, 3'R), in the ratio 1:2:2:1 (Higuera-Ciapara et al., 2006). However, the active form of astaxanthin is (3S, 3'S) which is only $16.67 \%$ of the synthetic astaxanthin mixture. On the other hand, naturally produced astaxanthin is $(3 \mathrm{~S}, 3$ 'S) isomer, and possess 10 times stronger antioxidant property than the one's produced synthetically (Lorenz and Cysewski, 2000; Wan et al., 2014). Also, due to food safety concerns and low bioavailability of astaxanthin produced via the chemical route, the US Food and Drug Administration (FDA) has not approved synthetic astaxanthin for human consumption (Dong et al., 2014). Among the natural producers that include various microorganisms, microalgal species, and animals, 
the most effective producer is the unicellular microalgae Haematococcus pluvialis (Chlorophyceae). This microalga can produce $0.5-4.0 \%$ dry weight of astaxanthin during the palmella encysted stage under environmentally stressed conditions (Solovchenko, 2014)

Typically, Haematococcus is cultured in BM, BG11, and M1B5 medium, and chemical additives such as ferric or acetate anions are added to stress the cells, which causes a morphological change of vegetative cells into cyst cells (M. Kobayashi et al., 1997; Ruen-ngam et al., 2010; Solovchenko, 2014). In recent years, the integration of nutrient removal from agricultural, municipal, dairy and distillery wastewater by microalgae and simultaneous by-product generation has gained attention; this strategy has been termed phyco-valorization (Querques et al., 2015). Wastewater can provide the carbon source, water, and nutrients (nitrates and phosphates) that microalgae require for growth (Kang et al., 2006; Razzak et al., 2013). Using wastewater as the growing medium eliminates the dependency on costly culture media, hence reducing the overall production cost. Kang et al. has verified nitrogen and phosphorous uptake from primary treated wastewater by $H$. pluvialis for astaxanthin biosynthesis, and (Wang et al., 2014) reported that Chlorella vulgaris has $95.7 \% \mathrm{~N}$ uptake and $96.4 \% \mathrm{P}$ uptake efficiency from primary effluent collected from a local wastewater treatment plant containing $36.1 \mathrm{mg} / \mathrm{L} \mathrm{N}$ and 4.0 $\mathrm{mg} / \mathrm{L}$ P. In this study, wastewater generated from the bioethanol production plant will be used to cultivate $H$. pluvialis.

The primary challenge, however, is the extraction of astaxanthin. Its content within the cell (e.g. $9.2 \mathrm{mg} / \mathrm{g}$ as reported by Domínguez-Bocanegra et al.) makes up only a fraction of the total cell mass (red cyst comprises of $70 \%$ carbohydrates, $66 \%$ hexoses, $3 \%$ cellulose 
and 6\% proteins (Hagen et al., 2016)). In addition, the thick sporopollenin cell wall hinders astaxanthin extraction and bioavailability. Reported methods of extraction of astaxanthin include maceration, hydrodistillation, soxhlet extraction, solvent extraction (Sarada et al., 2006), enzyme-assisted solvent extraction, and extraction with vegetable oils (Kang and Sim, 2007). The major drawbacks of these methods include costly lytic enzymes, large solvent consumption, time-consuming processing, and violent mechanical disruption, resulting in thermal degradation of the unsaturated double-bonded astaxanthin due to the heat generated by prolonged homogenization. These drawbacks make the process less sustainable, cost ineffective and also lead to carotenoid loss due to oxidation (Ambati et al., 2014; Bonnie and Choo, 1999; Xiao et al., 2009). Dimethyl sulphoxide (DMSO) has been reported to extract the maximum amount of astaxanthin (Boussiba and Vonshak, 1991a), but traces of DMSO can be found in the final product, which is not approved by Food and Drug Administration (FDA) as safe for human consumption. In addition, the high cost of DMSO makes it less favorable for commercial scale-up (Wu et al., 2011).

Efficient performance of ultrasound application for breaking the cystic H. pluvialis and recovering astaxanthin has been demonstrated by (Ruen-ngam et al., 2010) using a bath sonicator, with 73\% recovery being reported, while (Kim et al., 2008) obtained 1.5 times higher astaxanthin yield when using sonication than without it. The ultrasound waves pass through the solvent creating cavities during the expansion cycle and contract during the compression cycle; as these alternating compression and expansion cycles pass, the cavities grown until reaching instability and finally collapsing violently, leading to a sudden localized increase in pressure and temperature. This phenomenon leads to enhanced mass transfer and consequent disruption of microalgal cell walls (Dong et al., 2014; 
Pasquet et al., 2011; Ranjan et al., 2010; Ruen-ngam et al., 2010; Zou et al., 2013). However, a bath sonicator, as reportedly used in literature, offers a non-uniform distribution of cavitations in the system, leading to low and uneven intensity environment, which results in longer extraction time for the desired outcome (Ruen-ngam et al., 2010). In this study, an ultrasound probe (horn) will be used instead of a bath, for pretreating the astaxanthin rich cells. The ultrasound probe provided high and evenly distributed intensity environment, which should result in shorter extraction time.

Though astaxanthin constitutes $0.5-4.0 \%$ dry weight of the total biomass (Solovchenko, 2014), it has a great market potential of USD \$ 2,500 per kg of astaxanthin (Zhu et al., 2011). For an effective production of this valuable product, high-density $H$. pluvialis culture is a pre-requisite, and this depends on the nutrient composition of the growth media, and the choice of photobioreactor (PBR). Different types of photobioreactor have been used to cultivate algae, such as bubble column reactor (Ranjbar et al., 2008) and air - lift reactor (Kaewpintong et al., 2007). H. pluvialis cells are shear sensitive, so mechanically stirred reactor is not a desirable option, and pneumatic agitation is preferred. For example, Kaewpintong et al., 2007 studied the cultivation of $H$. pluvialis in standard F1 medium using air - lift photobioreactor (AL - PBR) and supplemented with $1 \% \mathrm{CO}_{2}$, and was able to achieve $0.31 \mathrm{day}^{-1}$ of specific growth rate. B. Santhose et al., 2014 cultivates a new strain of $H$. pluvialis in modified BBM media in an AL-PBR and was able to achieve $3 \mathrm{~g}$ of dried algal biomass from $2.5 \mathrm{~L}$ of culture. Ranjbar et al., 2008 was able to achieve $5 \mathrm{~g} / \mathrm{l}$ of algal biomass by cultivating $H$. pluvialis in basal media and using a continuous supply of $\mathrm{CO}_{2}$ in a Bubble column reactor. In this study, an air - lift 
photobioreactor will be used, supplemented with carbon dioxide supply, for indoor cultivation of $H$. pluvialis.

\subsection{Scope and Objectives}

Where $H$. pluvialis has a strong influence in production of a sustainable, high value antioxidant, astaxanthin, most of the research work has primarily been focused on culturing this microalgae in standard, chemically synthesized, growth media. Also, large scale cultivation of $H$. pluvialis has been feasible in countries with warm tropical climate, where outdoor cultivation is possible.

However, cultivation of $H$. pluvialis in wastewater generated by a bioethanol production plant represents a sustainable way of astaxanthin production, as $H$. pluvialis can utilize the nutrients present in the wastewater for their growth, as well as astaxanthin accumulation. Furthermore, using an air-lift photobioreactor for indoor cultivation of $H$. pluvialis signifies a strong potential in the best ways to utilize wastewater as well as carbon dioxide uptake. Another advantage of using bioethanol waste stream is that it's non-toxic and harmless, free of heavy metal or biological contaminants, because the bioethanol is produced from corn kernels, and such wastewater samples, generated by a brewery industry or a food industry, are generally high in suspended solids, TP, TN, COD and BOD (Fillaudeau et al., 2006; Gugała et al., 2015). This implies that the astaxanthin produced using such wastewater will be free of safety concerns arising due to the raw material used.

Extensive variety of literature review is available on astaxanthin production by culturing $H$. pluvialis under different stress conditions (light, nutrient, and salinity), however, very few studies exist that has examined culturing $H$. pluvialis in nutrient rich wastewater from biological industry process. The primary goal of the work presented in 
this thesis is intensified and green production of astaxanthin by optimizing the growth media conditions, in order to formulate a media to support high-density $H$. pluvialis culture, as well as astaxanthin production, and using ultrasound assisted extraction method for astaxanthin recovery. This work will be useful to investors and researchers in integrating astaxanthin production along with bioethanol production plant, as an added revenue stream, and to determine the potential of phyco-valorization for a wide range of industrial and environmental applications.

\subsection{Thesis Outline}

This thesis is organized as below:

Chapter II: Literature review chapter contains background information on astaxanthin; sources, structure, and applications, Haematococcus pluvialis, different growth media used for cultivation, cultivation systems; closed and open system, different astaxanthin extraction techniques, and market status of astaxanthin. This chapter ends with the problem statement and the research objectives.

Chapter III: The main objective of this chapter is to culture H. pluvialis in wastewater from bioethanol production and test the effect of wastewater dilutions, different wastewater samples, and formulation, in order to come up with an appropriate media. The second part of this chapter evaluates the effect of different cell - disrupting chemicals, the effect of different concentration of sodium hydroxide and extraction time, and the effect of different solvents coupled with ultrasonication for astaxanthin recovery. Several testing 
methods used for each experiment has been explained, followed by results and discussion.

Chapter IV: After formulating a growth media for $H$. pluvialis cultivation and astaxanthin production, a high-density culture was obtained in a $2.2 \mathrm{~L}$ Airlift photobioreactor ( $\mathrm{AL}-\mathrm{PBR})$. The effect of different concentration of carbon dioxide on $H$. pluvialis growth was examined. The wastewater was analyzed before and after the astaxanthin production, in order to understand the nutrient removal potential of $H$. pluvialis. Also, Microcystin detection test was carried out to evaluate the safety of astaxanthin produced using wastewater. In addition, the residual Haematococcus biomass, obtained after astaxanthin extraction, was characterized to evaluate its potential as a biofuel feedstock.

Chapter V: In this chapter, a summary of the research findings of this study is presented, followed by a recommendation for future works. References follow henceforth.

This research was financially supported by the Ontario Ministry of Agriculture, Food and Rural Affairs (LAAIR2014-5089).

Greenfield Ethanol Plant, Chatham, Ontario, provided the wastewaters, used in this research. 


\section{CHAPTER II - LITERATURE REVIEW}

\subsection{Introduction}

Astaxanthin is a xanthophyll ketocarotenoid with very strong antioxidant properties and a high market potential of $\$ 2500$ per $\mathrm{kg}$ (Lorenz and Cysewski, 2000). Natural astaxanthin is 10 times stronger and safer than the synthetic astaxanthin (Wan et al., 2014) and hence astaxanthin production from natural sources has gained recent interest. $H$. pluvialis is a freshwater green unicellular microalga, which can produce $0.5-4 \%$ of astaxanthin by weight (Kobayashi et al., 1993). Other sources of astaxanthin are krill, shrimp, salmon, and crab. It finds application as a coloring agent, nutraceutical, and pharmaceutical due to its high antioxidant property (Giannelli et al., 2015). H. pluvialis has a two-stage life cycle, the motile green phase where the cell number increases, and the encysted red immotile stage, where astaxanthin accumulation takes place, under environmentally stressed conditions, such as light, nitrate or salinity (Katsuda et al., 2006).

\subsection{Sources of Astaxanthin}

Astaxanthin can be derived from natural sources, bacteria, fungi, sea animals, like shrimps, crayfish, shrimp, trout, salmon, and green algae (Kang et al., 2007), as well as be produced through chemical synthesis. The natural sources of astaxanthin (algae, fungi, crustaceans, and bacteria) has been summarized in Table 2.1. Commercially, astaxanthin is derived from the microalgae Haematococcus pluvialis, yeast Xanthophyllomyces dendrorhous, and bacterium Paracoccus carotinifaciens (Bories et al., 2008; Schmidt et al., 2011). However, the major natural source of astaxanthin is the Haematococcus pluvialis microalgae which can accumulate up to $0.5-4 \%$ astaxanthin on dry weight basis (Kobayashi et al., 1992). 
Table 2.1: Sources of Astaxanthin.

\begin{tabular}{|c|c|c|}
\hline Sources & $\begin{array}{c}\text { Astaxanthin (\% Dry } \\
\text { weight) }\end{array}$ & References \\
\hline \multicolumn{3}{|c|}{ Microalgae } \\
\hline Haematococcus pluvialis & $0.5-4$ & (Goksan and Ak, 2006) \\
\hline Chlorococcum sp. & 0.2 & (Zhang and Lee, 1997) \\
\hline Chlorella zofingiensis & 0.001 & (Wang and Peng, 2008) \\
\hline Neochloris wimmeri & 0.6 & (Orosa et al., 2000) \\
\hline Protosiphon botryoides & 1.4 & (Orosa et al., 2000) \\
\hline \multicolumn{3}{|c|}{ Macroalgae } \\
\hline Enteromorpha intestinalis & 0.02 & (Banerjee et al., 2009) \\
\hline Catenella repens & 0.01 & (Banerjee et al., 2009) \\
\hline Paracoccus carotinifaciens & 2.2 & (Bories et al., 2008) \\
\hline Paracoccus haeundaensis & 2.1 & (Lee et al., 2004) \\
\hline \multicolumn{3}{|c|}{ Fungi } \\
\hline $\begin{array}{l}\text { Xanthophyllomyces } \\
\text { dendrorhous AS } 2.1557\end{array}$ & 0.5 & (Wang et al., 2006) \\
\hline $\begin{array}{l}\text { Xanthophyllomyces } \\
\text { dendrorhous }\end{array}$ & 0.5 & (Schmidt et al., 2011) \\
\hline \multicolumn{3}{|c|}{ Protists } \\
\hline $\begin{array}{l}\text { Thraustochytrium sp. CHN- } \\
3 \text { (FERM P-18556) }\end{array}$ & 0.2 & (Ambati et al., 2014) \\
\hline \multicolumn{3}{|c|}{ Crustaceans } \\
\hline Pandalus borealis (Shrimp) & 0.1 & (Jiao et al., 2015) \\
\hline Pandalus clarkia (crayfish) & 0.015 & (Pérez-Gálvez et al., 2008) \\
\hline
\end{tabular}

\subsection{Haematococcus pluvialis}

H. pluvialis is the most efficient producer of astaxanthin, in comparison to the other sources, and can accumulate maximum amount of astaxanthin ( $0.5-4 \%$ dry weight). It's a freshwater microalgae, with a two-stage life cycle (Figure 2.1); the first stage is the green phase, where the green motile cells grow in number, and the second red phase, where astaxanthin accumulation occurs. The transition from green to red phase occurs when the cells are environmentally stressed. The different ways of stress include nitrate deprivation 
(Suh et al., 2006), light stress (Katsuda et al., 2006), acetate supplementation (Kobayashi et al., 1993), and salinity stress (Boussiba and Vonshak, 1991a).

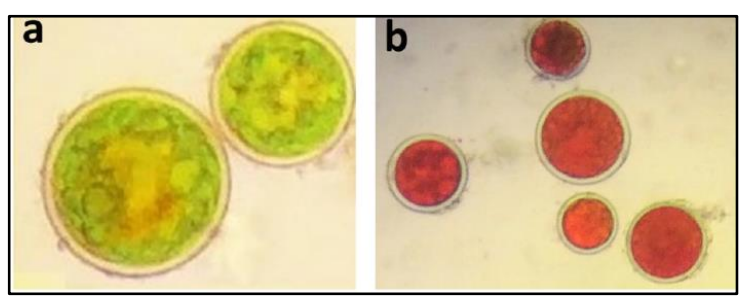

Figure 2.1: Two life phases of $H$. pluvialis, a) Green vegetative phase, and b) Red, astaxanthin accumulation phase.

\subsection{Growth Media}

Various growth media has been used to culture $H$. pluvialis, for example Bold Basal Media (BBM) (Hanan et al., 2013), marine culture media (MCM) (Borowitzka et al., 1991), BG11 (Boussiba and Vonshak, 1991), agricultural fertilizers (N-P-K) (Conk et al., 2007), Flora series fertilizers, example M1B5 media (Tocquin et al., 2012). In their study, Boussiba and Vonshak, 1991 reported the composition of $H$. pluvialis and it was seen that this microalga contain $53 \%$ carbohydrate, $19.5 \%$ protein, and $9.5 \%$ lipids. Hence, the main nutrients of the growth media are carbon, nitrogen, and phosphate. Based on the different growth media used for $H$. pluvialis culture, the nutrient composition chart was prepared, (Table 2.2). 
Table 2.2: Nutrient composition of different growth media.

\begin{tabular}{|c|c|c|c|}
\hline $\begin{array}{c}\text { Nutrients } \\
(\mathbf{g} / \mathbf{L})\end{array}$ & M1B5 & BG11 & BBM \\
\hline References & $\begin{array}{c}\text { (Tocquin et } \\
\text { al., 2012b) }\end{array}$ & $\begin{array}{c}\text { (Boussiba } \\
\text { and } \\
\text { Vonshak, } \\
1991)\end{array}$ & $\begin{array}{c}\text { (Hanan et } \\
\text { al., 2013) }\end{array}$ \\
\hline pH & 6.63 & 7.1 & 6.8 \\
\hline K & 0.176 & 0.008 & 0.084 \\
\hline N & 0.05 & 0.25 & 0.04 \\
\hline P & 0.053 & 0.006 & 0.053 \\
\hline Mg & 0.15 & 0.0035 & 0.007 \\
\hline S & 0.25 & 0.005 & 0.0106 \\
\hline Zn & 0.000015 & 0.00005 & 0.0000021 \\
\hline Mn & 0.00004 & 0.00003 & 0.000265 \\
\hline B & 0.00001 & 0.0005 & 0.00167 \\
\hline Co & 0.0000005 & 0.00001 & 0.00000009 \\
\hline Na & 0 & 0.41 & 0.0107 \\
\hline Cu & 0.00001 & 0.00002 & 0.0000028 \\
\hline Mo & 0.000008 & 0.00015 & 0.00001 \\
\hline Fe & 0.00012 & 0.0012 & 0.001 \\
\hline Cl & 0 & 0.000017 & 0.027 \\
\hline Ca & 0.007 & 0.00036 & 0.0068 \\
\hline C & 0.06 & 0.025 & 0.025 \\
\hline EDTA & 0.0039 & 0.00078 & 0.0039 \\
\hline Citric Acid & 0 & 0.056 & 0 \\
\hline
\end{tabular}


In recent years, the integration of nutrient removal from agricultural, municipal, dairy and distillery wastewater by microalgae and simultaneous by-product generation has gained attention; this strategy has been termed phyco-valorization (Querques et al., 2015). Wastewater can provide the carbon source, water, and nutrients (nitrates and phosphates) that microalgae require for growth (Kang et al., 2006; Razzak et al., 2013). Using wastewater as the growing medium eliminates the dependency on costly culture media, hence reducing the overall production cost. Kang et al. has verified nitrogen and phosphorous uptake from primary treated wastewater by $H$. pluvialis for astaxanthin biosynthesis, and (Wang et al., 2014) reported that Chlorella vulgaris has $95.7 \% \mathrm{~N}$ uptake and $96.4 \% \mathrm{P}$ uptake efficiency from primary effluent collected from a local wastewater treatment plant containing $36.1 \mathrm{mg} / \mathrm{L} \mathrm{N}$ and $4.0 \mathrm{mg} / \mathrm{L} \mathrm{P}$. Table 2.3 shows the total nitrogen (TN) and total phosphate (TP) content of different types of wastewater, which can be used as a potential source for $H$. pluvialis culture. Even though most of the sources of wastewater has good amount of TN and TP to support microalgal growth, however, for astaxanthin production, an acetate rich wastewater is desirable. 
Table 2.3: TN and TP content in different wastewater sources.

\begin{tabular}{|c|c|c|c|}
\hline Type of wastewater & TN (mg/l) & TP (mg/l) & References \\
\hline Piggery wastewater & 56 & 11.4 & $\begin{array}{c}\text { (Abou-Shanab et al., } \\
\text { 2013) }\end{array}$ \\
\hline $\begin{array}{c}\text { Primary effluent and } \\
\text { Anaerobic digestion } \\
\text { centrate }\end{array}$ & 64.1 & 4 & (Wang et al., 2014) \\
\hline $\begin{array}{c}\text { Dairy wastewater } \\
\text { (10\% dilution) }\end{array}$ & 81 & 2.6 & (Woertz et al., 2009) \\
\hline $\begin{array}{c}\text { Municipal } \\
\text { wastewater (San Luis } \\
\text { Obispo, California) }\end{array}$ & 51 & 2.1 & (Woertz et al., 2009) \\
\hline $\begin{array}{c}\text { Agro industrial } \\
\text { wastewater (Dairy } \\
\text { industry and pig } \\
\text { farm) }\end{array}$ & 38.2 & 111.8 & (González et al., \\
$1997)$
\end{tabular}

\subsection{Cultivation system}

There are two types of cultivation system; "open" or outdoor system, and "closed" or indoor system. The "open" system, such as lagoons, ponds, raceways, makes use of natural sunlight for algal growth, whereas the "closed" system, i.e. the photobioreactor, utilizes the artificial light source. Even though "closed" system can be expensive, it is an ideal option if wastewater is being used as a growth media, or if carbon dioxide supply is needed to support microalgal growth (Razzak et al., 2013). Cyanotech Corporation, Hawaii, follows an outdoor "open" system, paddle wheel raceway ponds as shown in Figure 2.2, for the astaxanthin production. As Hawaii has a warm climate, outdoor cultivation is a practical and feasible option (Zhu et al., 2011), however, in countries with 
a colder climate, "closed" system is the only option if round the year production is desired. For example, Algecan Biotech Ltd, Canada, makes use of continuously stirred photobioreactor and LED light for $H$. pluvialis cultivation, as shown in Figure 2.3. Different types of photobioreactor have been used to cultivate algae, such as bubble column reactor (Ranjbar et al., 2008) and air-lift reactor (Kaewpintong et al., 2007). H. pluvialis cells are shear sensitive, so mechanically stirred reactor is not a desirable option, and pneumatic agitation is preferred. For example, Kaewpintong et al., 2007 studied the cultivation of $H$. pluvialis in a standard F1 medium using air-lift photobioreactor (AL PBR) and supplemented with $1 \% \mathrm{CO}_{2}$, and was able to achieve 0.31 day $^{-1}$ of specific growth rate. B. Santhose et al., 2014 cultivates a new strain of $H$. pluvialis in modified BBM media in an AL-PBR and was able to achieve $3 \mathrm{~g}$ of dried algal biomass from $2.5 \mathrm{~L}$ of culture. Ranjbar et al., 2008 was able to achieve $5 \mathrm{~g} / \mathrm{l}$ of algal biomass by cultivating $H$. pluvialis in basal media and using a continuous supply of $\mathrm{CO}_{2}$ in a Bubble column reactor.

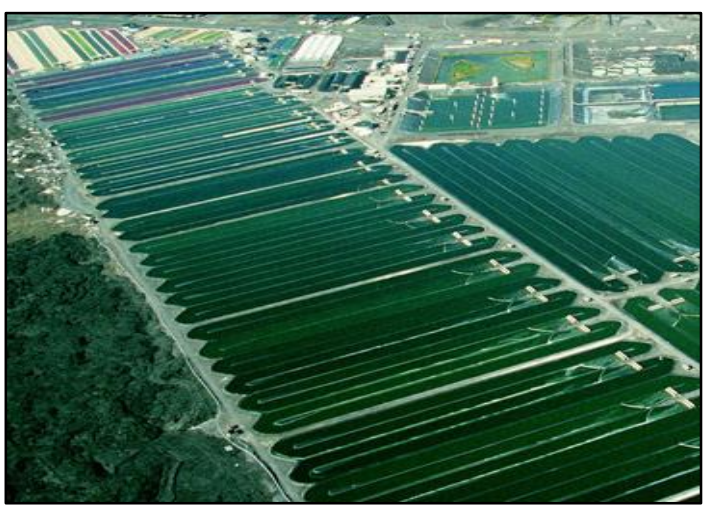

Figure 2.2: Paddle wheel Raceway pond used by Cyanotech Corporation, Hawaii.

(Adapted from www.cyantotech.com, retrieved on June 16, 2016). 


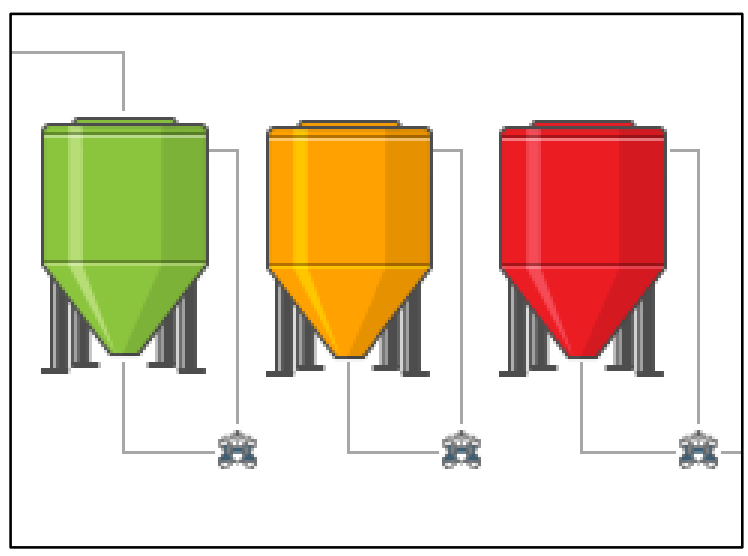

Figure 2.3: Closed Photobioreactor used at Algecan Biotech Ltd, Canada (Adapted from www.algecan.com, retrieved on June 16, 2016)

\subsection{Chemistry of Astaxanthin}

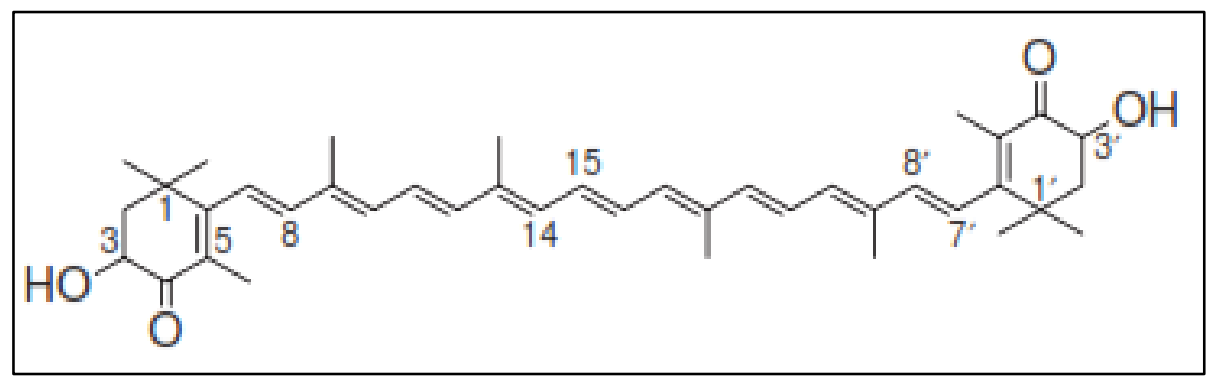

Figure 2.4: Planar structure of Astaxanthin (Higuera-Ciapara et al., 2006).

Astaxanthin $\left(\mathrm{C}_{40} \mathrm{H}_{52} \mathrm{O} 4\right.$, molar mass is $\left.596.84 \mathrm{~g} / \mathrm{mole}\right)$ is a symmetrical molecule with two chiral centers, at 3 and 3' positions of the aromatic ionone rings on both end of the molecule, as shown in Figure 2.4 (Guerin et al., 2003). There are 3 enantiomer isomers of astaxanthin (3S, 3'S), (3R, 3'R) and (3R,3'S), and the astaxanthin available from $H$. pluvialis is $(3 \mathrm{~S}, 3$ 'S) isomer, which is esterified with fatty acid to form mono $(70 \%)$ or diesters (25\%) (Lorenz and Cysewski, 2000). The esterified form of astaxanthin is more soluble and stable in the cellular lipid. The presence of the hydroxyl and keto groups, and the esterified form imparts lipophilic as well as hydrophilic properties to astaxanthin. The 
red color of astaxanthin is attributed to the presence of the conjugated double bonds, which is also responsible for the strong antioxidant property. The conjugated double bonds donate the electrons and reacts with free radicals, and hence terminates the free radical chain reaction (Higuera-Ciapara et al., 2006). Biosynthesis of astaxanthin is accompanied with the synthesis of various lipid soluble molecules such as sterols, steroids and prostaglandins and the positioning of astaxanthin relative to the cell membrane is shown in Figure 2.5.

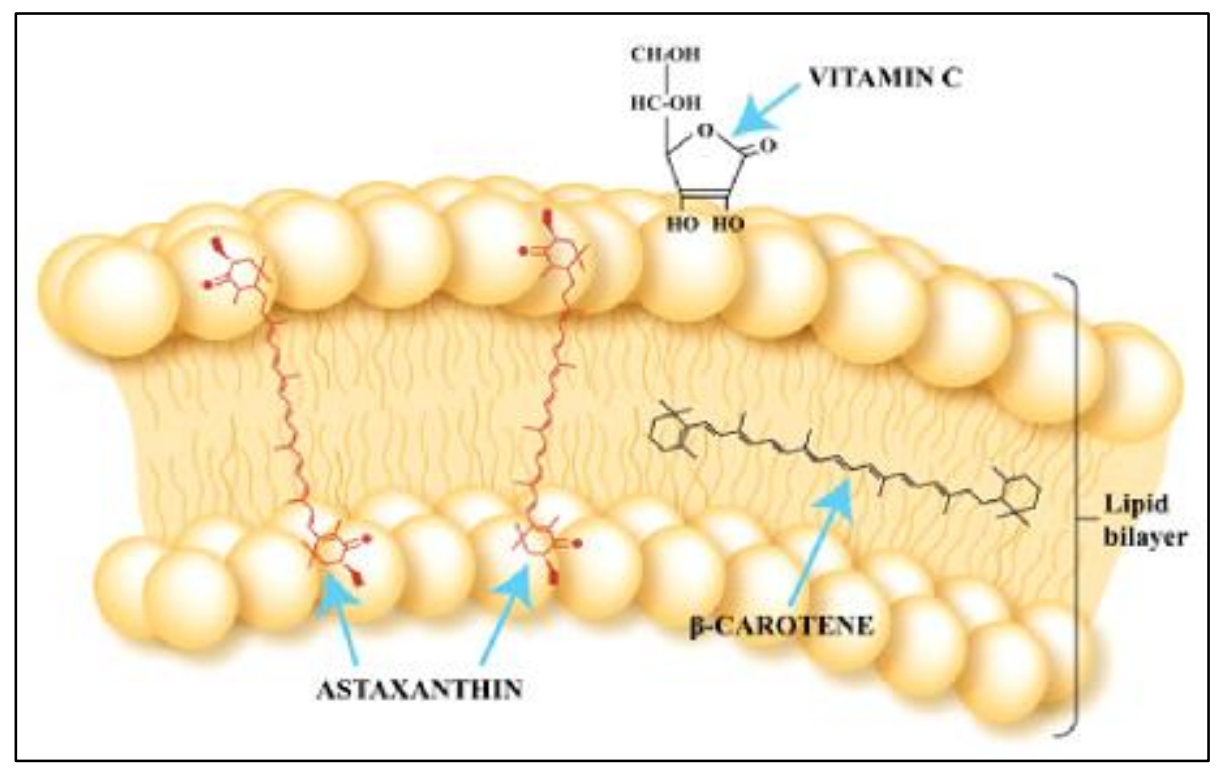

Figure 2.5: Position of Astaxanthin. (Adapted from

https://healthmasters.com/blog/hemmla-new-miracle-product, retrieved on 06/15/2016).

\subsection{Extraction of Astaxanthin}

Astaxanthin is synthesized within the thick sporopollenin cell wall, which blocks astaxanthin extraction. Different extraction techniques have been used by researchers, summarized in Table 2.4, to make the astaxanthin bioavailable. Ruen-ngam et al., 2010 compared the different extraction methods and reports that microwave assisted extraction 
(MAE) and ultrasound assisted extraction (UAE) are effective extraction methods, resulting in 74\% and 73\% astaxanthin recovery, respectively. Dong et al., 2014 and Sarada et al., 2006 reports that a combined treatment with hydrochloric acid followed by acetone extraction would result in $86 \%$ extractability of astaxanthin. Pretreatment of the astaxanthin rich cysts to disrupt the cell wall is necessary in order to extract the astaxanthin.

Table 2.4: Different astaxanthin extraction method.

\begin{tabular}{|c|c|c|}
\hline Methods & Particulars & Reference \\
\hline Solvent Extraction & Methanol-Acetone, & (Dong et al., 2014) \\
\hline Oil Extraction & Soybean oil & $\begin{array}{c}\text { (Dong et al., 2014; } \\
\text { Krichnavaruk et al., 2008) }\end{array}$ \\
\hline Acid-Solvent System & Hydrochloric acid-Acetone & (Dong et al., 2014) \\
\hline Supercritical extraction & Supercritical $\mathrm{CO}_{2}$ & $\begin{array}{l}\text { (Krichnavaruk et al., 2008; } \\
\text { Machado et al., 2014) }\end{array}$ \\
\hline $\begin{array}{l}\text { Ultrasound-assisted } \\
\text { extraction (UAE) }\end{array}$ & $\begin{array}{l}\text { UAE was carried out in } \\
\text { solvents, for example, } \\
\text { acetone, methanol, } \\
\text { acetonitrile, and ethanol, } \\
\text { using an ultrasonic bath. }\end{array}$ & $\begin{array}{c}\text { (Gogate and Nadar, 2015; } \\
\text { Pasquet et al., 2011; Ruen- } \\
\text { ngam et al., 2010; Zou et } \\
\text { al., 2013) }\end{array}$ \\
\hline Maceration & $\begin{array}{l}\text { Maceration was carried out } \\
\text { in solvents, for example, } \\
\text { acetone, methanol, } \\
\text { acetonitrile, and ethanol. }\end{array}$ & $\begin{array}{l}\text { (Mendes-Pinto et al., 2001; } \\
\text { Ruen-ngam et al., 2010; } \\
\text { Sarada et al., 2006) }\end{array}$ \\
\hline Autoclave & $30 \mathrm{~min}, 121^{\circ} \mathrm{C}, 1 \mathrm{~atm}$ & \multirow{3}{*}{ (Mendes-Pinto et al., 2001) } \\
\hline Spray drying & $\begin{array}{c}\text { Inlet } 180^{\circ} \mathrm{C} \text { and outlet } \\
115^{\circ} \mathrm{C}\end{array}$ & \\
\hline Enzyme-assisted extraction & protease $\mathrm{K}$ and driselase. & \\
\hline $\begin{array}{c}\text { Microwave-assisted } \\
\text { extraction (MAE) }\end{array}$ & $\begin{array}{l}\text { MAE was carried out in } \\
\text { solvents, for example, } \\
\text { acetone, methanol, } \\
\text { acetonitrile, and ethanol. }\end{array}$ & $\begin{array}{l}\text { (Csiktusnádi Kiss et al., } \\
\text { 2000; Pasquet et al., 2011; } \\
\text { Ruen-ngam et al., 2010) }\end{array}$ \\
\hline
\end{tabular}




\subsubsection{Ultrasound Assisted Extraction (UAE)}

The ultrasound passes through a solvent, which creates compression and expansion cycle, thus leading to the formation of cavities or micro - bubbles. These small bubbles eventually grow in size during the successive expansion cycle, and collapse during the compression cycle. As the pressure and temperature increases inside the bubbles due to the localized compression, the large bubble eventually collapses, hence resulting in enhanced heat and mass transfer, and disruption of the algal cell wall (Gogate and Nadar, 2015; Ruenngam et al., 2010; Zou et al., 2013). This principle has been shown in Figure 2.6.

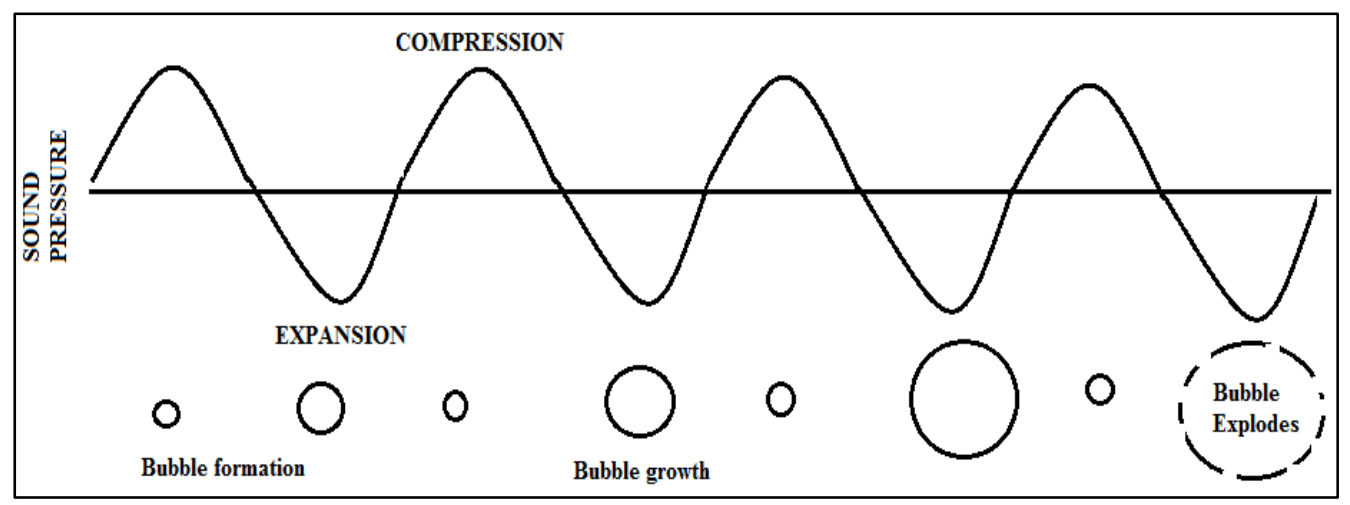

Figure 2.6: Principle of ultrasonication (Adapted from

http://www.sonotronic.de/technologies/ultrasonic/sonication-of-bio-solids, Retrieved on $06 / 25 / 2016)$ 


\subsubsection{Microwave Assisted Extraction (MAE)}

Microwaves are electromagnetic wave within the frequency range of $300 \mathrm{MHz}-$ $300 \mathrm{GHz}$, which when passes through a medium, gets converted into thermal energy (Csiktusnádi Kiss et al., 2000). This conversion occurs via two mechanisms: dipole rotation and ionic conduction. The medium gets heated homogeneously when the frequency of the radiation equals the rotational motions of the molecules, due to energy transfer. As the temperature rises, there is an enhanced heat and mass transfer, which results in heat dissipation. Also, as the pressure increases, the microalgal cell structure undergoes modification to enhance pigment extraction (Ruen-ngam et al., 2010). Figure 2.7 shows a schematic setup of a microwave unit utilized for extraction.

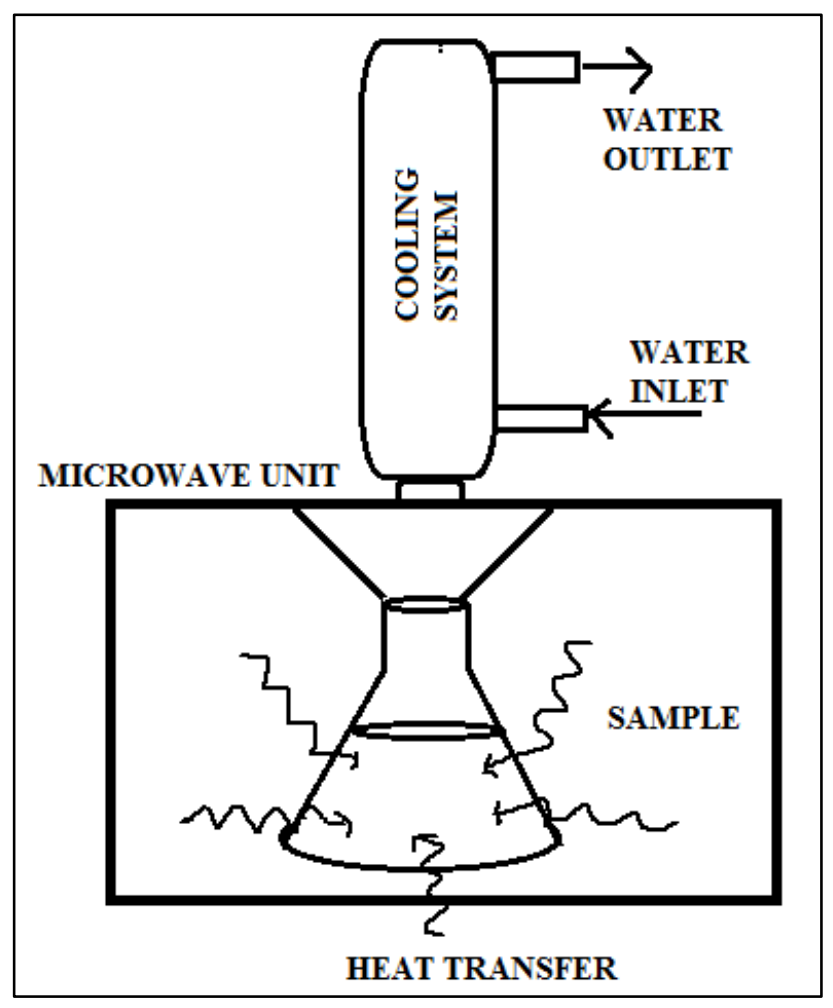

Figure 2.7: Schematic diagram of microwave extraction unit. (Adapted from Yao et al., 2012.) 


\subsubsection{Supercritical fluid extraction (SFE)}

Supercritical fluid extraction (SFE) method makes use of the thermodynamic properties of the fluids near the supercritical point. This point is reached when the fluid's temperature and pressure are increased over its critical point. These states are shown in Figure 2.8. Above the supercritical point, the supercritical fluid possesses low viscosity and surface tension, and high diffusivity, this property results in better diffusion of the fluid through the cell structure, hence resulting in enhances astaxanthin extraction (Thana et al., 2008). SFE using carbon dioxide has been widely used to extract astaxanthin (Krichnavaruk et al., 2008; Machado et al., 2014; Reyes et al., 2014). The supercritical temperature and pressure of carbon dioxide at the critical point is $340 \mathrm{~K}$ and $7.3 \mathrm{MPa}$, and the non - flammable and non - toxic nature makes it a preferable solvent for nutraceutical pigments. However, SFE technique has several challenges, including, choice of supercritical fluid, sample preparation, type of co - solvents, and the high pressure.

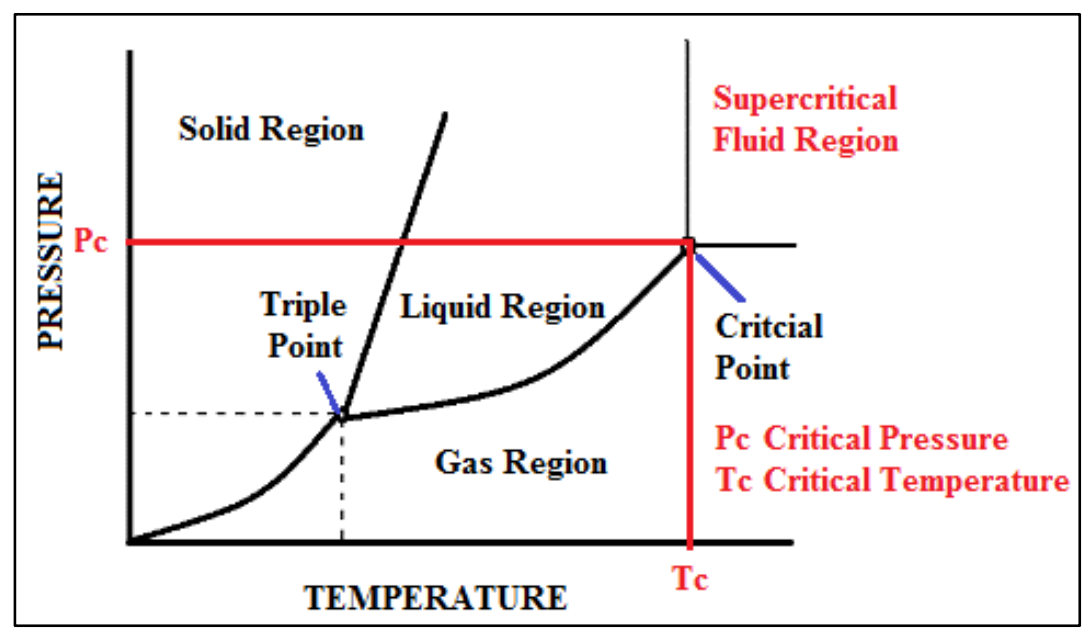

Figure 2.8: Phase Diagram showing the supercritical fluid region. (Adapted from http://cnx.org/contents/wmqmYmjc@ 2/Basic-Principles-of-Supercriti, Retrieved on $06 / 25 / 2016)$ 


\subsection{Application of Astaxanthin}

\subsubsection{Aquaculture}

The natural astaxanthin is used as a feed for salmonid aquaculture. The flesh and skin coloration in salmon and trout is due to the significant deposition of astaxanthin. Red colored Sea bream (red snapper) has a very high market price owing to the red pigmentation of their skin which is due to astaxanthin deposition. Naturally occurring Sea bream lacks astaxanthin in their diet, so artificial diet supplemented with astaxanthin provided the necessary pigmentation in cultured Sea bream. Astaxanthin supplementation is also used to raise ornamental luminous fish, such as clown anemone fish, rainbow sharks, rosy barbs, pink kissing gouramis and red velvet swordtails. Astaxanthin is used in shrimp farming, especially for kuruma prawn and tiger prawn, which has in high demand worldwide (Lorenz and Cysewski, 2000).

\subsubsection{Antioxidant}

Astaxanthin has stronger antioxidant properties than beta-carotene, zeaxanthin, Vitamin $\mathrm{C}$ and Vitamin E, owing to which they help in protecting the skin against UV radiation, immune system enhancer, and betterment of age-related macular degeneration (AMD). AMD (blindness) is caused due to exposure to high energy blue light, which results in photo-oxidative damage of the lipids, hence leading to the formation of free radicals and singlet oxygen molecules. Astaxanthin has free radical scavenging and singlet oxygen quenching properties, and can effectively destroy the peroxide chain reactions to protect the sensitive membranes (Lorenz and Cysewski, 2000). Astaxanthin can also reduce the risk of atherosclerosis, which is caused due to lipids deposition. It can also enhance the immune system by enhancing the production of immunoglobulins $\mathrm{A}, \mathrm{M}$, and G. UV light 
exposures can generate free radicals and singlet oxygen, and these can especially damage the skin and eye, and astaxanthin provides protection against UV light (Guerin et al., 2003).

\subsubsection{Human Health}

Astaxanthin provides protection against inflammation, for example, gastric inflammation, which is caused due to the generation of reactive oxygen species formed by the phagocytic leukocytes in response to the invasion by Helicobacter pylori. It also helps to reduce inflammation caused by asthma or muscle fatigue (Guerin et al., 2003). Astaxanthin helps to reduce the bad cholesterol, low-density lipoprotein (LDL) level and hence provides protection against heart diseases and atherosclerosis. It has been reported that astaxanthin has anti-cancer properties, helps in the detoxification of the liver, and lowers the risk of neurodegenerative diseases (Alzheimer's, Huntington's and Parkinson's disease) (Higuera-Ciapara et al., 2006). Table 2.5 summarizes the application of natural astaxanthin.

\section{Table 2.5: Application of Astaxanthin.}

\begin{tabular}{|l|l|}
\hline \multicolumn{1}{|c|}{ Application } & \multicolumn{1}{|c|}{ Reference } \\
\hline $\begin{array}{l}\text { As a natural coloring agent added to the aquaculture feed for } \\
\text { salmonid and crustaceans farming. }\end{array}$ & $\begin{array}{l}\text { (Higuera-Ciapara et } \\
\text { al., 2006; Lorenz and } \\
\text { Cysewski, 2000) }\end{array}$ \\
\hline Lowers the risk of cardiovascular diseases. & (Guerin et al., 2003) \\
\hline $\begin{array}{l}\text { Improves eye health, lowers cataract formation and macular } \\
\text { degeneration. }\end{array}$ & $\begin{array}{l}\text { (Lorenz and } \\
\text { Cysewski, 2000) }\end{array}$ \\
\hline $\begin{array}{l}\text { Suppression of cell proliferation, mutagenesis and } \\
\text { carcinogenesis by preventing oxidative damage of cells. }\end{array}$ & (Ambati et al., 2014) \\
\hline Treatment of gastric ulcers by fighting against H. pylori. & $\begin{array}{l}\text { (Ambati et al., 2014; } \\
\text { Guerin et al., 2003) }\end{array}$ \\
\hline Immunological system enhancer. & $\begin{array}{l}\text { (Guerin et al., 2003; } \\
\text { Lorenz and } \\
\text { Cysewski, 2000) }\end{array}$ \\
\hline Protection against UV radiations. & (Hagen et al., 2016) \\
\hline Prevention of Diabetes. & (Ambati et al., 2014) \\
\hline
\end{tabular}




\subsection{Market status}

Various natural astaxanthin products are marketed by companies worldwide (Table 2.6, Figure 2.9). The market price is dominated by the production technology employed by the commercial producers. AstaReal AB, Sweden, uses indoor photobioreactors and artificial light, whereas, Cyanotech corporation in Hawaii makes use of a combination of indoor photobioreactors and outdoor open ponds, and natural sunlight to produce astaxanthin (Lorenz and Cysewski, 2000; Zhu et al., 2011). Utilization of artificial light and photobioreactors adds to the capital and operation cost, however, if the production technology is optimized, the overall production cost can be reduced, and the revenue generation can be improved.
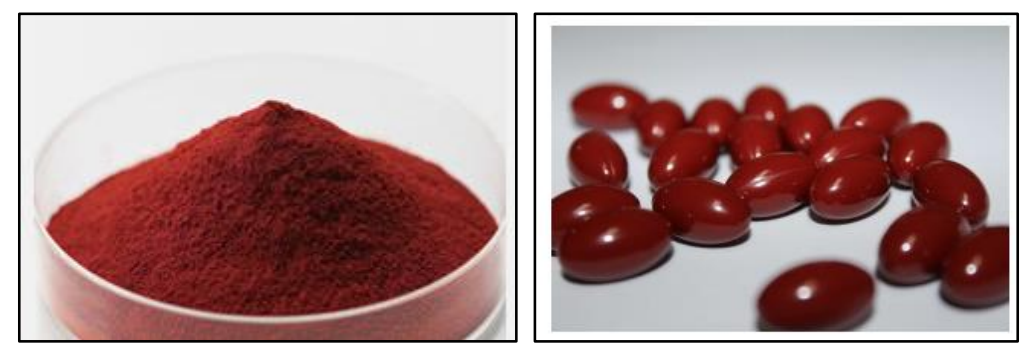

Figure 2.9: Different forms of astaxanthin available in the market: algal

biomass (left) and soft gels (right). (Source: http://www.astareal.se/products, http://rsahealth.com/?attachment_id=166, retrieved on 06/26/2016). 
Table 2.6 Manufacturers of Natural Astaxanthin (Website retrieved on 06/15/2016).

\begin{tabular}{|c|c|c|c|c|}
\hline Product & Company & Location & Application & Website \\
\hline $\begin{array}{l}\text { Asta } \\
\text { Factor }\end{array}$ & $\begin{array}{c}\text { Mera } \\
\text { Pharmaceuticals }\end{array}$ & USA & $\begin{array}{l}\text { Supplementary } \\
\text { soft gels for } \\
\text { human health } \\
\text { benefits. }\end{array}$ & www.astafactor.com \\
\hline Asta Pure & $\begin{array}{c}\text { Alga } \\
\text { Technologies }\end{array}$ & Israel & $\begin{array}{c}\text { Dietary } \\
\text { supplement and } \\
\text { cosmeceuticals. }\end{array}$ & www.algatech.com \\
\hline Asta Xin & Asta Real AB & Sweden & $\begin{array}{l}\text { Nutritional } \\
\text { Supplement. }\end{array}$ & www.astareal.com \\
\hline BioAstin & $\begin{array}{l}\text { Cyanotech } \\
\text { Corporation }\end{array}$ & USA & $\begin{array}{c}\text { Dietary } \\
\text { supplement. }\end{array}$ & www.cyanotech.com \\
\hline Novasta & Asta Real AB & Sweden & $\begin{array}{c}\text { Feed ingredient } \\
\text { and supplement } \\
\text { for animals }\end{array}$ & www.astareal.com \\
\hline NatuRose & $\begin{array}{l}\text { Cyanotech } \\
\text { Corporation }\end{array}$ & Hawaii & $\begin{array}{l}\text { Pigment for } \\
\text { aquatic } \\
\text { animals, birds, } \\
\text { horses and pigs. }\end{array}$ & www.cyanotech.com \\
\hline $\begin{array}{c}\text { Asta } \\
\text { Vantage }\end{array}$ & $\begin{array}{l}\text { Algaecan } \\
\text { Biotech ltd }\end{array}$ & Canada & Nutraceutical. & www.algaecan.com \\
\hline $\begin{array}{c}\text { Asta } \\
\text { Supreme }\end{array}$ & $\begin{array}{c}\text { Supreme } \\
\text { Biotechnologies }\end{array}$ & $\begin{array}{l}\text { New } \\
\text { Zealand }\end{array}$ & $\begin{array}{c}\text { Eye care, } \\
\text { Cardiac } \\
\text { Support and } \\
\text { healing Joint } \\
\text { ailments. }\end{array}$ & www.astasupreme.co.nz \\
\hline
\end{tabular}




\subsection{Problem Statement}

In recent years, extensive research has focused on the cultivation and exploitation of microalgae for the production of value-added by-products, as this unicellular microalgal biomass has a large potential for the production of nutritional and bio-based products. Microalgae can perform photosynthesis to convert light and carbon dioxide to a wide range of bio-products, such as extracellular excreted products: ethanol and hydrogen; and intracellularly accumulated product; biopolymers, fats, and anti-oxidants. However, the recovery of intracellular high-value components is economically feasible, and the main challenge is the recovery of extracellular by-products, which are entrapped within the cell structures. The target bio-product in this study is the strong antioxidant astaxanthin, which is an extracellular component, and its recovery from the thick cell wall of the $H$. pluvialis is a challenge.

Bio-ethanol production plants co-produce carbon dioxide - rich gasses, during the fermentation step, and nutrient-rich wastewater streams, during the ethanol recovery steps, and these waste streams may be readily taken up by $H$. pluvialis cultures. The main drive of this project is to efficiently use these resources for the generation of high-value astaxanthin that can become an additional revenue stream for the ethanol industry, which has important applications in aquaculture and as a nutritional food supplement. Astaxanthin sells for US\$2500/kg, with an annual worldwide market estimated at US\$200 million. While it can be produced synthetically, consumer demand for natural products provides an opportunity for the production of natural astaxanthin. Compared to other natural sources of astaxanthin, including krill and crawfish oil, and Phaffia yeast, which contains only 0.2$0.4 \%$ astaxanthin, $H$. pluvialis contains $0.5-4 \%$. 
Industrial $H$. pluvialis cultivation currently takes place primarily in open ponds. However, in the Canadian climate context, where year-round cultivation must be done indoors, closed photobioreactors (PBRs) are required. PBRs allow densification and intensification of the process, as well as lower contamination risk, better control of gasliquid contact, and lower harvesting costs.

\subsection{Research Objectives}

The research areas that are specifically focused in this study are:

1. Formulating a growth media using the wastewater generated by a bioethanol production plant, in order to support high-density $H$. pluvialis culture, as well as astaxanthin induction.

2. Recovery of astaxanthin using Ultrasound-assisted extraction.

3. Characterization of residual Haematococcus biomass as a potential biofuel feedstock. 


\section{CHAPTER III - INTENSIFIED GREEN PRODUCTION OF ASTAXANTHIN FROM Haematococcus pluvialis.}

\subsection{Introduction}

In this chapter, the objectives were to evaluate bioethanol wastewater streams (thin stillage, process condensate, and scrubber / dryer samples) as potential 'green' media to culture microalgae Haematococcus pluvialis, and to assess the effectiveness of ultrasound in microalgal cell disruption and astaxanthin extraction. $H$. pluvialis was cultured in wastewater dilutions $(20 \mathrm{x}-80 \mathrm{x})$ and formulations. Astaxanthin was extracted using ultrasound with cell-disrupting chemicals (acetic acid, citric acid, hydrogen peroxide and sodium hydroxide) and astaxanthin extracting solvents (acetone, ethanol, and methanol) at different extraction durations (5-35 $\mathrm{min})$.

In view of recent research and development on astaxanthin synthesis and extraction, an intensified approach that offers greener cell culturing and astaxanthin production, by means of shorter extraction time, reduced solvent usage, higher extraction yield, and elimination of harsh chemicals usage, is desirable. To achieve this, the present study is carried out in two stages, by culturing $H$. pluvialis in wastewater from bioethanol production in the first stage, and performing intensified extraction of astaxanthin in the second stage. Ultrasonication process is optimized by using a probe sonicator in combination with cell-disrupting chemicals as a pretreatment step to rupture the doublewalled red Haematococcus cysts, prior to solvent extraction. 


\subsection{Materials and Methods}

\subsubsection{Wastewater Sampling and Characterization}

The wastewater samples were collected from a local bioethanol plant, where corn kernels are used as the raw material (Figure 3.1). The samples were collected from three different steps of the production process, namely, the distillation unit (S1), the evaporation unit (S2), and the scrubber/dryer unit (S3). The $\mathrm{pH}$ of the samples was measured on-site using a $\mathrm{pH}$ meter. The wastewater samples were characterized for turbidity, dissolved oxygen (DO), total nitrogen (TN), total organic carbon (TOC), total phosphate (TP), acetic acid (as it helps in astaxanthin induction) and biological oxygen demand (BOD). Prior to use, all wastewater samples were autoclaved for sterilization.

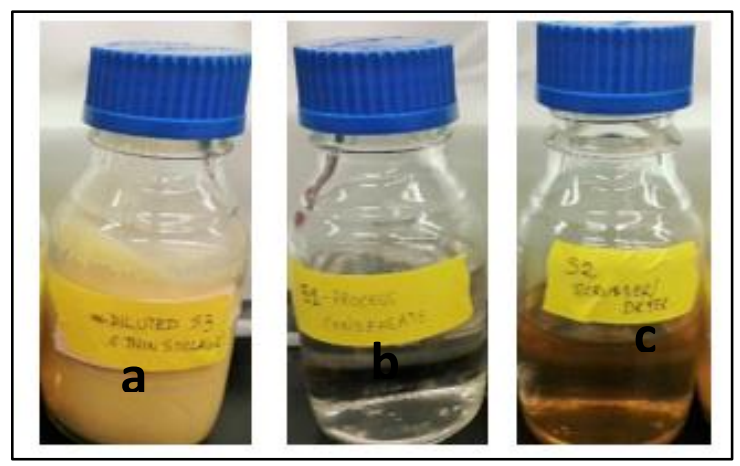

Figure 3.1: (a) Thin Stillage (S1), (b) Process Condensate (S2), (c) Scrubber/Dryer Sample (S3).

\subsubsection{Microalgal Stock and Cultivation}

Strains of Haematococcus pluvialis CPCC 93 were procured from the Canadian Phycological Culture Centre, University of Waterloo. Stock cultures were grown on modified M1B5, a modification of the media used by (Tocquin et al., 2012b): $0.5 \mathrm{ml} / \mathrm{L}$ Flora Micro and $2.5 \mathrm{ml} / \mathrm{L}$ Flora Bloom (General Hydroponics). The cultures were 
maintained at $\mathrm{pH} 7$ and incubated at $23 \pm 2^{\circ} \mathrm{C}, 12 \mathrm{~h} / 12 \mathrm{~h}$ light/dark cycle (600W MH light) with gentle agitation twice a day. Cultivation was done inside a 3'x 3' Expert Grow Tent equipped with reflective 600D Mylar fabric to maintain even lighting conditions.

\subsubsection{Microalgal Growth and Astaxanthin Accumulation in Bioethanol Wastewaters}

Microalgal growth was tested in wastewater sample S2 and S3 directly, and in dilutions of S1 (20, 40, 60 and 80 times), as S1 was a highly concentrated and thick sample, to optimize the microalgal growth. The microalgal inoculum was $10 \%(\mathrm{v} / \mathrm{v})$ of the wastewater with a four-day old seed culture. The wastewater culture condition is same as the microalgal stock culture condition. Cultures were done in $250 \mathrm{ml}$ Erlenmeyer flasks, manually agitated twice a day, in triplicates. After seven days, the culture was exposed to continuous light (600W HPS light) to stress the cells for astaxanthin induction. The astaxanthin induction and accumulation were conducted under continuous illumination for three weeks. The modified M1B5 standard medium was used as a sterile control.

To formulate the optimum growth medium for microalgal growth and astaxanthin accumulation (based on the obtained results), a mixture of $60 \%$ modified S1 and $40 \%$ S2 (denominated GroAst media) was made. Modified S1 was initially cultured by itself for seven days, and S2 was added on day 7. 


\subsubsection{Astaxanthin Extraction}

Astaxanthin extraction was investigated using two approaches: a) ultrasonication followed by solvent extraction, and b) ultrasonication with cell-disrupting chemicals pretreatment followed by solvents extraction. Acetic acid (5M), citric acid (5M), sodium hydroxide $(0.2-3.0 \mathrm{M})$ and hydrogen peroxide $(2 \mathrm{M})$ were used for the pretreatment experiments. The maximum possible concentration of acid used in the investigation was 5 $\mathrm{M}$ because acid concentrations above $5 \mathrm{M}$ were not suitable for application along with the ultrasound probe. Extraction solvents used were acetone (99.5\%), methanol (99.8\%) and ethanol (99\%). All chemicals used are Fisher Scientific analytical grade.

The cells in sampled broths were dewatered before addition of chemicals and sonication. An amount of $50 \mathrm{ml}$ of the algal culture broth was taken and centrifuged (Thermo Scientific Sorvall ST 24) at 5,000 g for $15 \mathrm{~min}$. Cells were dried overnight at room temperature. To the cell pellets obtained, $200 \mathrm{ml}$ of the cell damaging/pretreatment chemical solution or solvent was added. Extraction using ultrasonic horn was performed in a $500 \mathrm{ml}$ beaker at $35 \%$ sonication amplitude. The VC 750 ultrasonic processor (Sonics \& Materials Inc.) used in the work had a probe (horn) of $1.3 \mathrm{~cm}$ diameter, the maximum power rating of $750 \mathrm{~W}$, and operating frequency of $20 \mathrm{kHz}$, as shown in Figure 3.2. Amounts of $10 \mathrm{ml}$ were sampled at intervals of 5, 15, 25 and 35 minutes of sonication before further analysis. For extractions with pretreatment, the solutions were centrifuged again to recover the cell pellets, before continuing with solvent extraction using the same procedure. 

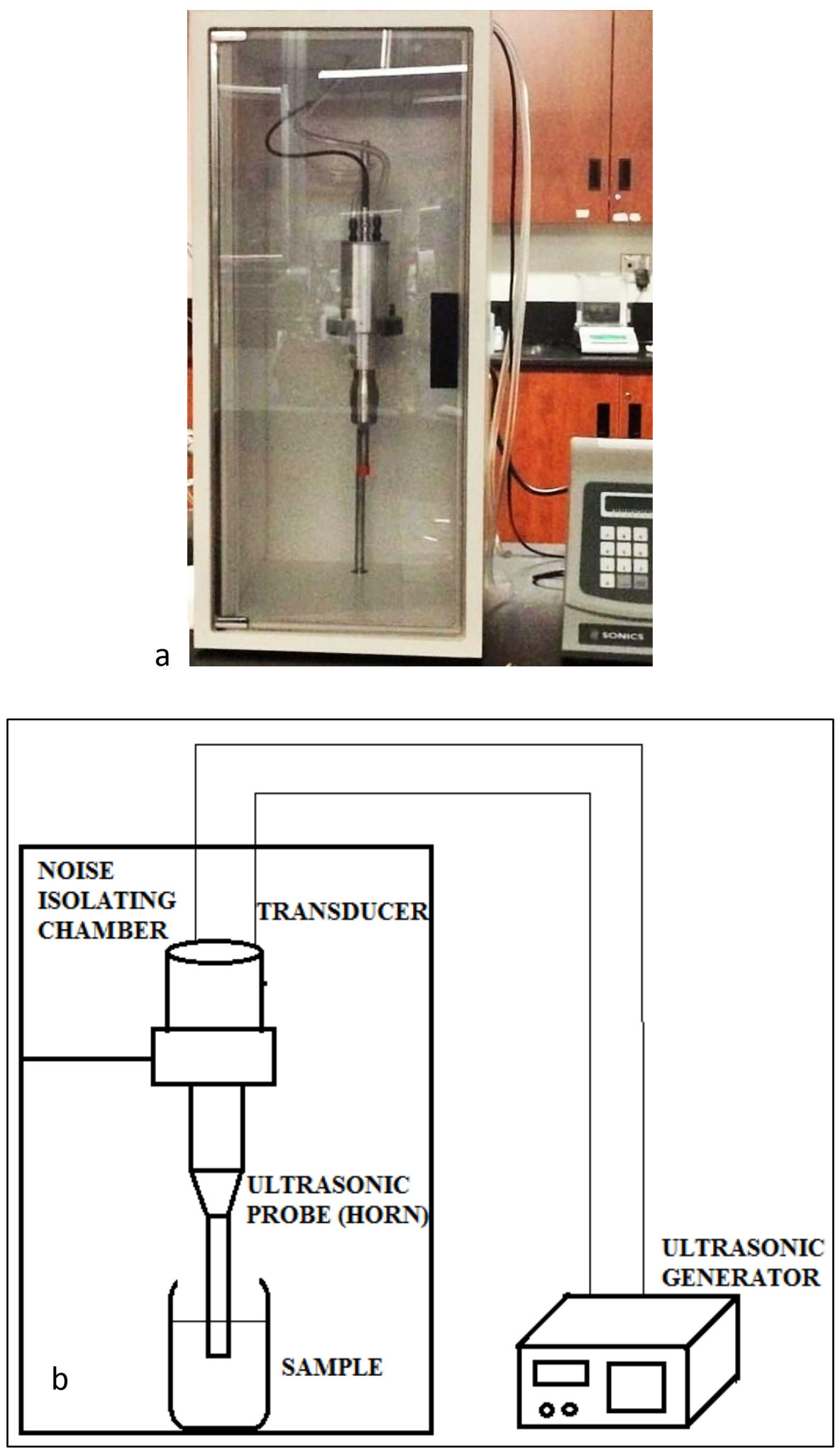

Figure 3.2: (a) Ultrasound Unit, and (b) Schematic outline of the ultrasound set up used in this study. 


\subsubsection{Analysis}

\subsubsection{Cell and Cyst Density Determination}

For analysis of cell growth and cyst accumulation, the algal broths were centrifuged at 5,000 x $\mathrm{g}$ for 15 minutes; the supernatant was discarded, and the dry weight was determined after drying the cell pellet overnight at room temperature. The pellet was homogenized in pure acetone, and absorbance was measured, using a spectrophotometer (Genesys 20 Visible, Thermo Fisher Scientific), at $670 \mathrm{~nm}$ and $450 \mathrm{~nm}$ for determination of microalgal cell growth and cyst content, respectively, based on optical density (OD) calibration.

\subsubsection{Astaxanthin Extraction Yield Determination}

Total carotenoid content was determined using spectrophotometric measurements as per the method reported by Meyer and Du Preez, 1994. The absorbance of $4 \mathrm{ml}$ of the extraction solutions was measured at $450 \mathrm{~nm}$, and a specific extinction coefficient (E1\%) of 2,100 was used. Based on prior studies (Vustin et al., 2004), it was assumed that total astaxanthin content represented the majority of the total carotenoid content detected at this wavelength. The yield of total astaxanthin content (TAC, $\mu \mathrm{g} / \mathrm{g} \mathrm{DW}$ ) was then estimated using the following equation (Gogate and Nadar, 2015):

$$
\mathrm{TAC}=\frac{\mathrm{V} \cdot \mathrm{A} \cdot 100}{21 \cdot \mathrm{W}}
$$

where, $\mathrm{V}$ is volume $(\mathrm{ml})$ of solvent used, A is absorbance and $\mathrm{W}$ is dry weight $(\mathrm{g})$ of biomass in the solvent (determined by drying the solvent solution). 
The increase in the TAC compared to $\mathrm{HCl}-\mathrm{ACE}$ extraction (Dong et al., 2014) as the control was estimated using Relative Astaxanthin Amount Increase (RACI, \%) using the following equation:

$$
\mathrm{RACI}=\frac{\mathrm{TAC}_{\text {sample }}-\mathrm{TAC}_{\mathrm{HCl}-\mathrm{ACE}, \text { control }}}{\mathrm{TAC}_{\mathrm{HCl}-\mathrm{ACE}, \text { control }}} \cdot 100 \%
$$

\subsubsection{Extractability Calculation}

The main objective of the study was to develop an intensified method for cell disruption, followed by solvent extraction, for obtaining maximum recovery of astaxanthin. Hence, the effectiveness of the process was measured in terms of the percent ratio of astaxanthin extracted over the total astaxanthin content present in the microalgae. The degree of Extractability (\%) was calculated using the following equation:

$$
\text { Extractability }=\frac{\text { TAC }_{\text {sample }}}{\text { TAC }_{\text {DMSO,control }}} \cdot 100 \%
$$

where, TAC of control was determined using DMSO method (Boussiba and Vonshak, 1991a), assuming complete recovery of astaxanthin is achieved by treating the cells with DMSO.

\section{$\underline{\text { Microscopic Observation }}$}

Algal cells were observed under a compound microscope (Fisher) at 100x magnification.

\subsubsection{Data Analysis}

All readings were taken in triplicates and results were represented along with standard deviation.

The data, in the graphs, have been represented along with standard errors. 


\subsection{Results}

\subsubsection{Wastewater characterization}

Table 3.1 summarizes the wastewater characteristics along with the nutrient composition present in the standard media (modified M1B5). The wastewater samples had acidic $\mathrm{pH}(3.25-3.98)$ with very low DO $(0.007 \mathrm{~g} / \mathrm{l}-0.005 \mathrm{~g} / \mathrm{l})$ for the thin stillage $(\mathrm{S} 1)$ and the process condensate (S2); and a relatively higher DO for the wastewater obtained from the scrubber/dryer zone (S3). S1 had a very high turbidity (> 1000 NTU), which gave it a very dense yellow color. It also contained a high amount of TOC, TP and TN compared to S2, whereas it was devoid of acetate anions, which was present in S2. S3 did not contain any phosphate. Comparison of the wastewater nutrient composition with that of the standard media shows that $\mathrm{S} 1$ contains the nutrients required for microalgae growth but in roughly 60 times stronger concentration, therefore a diluted S1 could be optimal for the microalgae growth (dilution factor was investigated in Section 3.3.2.1). In the case of S2, it contains acetate anions, which could benefit astaxanthin induction. 
Table 3.1: Wastewater characteristics and nutrient composition of the culture media.

\begin{tabular}{|l|l|l|l|l|l|}
\hline Analysis & Sample S1 & Sample S2 & Sample S3 & $\begin{array}{l}\text { Modified } \\
\text { S1 }\end{array}$ & $\begin{array}{l}\text { Standard } \\
\text { Media }\end{array}$ \\
\hline $\mathrm{pH}$ & 3.98 & 3.25 & 3.6 & 7 & 6.74 \\
\hline $\begin{array}{l}\text { Turbidity } \\
(\mathrm{NTU})\end{array}$ & $\begin{array}{l}\text { Greater than } \\
1000\end{array}$ & 38.6 & 25 & - & - \\
\hline DO $(\mathrm{g} / \mathrm{l})$ & 0.005 & 0.007 & 0.007 & 0.00009 & - \\
\hline $\begin{array}{l}\text { Acetic Acid } \\
(\mathrm{g} / \mathrm{l})\end{array}$ & 0.864 & 0.344 & 0.775 & 0.014 & - \\
\hline TN $(\mathrm{g} / \mathrm{l})$ & 1.50 & 0.018 & 0.078 & 0.025 & 0.025 \\
\hline TOC $(\mathrm{g} / \mathrm{l})$ & 24.7 & 1.36 & 3.68 & 1.24 & 0.03 \\
\hline TP $(\mathrm{g} / \mathrm{l})$ & 1.84 & 0.0015 & 0 & 0.031 & 0.026 \\
\hline BOD $(\mathrm{g} / \mathrm{l})$ & 30.82 & 3.56 & 2.54 & 0.51 & - \\
\hline
\end{tabular}

\subsubsection{Wastewater test}

\subsubsection{Effect of wastewater dilutions}

H. pluvialis survived in all the dilutions tested for wastewater sample S1 and succumbed when grown in the undiluted sample. The microalgae showed a gradual increase in growth from 20 times dilution to 60 times dilution; thereafter, a downfall in growth occurred when grown in 80 times dilution (Figure 3.3). Maximum growth of 0.69 $\pm 0.008 \mathrm{mg} / \mathrm{ml}$ was recorded at 60 times dilution of wastewater sample $\mathrm{S} 1$ on the $11^{\text {th }}$ day. The cell density at this condition was $\pm 5 \%$ to that of the control (standard media). S1 samples diluted 20-40 times showed reduced microalgal growth, in the range of $0.223 \pm$ $0.006 \mathrm{mg} / \mathrm{ml}$ to $0.413 \pm 0.005 \mathrm{mg} / \mathrm{ml}$, as the high nutrient content of the culture media hinders algal growth. Similarly, at 80 times dilution, the algal growth decreases as the 
culture media contains an insufficient amount of nutrients for algal growth. Therefore, for subsequent experiments, the 60x diluted S1 (referred to as "modified S1"), was used.

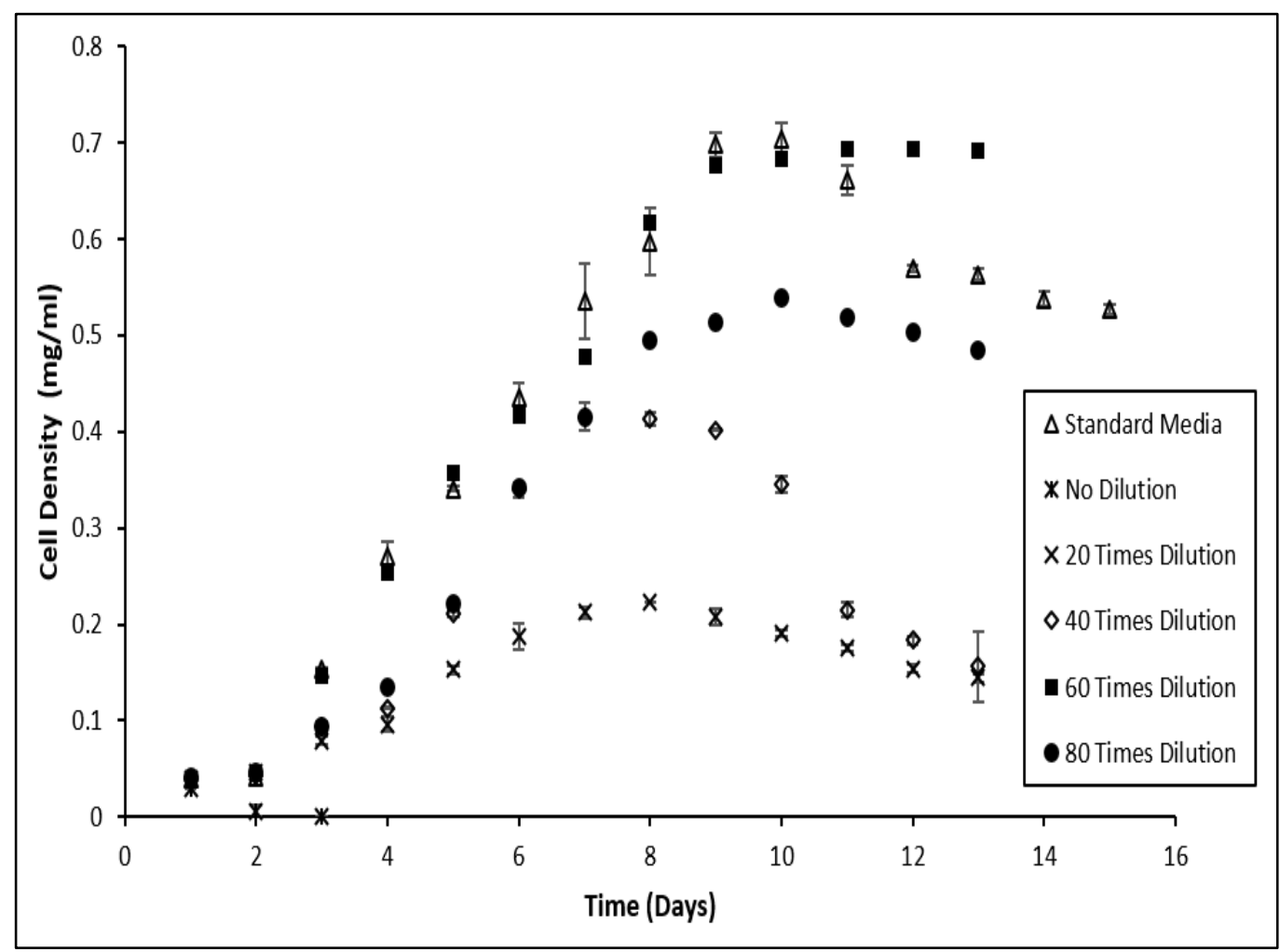

Figure 3.3: Growth curve of $\boldsymbol{H}$. pluvialis in S1 wastewater dilutions, expressed as total cell density measured by OD $(670 \mathrm{~nm})$.

\section{$\underline{3.3 .2 .2 . ~ E f f e c t ~ o f ~ d i f f e r e n t ~ w a s t e w a t e r ~ s a m p l e s ~ a n d ~ f o r m u l a t i o n s ~}$}

Figures $3.4 \mathrm{a}$ and $3.4 \mathrm{~b}$ present the total cell density and cyst accumulation concentrations, respectively, of $H$. pluvialis grown in different wastewater samples and formulations. In standard media, Haematococcus showed maximum cell growth of 0.704 $\pm 0.016 \mathrm{mg} / \mathrm{ml}$ on the $10^{\text {th }}$ day and reached a stationary phase for cyst accumulation of 
$0.574 \pm 0.002 \mathrm{mg} / \mathrm{ml}$ on the $21^{\text {st }}$ day. Modified S1 ( $\mathrm{S} 1$ diluted $60 \mathrm{x}$ ) supported the maximum microalgal growth of $0.693 \pm 0.005 \mathrm{mg} / \mathrm{ml}$ on the $11^{\text {th }}$ day; astaxanthin induction started on the $11^{\text {th }}$ day and cyst accumulation reached a maximum of $0.475 \pm 0.007 \mathrm{mg} / \mathrm{ml}$ on the $29^{\text {th }}$ day. In S2, the microalgae showed maximum cell growth of $0.122 \pm 0.003 \mathrm{mg} / \mathrm{ml}$ by the $5^{\text {th }}$ day, much reduced compared to standard media and modified. However, microalgae cultured in S2 showed astaxanthin induction from the $3^{\text {rd }}$ day, reaching a stationary cyst accumulation of $0.233 \pm 0.002 \mathrm{mg} / \mathrm{ml}$ by the $7^{\text {th }}$ day. $\mathrm{S} 3$ did not support Haematococcus growth, with cell density decreasing from the $1^{\text {st }}$ day onwards. The formulation GroAst media (60\% 60x diluted S1 and 40\% S2) showed similar cell growth as modified S1, with a maximum of $0.688 \pm 0.002 \mathrm{mg} / \mathrm{ml}$ on the $13^{\text {th }}$ day. Astaxanthin induction started on the $9^{\text {th }}$ day, with cyst accumulation reaching $0.478 \pm 0.005 \mathrm{mg} / \mathrm{ml}$ on the $21^{\text {st }}$ day, and a maximum of $0.634 \pm 0.009 \mathrm{mg} / \mathrm{ml}$ on the $26^{\text {th }}$ day. Figure 3.5 shows the $H$. pluvialis growth and astaxanthin accumulation in GroAst media. 


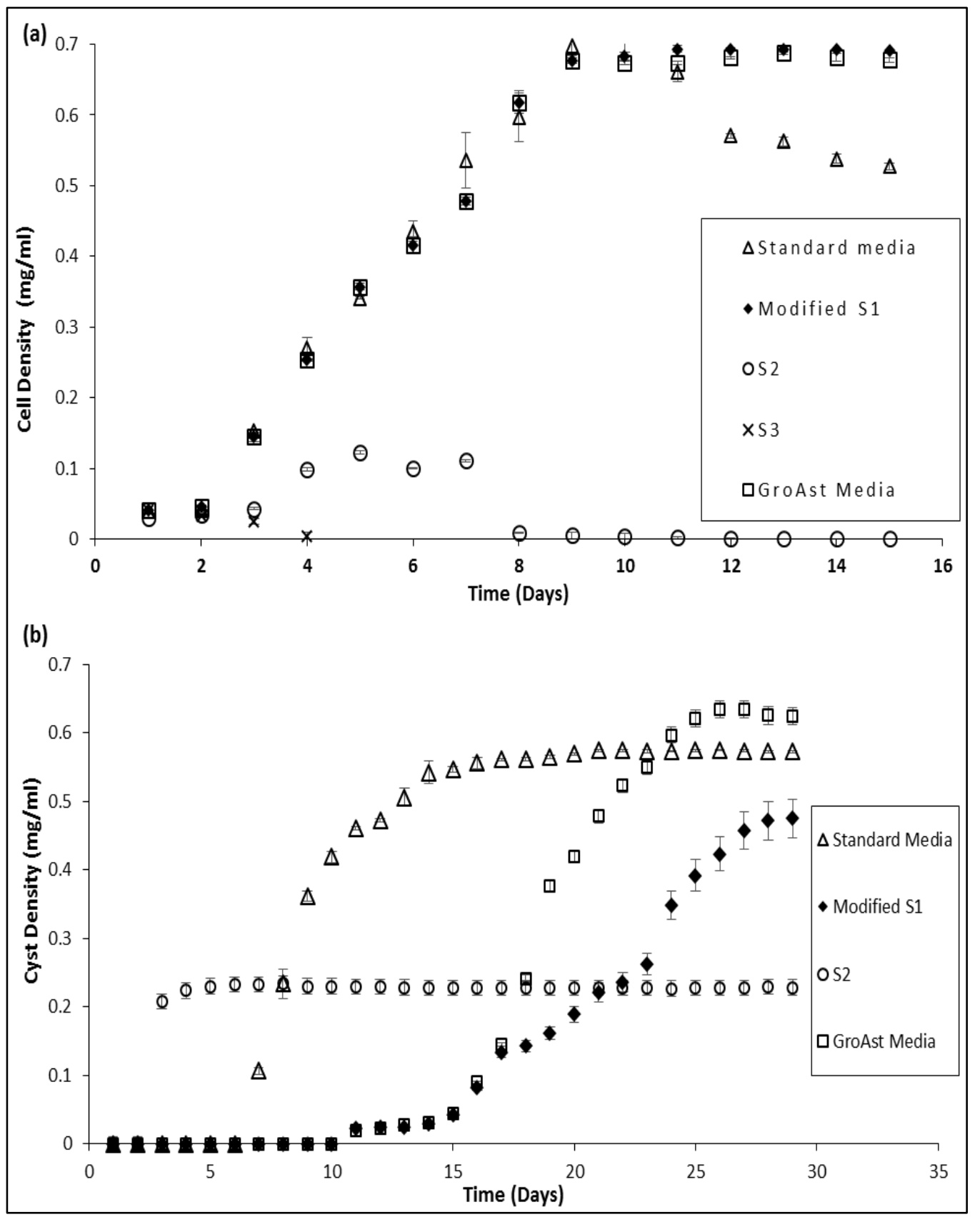

Figure 3.4: (a) Growth curve of $\boldsymbol{H}$. pluvialis in culture medium formulated from wastewater, expressed as total cell density measured by OD $(670 \mathrm{~nm})$. (b) Cyst accumulation curve in culture medium formulated from wastewater, expressed as cyst density measured by OD $(450 \mathrm{~nm})$. 


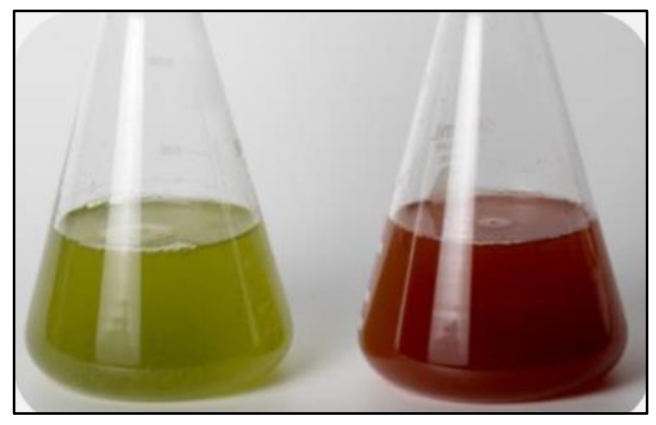

Figure 3.5: H. pluvialis growth and astaxanthin accumulation in GroAst Media.

\subsubsection{Screening of effective medium for cell disruption}

\subsubsection{Effect of cell-disrupting chemicals}

Figure 3.6 shows that pretreating the microalgal cells with ultrasonication coupled with sodium hydroxide $(2 \mathrm{M})$ treatment results in the maximum cell disruption, enabling intensified astaxanthin extraction; this level of disruption is followed by treatments with hydrogen peroxide, acetic acid, and citric acid, in the decreasing order of efficacy. Figure 3.6 shows the microscopic observations of the cell at different stages. First in the vegetative (green) stage, at the onset of astaxanthin induction (Fig. 3.6a). Then the encysted cells, still intact and dark red, with no signs of shredding or pitting on the thick cell wall (Fig. 3.6b). After ultrasonication with sodium hydroxide, the encysted cells become less intense in color, are damaged and some cells whiten (Fig. 3.6c), indicating that the cell walls have been broken down and the cell is ready for astaxanthin extraction by solvents. The morphologies of the cell that underwent ultrasonication with citric acid showed a small extent of damage (Fig. 3.6f), whereas the cells pretreated with hydrogen peroxide and acetic acid showed more substantial damage and some white cells (Figs. 3.6d and 3.6e). 


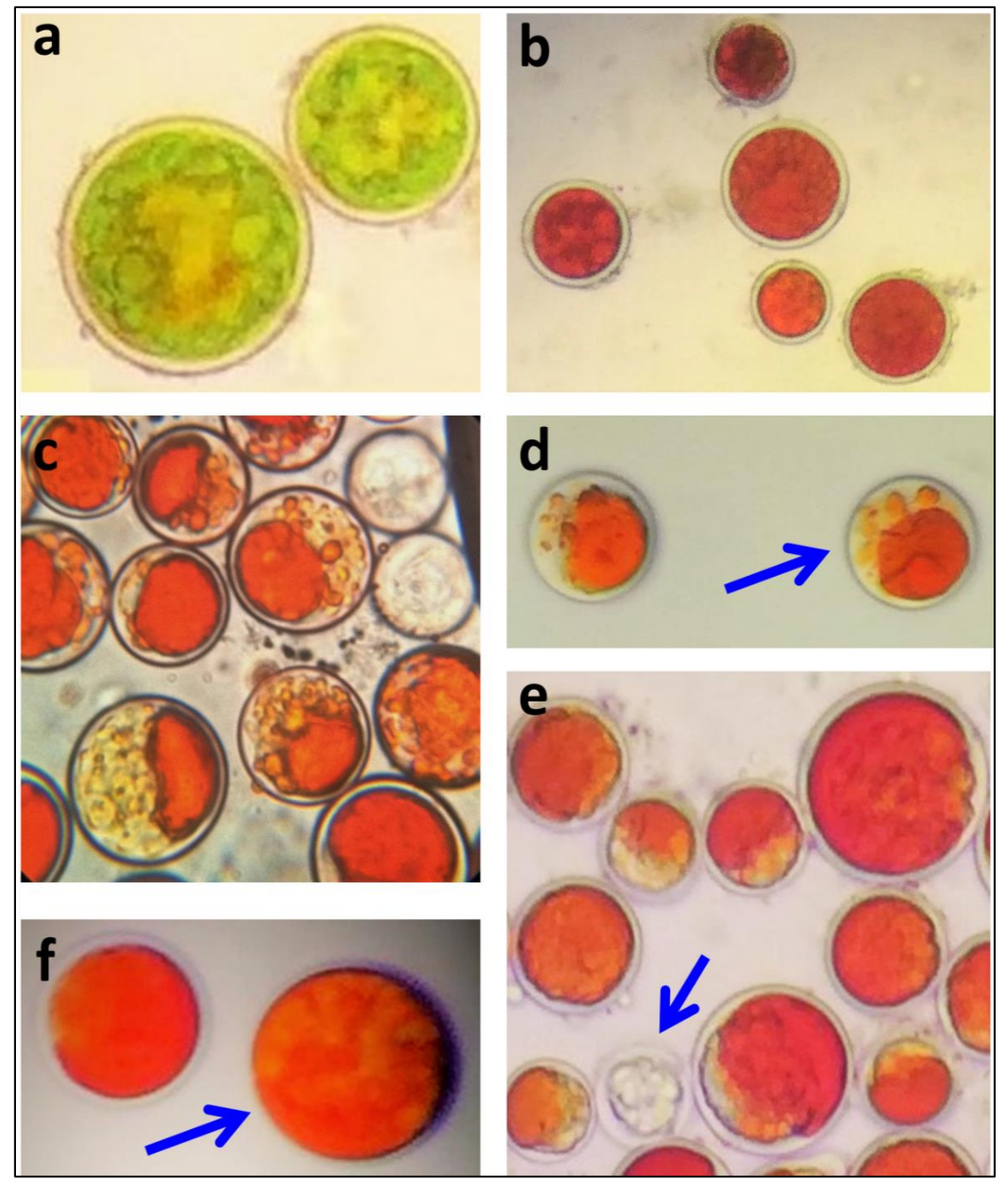

Figure 3.6: Microscopic observation of $H$. pluvialis cells in a) vegetative stage, b) cyst stage (without pretreatment), c) after pretreatment with sodium hydroxide (2M), d) after pretreatment with hydrogen peroxide $(2 \mathrm{M})$, e) after pretreatment with acetic acid (5M), and f) after pretreatment with citric acid (5M). 
The optical density (OD) of the supernatant indicates the degree of cell disruption, and by extension the density of carotenoids (including astaxanthin) extracted into the solution. The OD curve, obtained over a varying time range (5-35 $\mathrm{min})$ for the cell disruption chemicals is shown in Figure 3.7a. With the increase in the ultrasonication time, more cell disruption occurs, as indicated by the increase in the OD value as a function of extraction time. Ultrasonication with sodium hydroxide showed maximum OD, followed by hydrogen peroxide, acetic acid, and citric acid. These results are in agreement with the astaxanthin content reported in Table 3.2, where extractability (based on DMSO as the control) and RACI \% (based on HCl-ACE as the control) have been estimated. Increments of $62.8 \pm 0.006 \%$ astaxanthin recovery and $80.6 \pm 0.07 \%$ extractability are achieved with pretreatment with sodium hydroxide followed by methanol extraction, as compared to the controls (HCl-ACE and DMSO, respectively). 


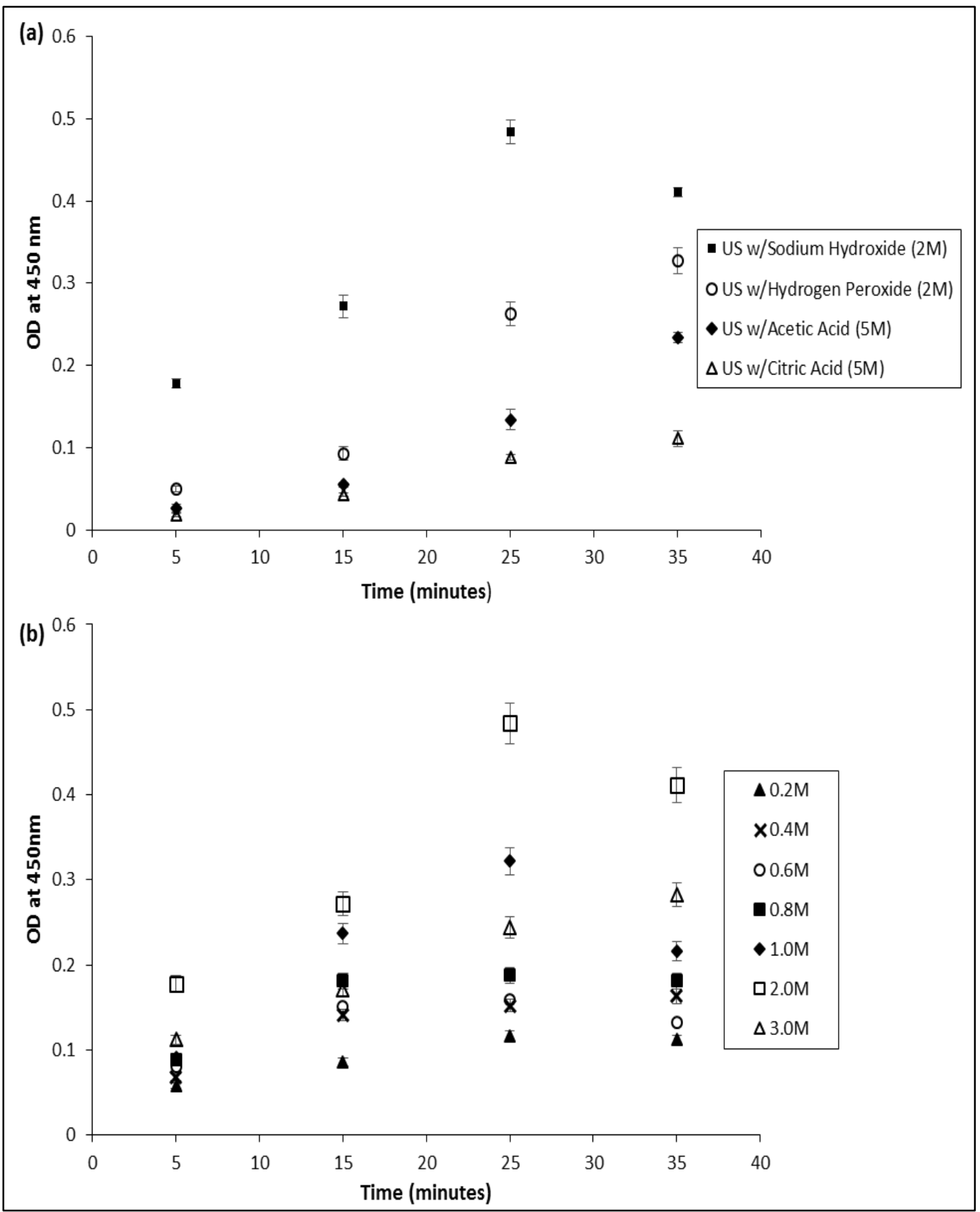

Figure 3.7: (a) Effect of pretreatment chemicals and pretreatment time on cell disruption, expressed as OD after solvent (methanol) extraction. (b) Effect of sodium hydroxide concentration and pretreatment time on cell disruption, expressed as OD after solvent (methanol) extraction. 
Table 3.2: Astaxanthin Content, Extractability, and RACI Estimation.

\begin{tabular}{|c|c|c|c|}
\hline $\begin{array}{l}\text { Extraction Process } \\
\text { (Mechanism w/ Chemical w/ } \\
\text { Solvent) }\end{array}$ & $\begin{array}{|ll|}\text { TAC } & (\mathrm{mg} / \mathrm{g} \\
\text { DW }) & \end{array}$ & $\begin{array}{l}\text { Extractability } \\
\% \\
\text { (Based on } \\
\text { Control 1) }\end{array}$ & $\begin{array}{ll}\text { RACI \% } & \\
\text { (Based } & \text { on } \\
\text { Control 2) }\end{array}$ \\
\hline Control 1 (DMSO) & $1.144 \pm 0.005$ & - & - \\
\hline Control 2 (HCl-ACE) & $0.343 \pm 0.002$ & - & - \\
\hline US w/ Acetone & $0.151 \pm 0.001$ & 13.2 & -56.0 (negative) \\
\hline US w/ Ethanol & $0.211 \pm 0.001$ & 18.4 & -38.5 (negative) \\
\hline US w/ Methanol & $0.362 \pm 0.011$ & 31.6 & 5.5 \\
\hline $\begin{array}{l}\text { US w/ Citric Acid (5M) w/ } \\
\text { Methanol }\end{array}$ & $0.212 \pm 0.009$ & 18.5 & -38.2 (negative) \\
\hline $\begin{array}{l}\text { US w/ Acetic Acid (5M) w/ } \\
\text { Methanol }\end{array}$ & $0.445 \pm 0.006$ & 38.9 & 29.7 \\
\hline $\begin{array}{l}\text { US w/ Sodium Hydroxide (2M) } \\
\text { w/ Methanol }\end{array}$ & $0.923 \pm 0.006$ & 80.6 & 169 \\
\hline $\begin{array}{l}\text { US w/ Hydrogen Peroxide (2M) } \\
\text { w/ Methanol }\end{array}$ & $0.623 \pm 0.016$ & 54.5 & 81.6 \\
\hline
\end{tabular}

\subsubsection{Effect of sodium hydroxide concentration and extraction time}

Figure 3.7 shows the effect of the concentration of sodium hydroxide and of extraction duration on cell disruption and carotenoid extraction, as indicated by OD. Maximum OD of $0.484 \pm 0.025$ was achieved in $25 \mathrm{~min}$ at $2 \mathrm{M}$ sodium hydroxide. From the Figure 3.7b, it can be observed that the OD increased with increasing concentration and peaked at 2M. Higher concentration of $3 \mathrm{M}$ seems to impose an inversed effect on the cell disruption, with a significantly reduced OD. It can be seen that when the extraction time was increased above $25 \mathrm{~min}$, the OD for astaxanthin begins to reverse to lower levels. 


\subsubsection{Effect of solvents coupled with ultrasonication}

Ultrasonication coupled with chemical treatment of the cells, followed by solvent extraction, resulted in 65\%-213\% more astaxanthin recovery in comparison to ultrasonication and solvent extraction alone (Table 3.3). Ethanol and methanol were found to be effective solvents for the extraction of astaxanthin, followed by acetone (Figure 3.8). Using acetone with pretreated cells resulted in $0.472 \pm 0.002 \mathrm{mg} / \mathrm{g}$ DW astaxanthin extraction, whereas methanol resulted in $0.923 \pm 0.006 \mathrm{mg} / \mathrm{g}$ DW astaxanthin.

Table 3.3: Comparison of astaxanthin content extracted from ultrasonicated ( 25 min) microalgal cells (a) not pretreated and (b) pretreated with 2M sodium hydroxide.

\begin{tabular}{|c|c|c|c|c|}
\hline $\begin{array}{c}\text { (a) Extraction } \\
\text { Process } \\
\text { without } \\
\text { Pretreatment }\end{array}$ & $\begin{array}{c}\text { TAC (mg/g } \\
\text { DW) }\end{array}$ & $\begin{array}{c}\text { (b) Extraction } \\
\text { Process with } \\
\text { Pretreatment }\end{array}$ & $\begin{array}{c}\text { TAC (mg/g } \\
\text { DW) }\end{array}$ & $\begin{array}{c}\text { Pretreatment } \\
\text { enhancement } \\
\text { (\%) }\end{array}$ \\
\hline US w/ Acetone & $0.151 \pm 0.001$ & $\begin{array}{c}\text { US w/ NaOH } \\
\text { w/Acetone }\end{array}$ & $0.472 \pm 0.002$ & 213 \\
\hline US w/ Ethanol & $0.211 \pm 0.001$ & $\begin{array}{c}\text { US w/ NaOH w/ } \\
\text { Ethanol }\end{array}$ & $0.349 \pm 0.017$ & 65.4 \\
\hline $\begin{array}{c}\text { US w/ } \\
\text { Methanol }\end{array}$ & $0.362 \pm 0.011$ & $\begin{array}{c}\text { US w/ NaOH w/ } \\
\text { Methanol }\end{array}$ & $0.923 \pm 0.006$ & 155 \\
\hline
\end{tabular}




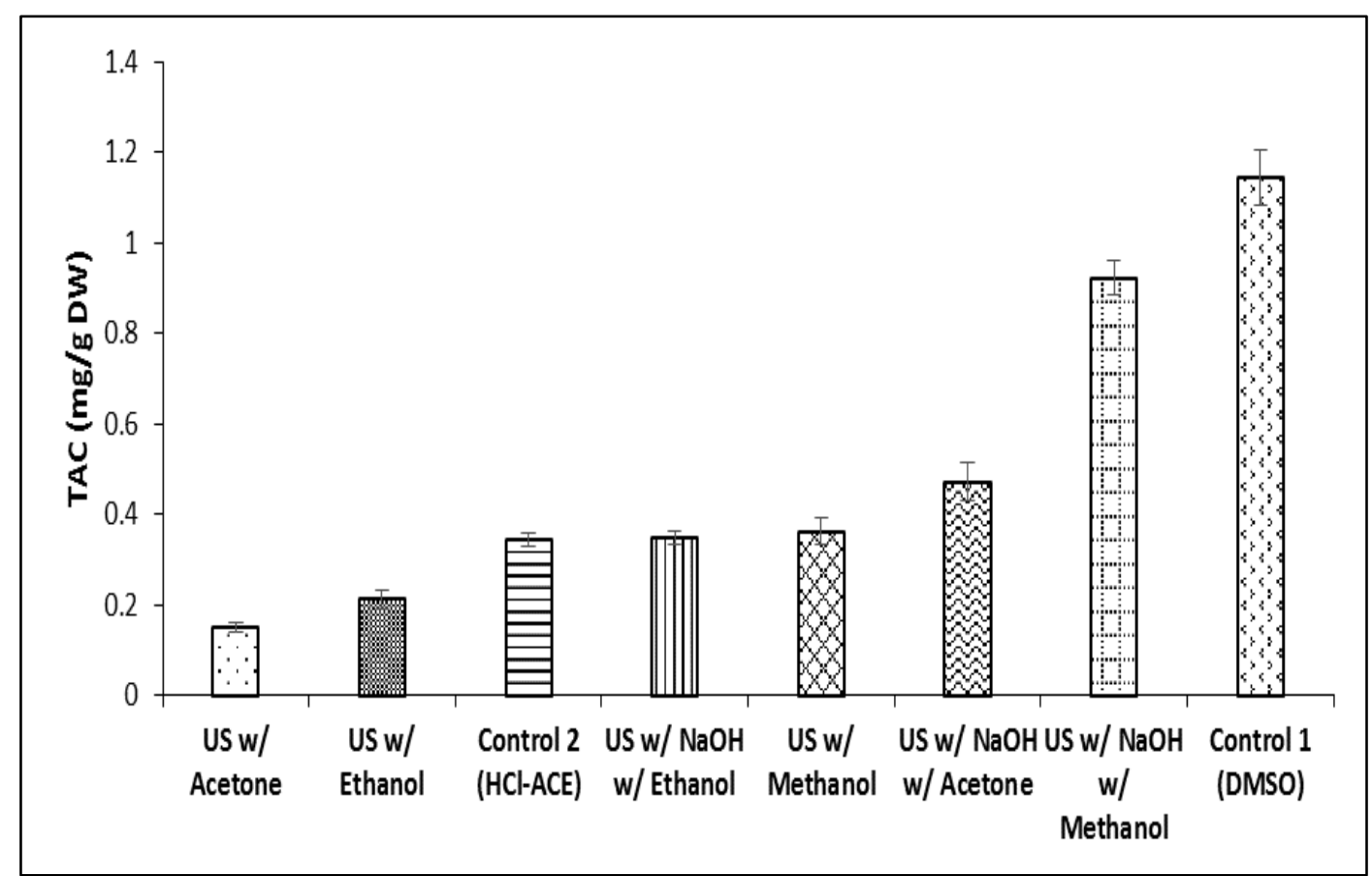

Figure 3.8: Astaxanthin extraction amounts using different intensified approaches compared to controls; in order of increasing $\mathrm{TAC} ; \mathrm{NaOH}=2 \mathrm{M}$.

\subsection{Discussion}

The present study aims to develop a greener process to produce astaxanthin, using the approach of culturing $H$. pluvialis in bioethanol waste streams, since the microalgae assimilate the nutrients present in the wastewater to grow and to accumulate high amount of carotenoids. This was investigated by formulating an optimum mixture of wastewater streams for maximum microalgal growth and astaxanthin accumulation. An additional objective was to intensify the cell disruption and astaxanthin extraction stages, to improve yield and minimize the use of harsh chemicals and solvents. 
The composition of the culture medium affects the cell growth and the astaxanthin yield (García-Malea et al., 2009). In this study, ethanol production wastewaters were used as media. Their composition and characteristics are determined by the type of feedstock used in the production plant and the various process steps involved, i.e., a) milling, b) liquefaction, c) saccharification, and d) fermentation, as shown in Figure 3.9. The wastewater samples obtained for this study had very low $\mathrm{pH}$ values, in the range of 3.254.0; this was due to the saccharification step, where an acidic $\mathrm{pH}$ is required to activate the glucoamylase enzyme. Also, during this step, additional nitrogen and phosphorous is inputted, for the bioethanol production, because the nutrient level of the feedstock eventually is exhausted (Wilkie et al., 2000).

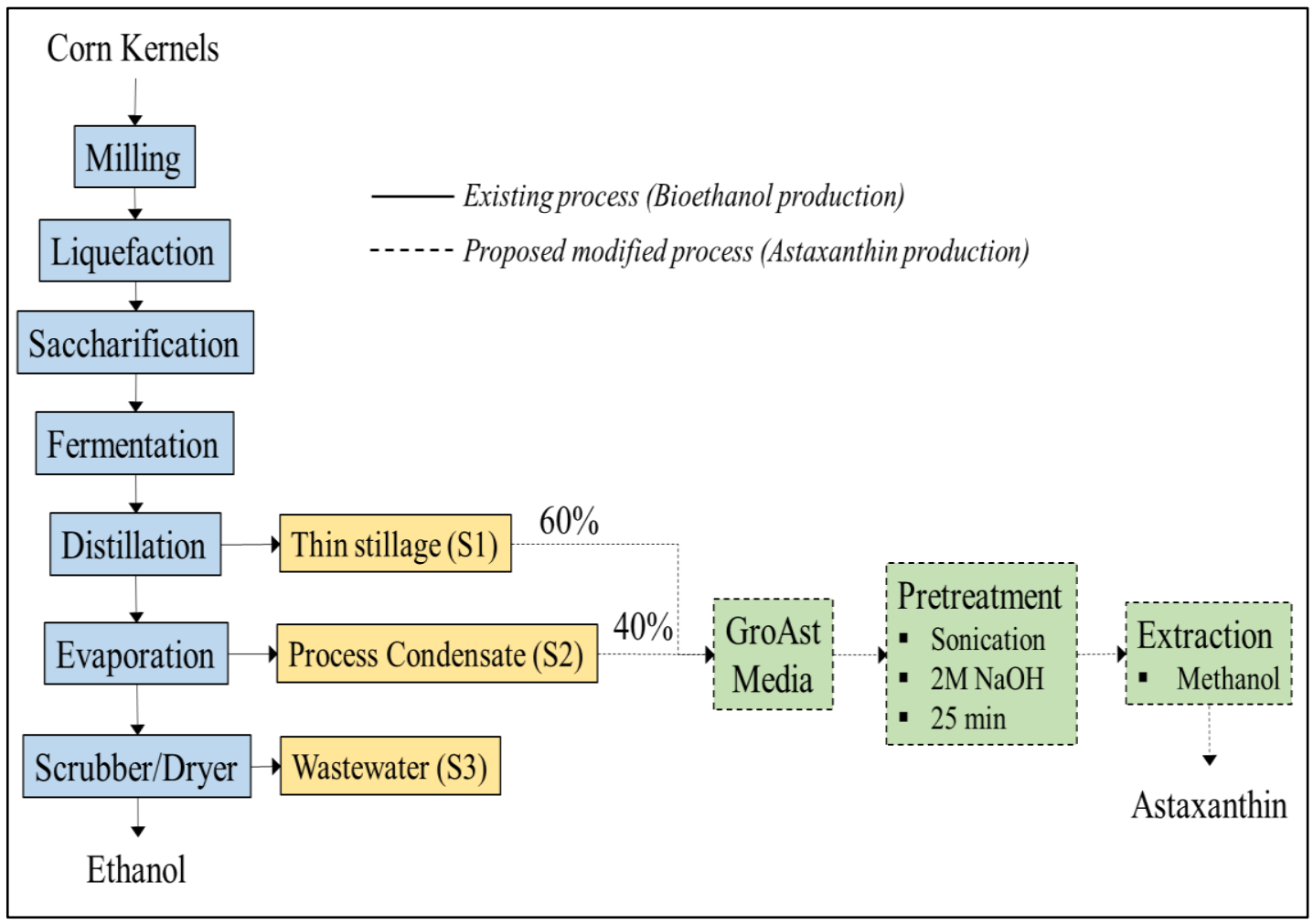

Figure 3.9: Schematic diagram of bioethanol production, wastewater generation, and proposed microalgal culture and astaxanthin production. 
The thin stillage (sample S1) is the wastewater collected from the distillation unit, the first step in the separation of bioethanol from the waste residues, thus making it most concentrated and nutrient rich; the high density of solids is responsible for the high turbidity value (>1000 NTU), imparting it a yellow color. The high nitrogen content is due to the protein content of the corn kernel (12\% of its composition), as well as additional nutrient added during the fermentation step.

Many inhibitors, such as furfurals, phenolic acids, lactic acid, and acetic acid, are also formed during fermentation, due to microbial contamination if a $\mathrm{pH}$ change occurs (Satyawali and Balakrishnan, 2008), thus contributing to the high BOD content of the wastewaters, in the range of 2.54-30.82 g/l. With such a nutrient-rich wastewater available readily, it can provide carbon, nitrogen and phosphorous for $H$. pluvialis growth, and provide acetate anions required for astaxanthin accumulation. Thus dependency on costly chemicals to prepare culture media can be eliminated. Also, via the proposed process, the nutrient-rich wastewater is put to a useful purpose with minimal processing, rather than being disposed of into waterways or undergoing evaporation to animal feed (Willington and Marten, 1982), thus making this process of astaxanthin production a potentially more sustainable route compared to conventional production.

Under favorable growth conditions, $H$. pluvialis remains in the green vegetative stage, where the accumulation of astaxanthin is low. The use of $60 x$ diluted sample of thin stillage (modified S1) provided the essential nutrients in the correct amount to support algal growth during this stage. The process condensate's (S2) lower nutrient content did not support $H$. pluvialis growth for an extended time, but its acetate anions may have anticipated the astaxanthin induction stage. The wastewater from the scrubber/dryer unit 
(S3) did not support microalgal growth at all, as it is devoid of phosphorus. Phosphorous is an important nutrient for algal growth and is responsible for the formation of cell membranes and nucleic acids (Wang et al., 2014). Based on these results, it was decided to compose GroAst media using modified S1 and S2, to exploit the advantages of each (high nutrient content and high acetate content, respectively).

H. pluvialis cultured in modified $\mathrm{S} 1$ takes 11 days to start astaxanthin accumulation, upon exposure to continuous illumination, whereas the microalgae cultured in GroAst media starts astaxanthin accumulation on $9^{\text {th }}$ day, reaching a maximum cell density of $0.634 \pm 0.009 \mathrm{mg} / \mathrm{ml}$ on $26^{\text {th }}$ day, which is $33.5 \pm 0.009 \%$ more than the astaxanthin accumulated when culturing in modified S1 alone, and occurring 3 days earlier, thus making the process more intensified. The GroAst media contains acetate anions, which are responsible for the faster and enhanced red cyst formation. Kobayashi et al., 1993; M Kobayashi et al., 1997 linked the acetate effect on encystment to a higher $\mathrm{C} / \mathrm{N}$ ratio, which otherwise became delayed or suppressed. The microalgae cultured in GroAst media was exposed to acetate ions as well as continuous illumination; (Jeon et al., 2006) showed this combination being effective in enhanced astaxanthin accumulation.

Sodium hydroxide is shown to be the most effective cell-disrupting chemical, coupled with ultrasonication pretreatment. (Mendes-Pinto et al., 2001) also reported that upon exposure to sodium hydroxide, microalgal cells undergo some distortion, and collapse upon longer treatment. (Kang and Sim, 2007) explained the mechanism of cell disruption due to sodium hydroxide as selective separation of free astaxanthin by saponification. This is demonstrated in Figure 3.10, which shows that the advantage of using sodium hydroxide can be attributed to the fact that the trans configuration is retained in the alcohol moiety of 
the ester containing the chiral carbon, as the sodium hydroxide's hydroxyl anion cleaves the carbonyl - oxygen bond instead of the alkyl - oxygen bond.

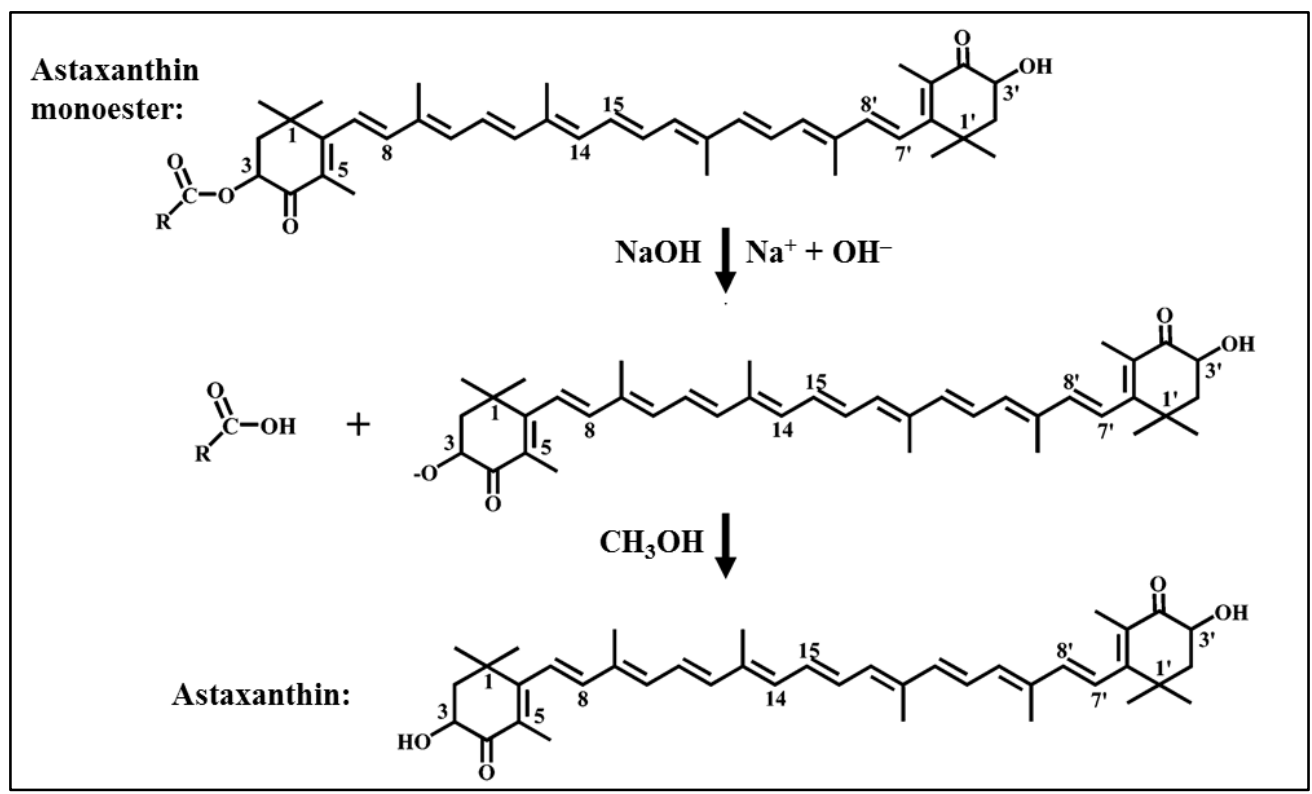

Figure 3.10: Mechanism of sodium hydroxide action (Ambati et al., 2014; Kang and Sim, 2007). Licensed and adapted from John Wiley and Sons, Biotechnology Progress, license number 3783210554285.

Besides sodium hydroxide, the effect of citric acid and acetic acid on cell disruption has been studied by Gogate and Nadar, 2015, who attribute the disruption efficiency to the acidic intensity of the acid. They reported that acetic acid $\left(\mathrm{pK}_{\mathrm{a}}=4.75\right)$ resulted in greater cell disruption in comparison to citric acid $\left(\mathrm{pK}_{\mathrm{a}}=4.98\right)$, owing to the former's lower $\mathrm{pK}_{\mathrm{a}}$ value. Their findings support the results of this study. Schroeder and Johnson, 1995 reported that hydrogen peroxide is effective in cell disruption of yeast, but also stated that though cell disruption occurred due to the scavenging activity of the peroxyl radicals, astaxanthin degradation also took place. The critical review by Boon et al., 2010 reports that acid and singlet oxygen results in astaxanthin degradation by carbocation and thermal 
degradation, respectively. Hence, sodium hydroxide proves to be the most appropriate option for microalgal cell disruption.

In the present study, by combining ultrasonication with alkali treatment, the amount of alkali required has been optimized at $2 \mathrm{M} \mathrm{NaOH}$, with 25 min extraction time. A bath sonicator, as reportedly used in literature, offered a non-uniform distribution of cavitations in the system, leading to low and uneven intensity environment, which resulted in longer extraction time for the desired outcome because of the mass transfer resistance (Ruen-ngam et al., 2010). So, using an ultrasound probe (horn), instead of a bath, provides a high and evenly distributed intensity environment, which results in shorter extraction time. However, increasing the alkali concentration beyond $2 \mathrm{M}$ or extraction time above $25 \mathrm{~min}$ could cause degradation of astaxanthin. This can be caused by localized hot spots created due to ultrasonic cavitation. A similar trend of decrease in astaxanthin content with an increase of ultrasonication time has been reported by Dong et al., 2014. Optimizing the alkali concentration to $2 \mathrm{M}$ and limiting the extraction time to 25 min makes this extraction process intensified, as chemical consumption and processing time are minimized.

Ethanol and methanol were found to be effective solvents for extraction of astaxanthin. Acetone was found to be least effective in extraction, which can be attributed to the fact that acetone is less polar in comparison to the other solvents, resulting in a lower degree of recovery. The difference between acetone and the other two alcohols used in the study can also be explained on the basis of polarity. The extent of extraction of astaxanthin will depend on the selectivity of the solvent, which is higher for the case of methanol due to its polar nature (Ranjan et al., 2010). As reported by Ruen-ngam et al. , the dielectric constant, which is a measure of polarity, of methanol (32.6) is more than that of ethanol 
(24.6) and acetone (20.7). Higher extraction of astaxanthin in methanol as compared to acetone clearly indicates that solvent selectivity is the dominant factor in deciding the extent of extraction. The polar - non-polar - polar structure of astaxanthin, with hydroxyl and keto moieties at free ends, makes it easier for the polar methanol to extract astaxanthin to a greater extent (Yang et al., 2013). Moreover, methanol is a GRAS (Generally Regarded As Safe) Class 2 solvent approved by the FDA, which makes it a suitable additive in view of process safety.

The experimental data in this study showed that integration of ultrasonication with chemical pretreatment and solvent extraction is more effective than using ultrasonication with solvents alone. The HCl-ACE method (Dong et al., 2014) used as a control showed $0.343 \pm 0.002 \mathrm{mg} / \mathrm{g}$ DW of extracted astaxanthin, while the maximum astaxanthin extracted by ultrasound (US)-solvent (methanol) method was $0.362 \pm 0.011 \mathrm{mg} / \mathrm{g} \mathrm{DW}$ (Figure 5), demonstrating a small difference between the control and this combination, as the thick cell-wall of the algae is one of the factors that hinders pigment recovery. However, intensification of the extraction process was possible when ultrasonication and alkali pretreatment were synergized with solvent extraction; astaxanthin yield increased by an enhancement factor of $155 \%$ for US w/ $\mathrm{NaOH}$ w/ methanol method in comparison to US w/ methanol method, as shown in Table 3. The ultrasonication treatment with sodium hydroxide leads to the formation of cavitation in solution, whereby the adjacent microalgal cells undergo cell disruption due to the localized high temperatures and pressures, in the presence of sodium hydroxide. Since the high temperature is localized, the astaxanthin in the cell and in the solution is minimally exposed to degrading temperatures. Hence, the use 
of ultrasonication does not lead to noticeable loss of astaxanthin caused by thermal degradation.

\subsection{Conclusions}

This work demonstrated that culturing Haematococcus pluvialis in bioethanol wastewater streams can be a greener alternative to conventional media, as it not only puts the readily available wastewaters to better use, but also eliminates the dependency on synthetic chemicals for culture media preparation. The maximal growth of $H$. pluvialis (vegetative cells) was obtained in 60x diluted thin stillage, and maximal astaxanthin accumulation was obtained in GroAst media (60\% 60x thin stillage, and 40\% acetate-rich process condensate), coupled with continuous illumination (to induce astaxanthin production). The total astaxanthin content extracted from $H$. pluvialis after ultrasonication using several cell-disrupting chemicals differed significantly. The best extraction method in terms of extraction efficiency was ultrasonication with sodium hydroxide pretreatment, followed by methanol extraction (US w/ $\mathrm{NaOH}$ w/ methanol). Astaxanthin extraction using ultrasonication proved advantageous in terms of short extraction time (25 min), less chemical consumption (2M NaOH), GRAS solvent usage (methanol), high efficiency in cell disruption, high extraction yield $(80.6 \pm 0.005 \%)$ and suitability to extract thermolabile astaxanthin. The use of ultrasound at industrial scale, however, still needs to be verified, as high energy consumption and scalability limitations may not make it the economically optimal technique for astaxanthin extraction. As all the results obtained in this study were from lab-scale cultivation and extraction, future work on optimizing the culture and the extraction conditions at pilot scale might lead to the eventual development of intensified and greener protocols for astaxanthin production at a commercial level. 


\section{CHAPTER IV - CHARACTERIZATION OF THE Haematococcus pluvialis RESIDUAL BIOMASS, OBTAINED AFTER ASTAXANTHIN EXTRACTION, AS A POTENTIAL BIOFUEL FEEDSTOCK.}

\subsection{Introduction}

The previous chapter reported about the culture of $H$. pluvialis in bioethanol waste stream (Thin stillage and Process condensate), and the growth media, known as the GroAst media (60\% of 60 times diluted thin stillage and $40 \%$ of process condensate) which supported astaxanthin production. It also reported that the ultrasonication of the encysted cells with $2 \mathrm{M} \mathrm{NaOH}$ for $25 \mathrm{~min}$, for cell disruption, followed by extraction with methanol, resulted in high extraction yield $(80.6 \pm 0.005 \%)$. In this chapter, $H$. pluvialis culture was carried out in GroAst media, using a 2.2 L Air-lift photobioreactor.

Not only $H$. pluvialis can utilize the nutrient present in the wastewater for their growth, but it can also help in $\mathrm{CO}_{2}$ mitigation. The fermentation unit, of the bioethanol production process, produces $\mathrm{CO}_{2}$, which is a greenhouse gas (GHG). There has been an increase in the GHG emission due to industrial activities. Hence many restrictive regulations are being implemented by the industrial sector to reduce the accelerating global warming issue. The annual report submitted by Environment Canada 2014, mentions how mitigation of GHG emission is the current topic of concern, and business sector, provinces, and territories are setting an emission threshold. Not only this, but the industrial sector is also contributing to this environmental cause by making use of greener and cleaner technologies (EC, 2014). In this chapter, an Air-lift photobioreactor will be supplemented with $\mathrm{CO}_{2}$ gas, to support $H$. pluvialis growth. 
It is well known that microalgae are seen as a potential bioenergy feedstock (Jiang et al., 2011; Rosana et al., 2013) and there are many papers available that have investigated about energy production from microalgal biomass (Chisti, 2007; Ehimen et al., 2009). In the previous chapter, a protocol (Figure 4.1) for astaxanthin production was proposed, which can be integrated with bioethanol production plant, thus adding an extra revenue stream along with wastewater utilization. However, after astaxanthin extraction, residual biomass was left behind, and it will be desirable to use this residual Haematococcus biomass for bioethanol energy production, so as to make the whole process more integrated and intensified.

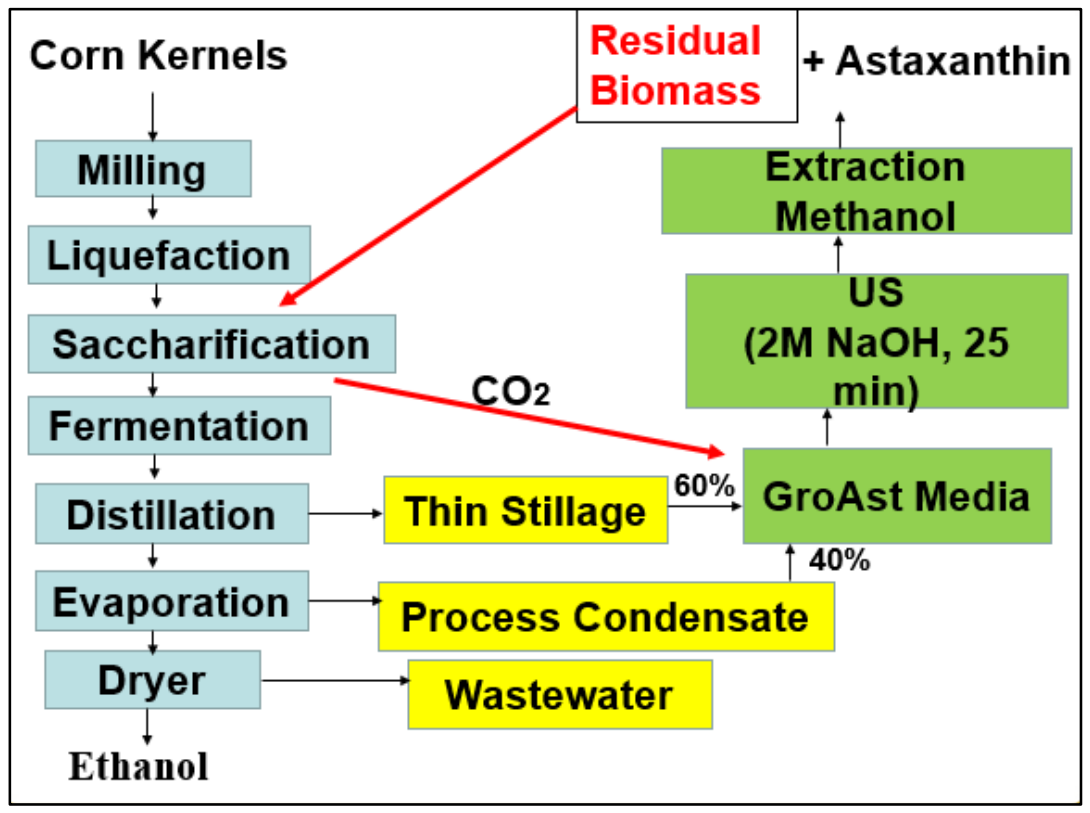

Figure 4.1: Schematic diagram of bioethanol production, wastewater generation, and proposed microalgal culture with $\mathrm{CO}_{2}$, astaxanthin production, and residual biomass utilization. 
Though many works of literature are available on microalgae as a source of bioenergy, very few papers can be found on using Haematococcus pluvialis as a bioenergy fuel, as $H$. pluvialis is an efficient producer of astaxanthin rather than bioenergy. However, literature does report that $H$. pluvialis is rich in lipids as well as hexoses. Astaxanthin's content within the algal cell makes up only a fraction of total cell mass ( $0.5-4.0 \%)$, and Hagen et al., 2002 mentions that the cellular composition of the red cyst comprises of $70 \%$ carbohydrates (66\% Hexoses and 3\% celluloses) and 6\% proteins, so after astaxanthin extraction, a significant amount of residual biomass is left behind. To use this residual Haematococcus biomass, understanding the composition of the biomass to decide to how and where this can be useful. Damiani et al., 2010 analyzed the lipid content of $H$. pluvialis and found that the main component of the algal oil was palmitic, stearic, oleic, linoleic, linolenic, and linolelaidic acids. The physical and chemical characteristics of the residual Haematococcus biomass can be analyzed using Proximate and Ultimate Analysis, Thermogravimetric analysis (TGA) and FTIR, to evaluate this residue as a potential feedstock for biofuel production ( $\mathrm{Bi}$ and $\mathrm{He}, 2013$ ).

In this chapter, the purpose is specifically aimed to attain high $H$. pluvialis culture using wastewater, in an air-lift photobioreactor ( $\mathrm{AL}$ - $\mathrm{PBR}$ ). In an air-lift photobioreactor, the bubbles are dispersed without mechanical agitation. Thus cells with low mechanical strength do not suffer high shear stress. Also, during the cultivation of photosynthetic cells, oxygen acts as an inhibitor, so the air bubbles dispersion ensures the removal of oxygen and enhances the mass transfer rate, hence preventing the settling of cells (Kaewpintong et al., 2007; Ranjbar et al., 2008). Although aeration is an essential parameter to provide a proper mixing in the ALR, it should be maintained at a minimal level to avoid shear stress. 
The main objective of this research study is to answer the following research questions:

- Can high-density production of $H$. pluvialis result in wastewater utilization?

- Is $H$. pluvialis able to take up $\mathrm{CO}_{2}$ in the bioethanol production effluent?

- Is the residual Haematococcus biomass a good source for bioenergy fuel? If yes, then which characteristics makes it a potential source?

\subsection{Materials and Methods}

\subsubsection{Microorganism, media, and cultivation condition}

H. pluvialis CPCC 93 strains were obtained from the Canadian Phycological Culture Centre. The stock cultures were maintained on modified M1B5, a modification of the media used by Tocquin et al., 2012: $0.5 \mathrm{ml} / \mathrm{L}$ Flora Micro and $2.5 \mathrm{ml} / \mathrm{L}$ Flora Bloom (General Hydroponics). The cultures were maintained at $\mathrm{pH} 7$ and incubated at $23 \pm 2{ }^{\circ} \mathrm{C}$, 12h/12h light/dark cycle (600W MH light) with gentle agitation twice a day.

The wastewater sample was procured from a local bioethanol plant, where corn kernels are used as the raw material. The wastewater samples used were a) the thin stillage (S1) obtained from the distillation unit, and b) the process condensate (S2) obtained from the evaporation unit of the production plant. GroAst media was formulated using $60 \%$ modified S1 and 40\% S3. In the previous study it was seen that 60 times diluted S1 ( denoted as modified S1) supported maximum algal growth, and once the green cells reached the stationary phase of the growth curve, S2 addition and continuous light (30 klx) resulted in astaxanthin induction (Haque et al., 2016). 


\subsubsection{Enhanced Biomass Production of $\boldsymbol{H}$.pluvialis}

\subsubsection{Effect of $\mathrm{CO}_{2}$ on algal growth in an air - lift batch photobioreactor}

H. pluvialis culture was carried out in a 2.2 L AL-PBR. Figure 4.2a demonstrates the experimental set up and Figure 4.2b shows the PBR used for the study. The column was made up of glass ( $11.2 \mathrm{~cm}$ internal diameter and $22.5 \mathrm{~cm}$ height), with a draft tube (5.6 $\mathrm{cm}$ internal diameter and $11 \mathrm{~cm}$ height) centrally installed inside it. Prior to each experiment, the column reactor, and the draft tube were sterilized by spraying with isopropyl alcohol (70\%), and the draft tube was installed within the column reactor inside the fume hood to prevent contamination. The AL-PBR was filled with $1500 \mathrm{ml}$ GroAst media and $150 \mathrm{ml}$ starter inoculum (a four-day old seed culture). The $\mathrm{CO}_{2}$ gas cylinder (purity 99.99\%, Linde) and the air pump (Tetra, Whisper 10) were connected as shown in Figure 4.2a, and the gas flow was controlled by a flow meter with a control valve (Key Instruments, Cole-Parmer, $\mathrm{CA}$ ). This $\mathrm{CO}_{2}$ and air mixture entering through the base of the AL-PBR at a speed of $45 \mathrm{ml} / \mathrm{min}$ provides sufficient mixing to keep the cells in suspension. The concentration of $\mathrm{CO}_{2}$ studied were $2.5 \%, 5 \%$, and $10 \%$. For the control, only compressed air was introduced inside the AL-PBR. The initial $\mathrm{pH}$ of the media was maintained at $\sim 7$ and the AL-PBR was placed inside a temperature-controlled, illuminated $3^{\prime} \mathrm{X} 3^{\prime}$ Expert growth tent at $23 \pm 2^{\circ} \mathrm{C}$ and $12 \mathrm{~h} / 12 \mathrm{~h}$ light / dark cycle (600W MH light). The growth tent is made up of reflective 600D Mylar fabric which helped to maintain even lighting conditions and prevented the effect of any other light source on the reactor. The distance between the light source and the AL-PBR was maintained at $70 \mathrm{~cm}$. The average illumination intensity incident on the outer surface was measured using a digital lux meter (Fisher Scientific) and it was maintained at $15 \mathrm{klx}$ for growth conditions (green phase) and 
$30 \mathrm{klx}$ for astaxanthin induction (red phase). $\mathrm{CO}_{2}$ not only act as a carbon source for the photoautotrophic growth of $H$. pluvialis but the $\mathrm{CO}_{2}$ bubbles help in sufficient mixing inside the PBR.

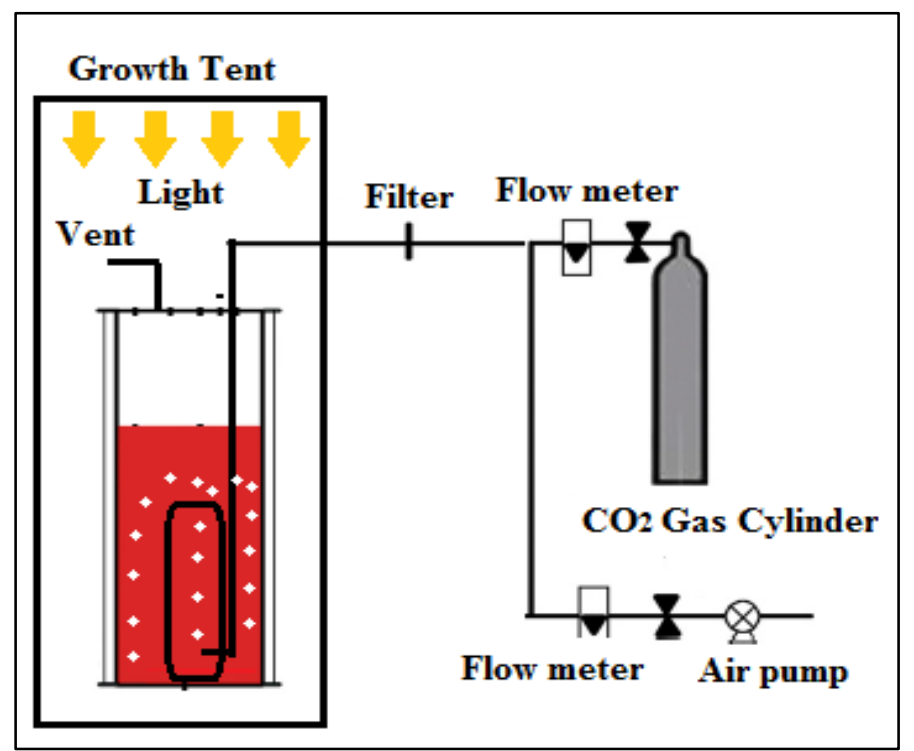

Figure 4.2: (a) Experimental Set up for $H$. pluvialis culture.

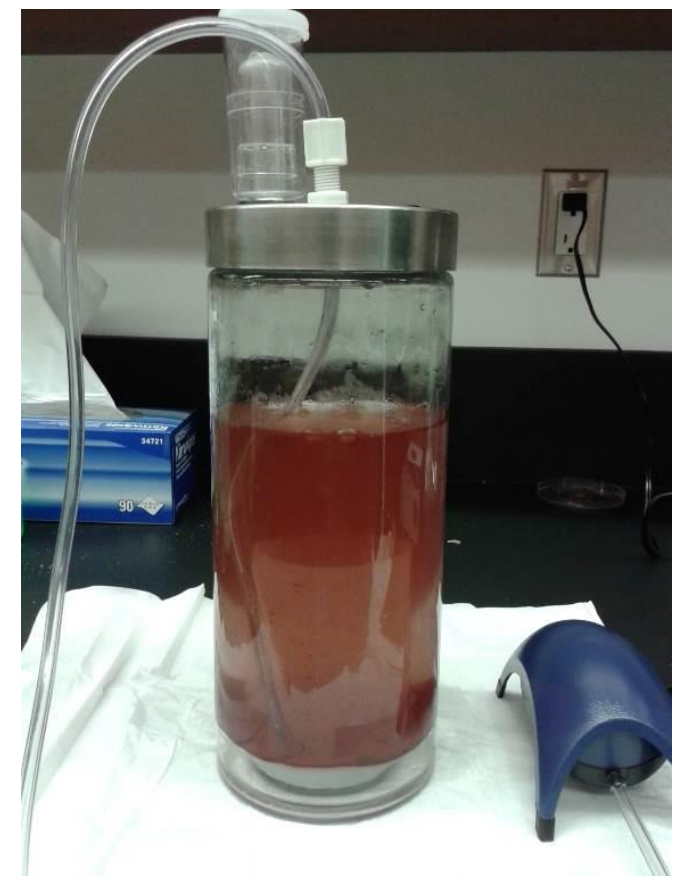

Figure 4.2: (b) The photobioreactor used for the study. 


\subsubsection{Astaxanthin extraction}

Astaxanthin extraction was carried out by pretreating the cyst cells using ultrasonication with sodium hydroxide, followed by methanol extraction (Haque et al., 2016). 50ml of the algal samples were taken and centrifuged (Thermo Scientific Sorvall ST 24) at 5,000 g for $15 \mathrm{~min}$. Cells were dried overnight at room temperature. To the dry cells, $200 \mathrm{ml}$ of $2 \mathrm{M} \mathrm{NaOH}$ was added and ultrasonicated using VC 750 ultrasonic processor (Sonics \& Materials Inc.) of the maximum power rating of $750 \mathrm{~W}$, and operating frequency of $20 \mathrm{kHz}$. An ultrasonic probe (horn) of $1.3 \mathrm{~cm}$ diameter was used for $25 \mathrm{~min}$ at $35 \%$ amplitude. The solution was centrifuged to recover the cell pellets, and to $20 \mathrm{mg}$ of the dry cells, $40 \mathrm{ml}$ of methanol (99.8\%) was added. After four hours, the sample was centrifuged at 5,000 $\mathrm{g}$ for $15 \mathrm{~min}$. The cells were dried overnight at room temperature and weighed using an analytical balance (Mettler Toledo). The total astaxanthin extracted (TAE) was estimated using a mass balance on the initial weight of the algal sample and the final weight after extraction. TAE was expressed using the formula:

$$
\operatorname{TAE}(\mathrm{mg} / \mathrm{g})=\frac{\text { Initial weight }(\mathrm{mg})-\text { Final weight }(\mathrm{mg})}{\text { Initial weight }(\mathrm{g})}
$$

All chemicals used are Fisher Scientific analytical grade. 


\subsubsection{Analysis}

\subsubsection{Growth and astaxanthin accumulation curve estimation}

For the analysis of cell growth and astaxanthin accumulation, $10 \mathrm{ml}$ of the algal broths were centrifuged at 5,000 $\mathrm{g}$ for 15 minutes; the supernatant was discarded, and the dry weight was determined after drying the cell pellet overnight at room temperature. The pellet was homogenized in pure acetone, and absorbance was measured, using a spectrophotometer (Genesys 20 Visible, Thermo Fisher Scientific), at $670 \mathrm{~nm}$ and $450 \mathrm{~nm}$ for determination of microalgal cell growth and astaxanthin accumulation, respectively, based on optical density (OD) calibration. Specific growth rate $\left(\mu\right.$ day $\left.^{-1}\right)$ was determined using the following formula (L. Shuler and Kargi, 2002):

$$
\mu=\frac{\ln (\mathrm{DW} \mathrm{i})-\ln (\mathrm{DW} 0)}{\mathrm{ti}-\mathrm{t} 0}
$$

Where $\mathrm{DW}_{0}$ and $\mathrm{DW}_{\mathrm{i}}$ is the dry weight $(\mathrm{g} / \mathrm{l})$ of the algal sample on the initial day $\left(\mathrm{t}_{0}\right)$ and day $\mathrm{t}$ i, respectively. Also, $\mathrm{pH}$ of the media was measured at the end of the lag phase, exponential phase, and stationary phase to analyze the effect of $\mathrm{CO}_{2}$ concentration on the $\mathrm{pH}$ of the media.

\subsubsection{Initial and Final Wastewater characterization}

The wastewater samples were characterized on the basis of $\mathrm{pH}$, total nitrogen (TN), total organic carbon (TOC), total phosphate (TP) and acetic acid. These parameters were tested for a) the Thin Stillage (S1) and the Process Condensate (S2) initially, b) the modified S1 (60 times diluted), i.e., GroAst media during the green phase, c) the GroAst media during the red phase, i.e., when $40 \% \mathrm{~S} 2$ is added to $60 \%$ modified $\mathrm{S} 1$, and d) the final media, denoted as the residual media, which was obtained at the end of the 
experimental run. The sample was centrifuged at 5,000 g for $15 \mathrm{~min}$, and the supernatant was analyzed. Nutrient removal (\%) was calculated as:

$$
\% \text { Nutrient Removal }=\frac{[\text { Nutrient }] \text { final }-[\text { Nutrient }] \text { initial }}{[\text { Nutrient }] \text { initial }} * 100
$$

Where, [Nutrient] final and [Nutrient] initial is the nutrient composition (g/l) of the GroAst media finally, and initially, respectively.

\section{$\underline{\text { 4.2.3.3. Microcystin Detection Test }}$}

For the quantitative laboratory detection of Microcystin (MC) toxin in algal samples, the EnviroLogix QuantiPlate Kit was used, which uses the principle of a competitive Enzyme - Linked Immuno Sorbent Assay (ELISA). The experiment was carried out as mentioned in the kit manual (Catalog number EP 022, EnviroLogix), using a Negative control and standard Microcystin (0.16 ppb, $0.6 \mathrm{ppb}$, and $2.5 \mathrm{ppb})$ as calibrators. The OD was measured at $450 \mathrm{~nm}$ using a UV-VIS spectrophotometer (Multiskan Go Microplate Spectrophotometer, Thermo Fisher Scientific). A standard curve was obtained by plotting $\% \mathrm{~B}_{\mathrm{o}}$ and the calibrator's concentration on a semi - log graph, where,

$$
\% \text { Bo }=\frac{\text { Average OD of calibrator or sample }}{\text { Average OD of Negative Control }} * 100
$$

The calibration curve was used to determine the microcystin concentration in the algal sample. The green as well as the red cells of $H$. pluvialis, cultured in a) the modified M1B5, and b) the GroAst media, were tested for microcystin's presence. The detection limit of this ELISA kit is $0.16 \mathrm{ppb} \mathrm{MC}$. 


\subsubsection{Residual algal biomass characterization}

\subsection{Proximate and Ultimate Analysis, and High Heating value (HHV)}

ASTM standards were used to perform the proximate analysis (ash, volatile matter and fixed carbon) of the residual biomass. A measured amount of the sample was placed in the muffle furnace (Thermo Scientific- F48055-60, Waltham, MA) maintained at $103 \pm$ $2^{\circ} \mathrm{C}$ for at least $15 \mathrm{~h}$ and then cooled in a desiccator, containing silica gel. The samples were then re-weighed, and the change in initial and final weight was expressed as percentage moisture (ASTM-E871). The dried samples were then burnt at $575^{\circ} \mathrm{C}$ for $5 \mathrm{hrs}$ in a muffle furnace to determine percentage ash (ASTM-E1755). For determining the volatile matter (VM), the sample was heated at $950^{\circ} \mathrm{C}$ for $7 \mathrm{mins}$ (ASTM- E872). The fixed carbon was calculated by the difference in the remaining percentages. The elemental analyzer (Thermo Fisher Flash EA 1112, Waltham, MA) was used to perform the ultimate analysis (carbon $(\mathrm{C})$, hydrogen $(\mathrm{H})$, nitrogen $(\mathrm{N})$, Sulphur $(\mathrm{S})$, and Oxygen $(\mathrm{O})$ ) of the samples.

The higher heating values (HHV) of the samples were determined using IKA-C200 bomb calorimeter (Wilmington, NC). All the samples were oven dried at $105^{\circ} \mathrm{C}$ for $24 \mathrm{hrs}$ before analysis. Approximately $0.5 \mathrm{~g}$ of the sample was placed in the steel container fitted with a ceramic crucible. The pure oxygen at 30 bars was used to pressurize the adiabatic vessel, and a cotton thread connected to an ignition wire in the steel container was used to ignite the sample. 


\subsection{FTIR Analysis}

FTIR spectrum of the dried algal sample was recorded on Varian 660 IR (Agilent Technology) at room temperature. A region of 4000-400 $\mathrm{cm}^{-1}$ was used for scanning.

\subsection{Thermal Analysis}

To study the combustion behavior of the residual biomass sample, thermogravimetric analysis (TGA) was performed. The dried residual biomass was run in a TG/DT analyzer (Thermo Scientific Nicolet 700 FTIR) in a nitrogen atmosphere at heating rates of $10{ }^{\circ} \mathrm{C} / \mathrm{min}$. Approximately $10 \mathrm{mg}$ of the sample was heated at the preselected heating rate from ambient temperature to $750{ }^{\circ} \mathrm{C}$. Nitrogen gas of high purity (99.99\%) was supplied at a constant flow rate of $100 \mathrm{ml} / \mathrm{min}$ as an inert purge gas. Nitrogen gas eliminates unwanted oxidation of the sample by displacing the air in the pyrolytic zone. The weight loss with an increase in temperature is recorded and the TGA -DTG (derivative) curves were plotted.

\subsubsection{Data Analysis}

All readings were taken in triplicates and results were represented along with standard deviation.

The data, in the graphs, have been represented along with standard errors. 


\subsection{Results}

\subsubsection{Effect of $\mathrm{CO}_{2}$ on $\mathrm{H}$. pluvialis growth}

Figure 4.3 shows the growth curve and astaxanthin accumulation curve at different $\mathrm{CO}_{2}$ concentrations. It can be seen that as the $\mathrm{CO}_{2}$ concentration is increased from atmospheric $\mathrm{CO}_{2}$ to $5 \%$, there is an increase in growth of algal cells. For $5 \% \mathrm{CO}_{2}$ concentration, maximum growth absorbance of $0.55 \pm 0.02$ was obtained on the $8^{\text {th }}$ day, after which, algal culture was exposed to continuous light stress, and maximum astaxanthin accumulation (absorbance of $0.41 \pm 0.01$ ) was observed on the $15^{\text {th }}$ day with total astaxanthin extracted (TAE) being $38 \pm 2.55 \mathrm{mg} / \mathrm{g}$. As the $\mathrm{CO}_{2}$ concentration is increased to $10 \%$, a decline in the growth occurs. The $10 \% \mathrm{CO}_{2}$ gas supplies more $\mathrm{CO}_{2}$ than required for sufficient growth, and excess nutrients are not good for the cell survival. Samples grown under atmospheric $\mathrm{CO}_{2}$ concentration gas supply showed less growth compared to the samples supplied with $2.5 \%$ and $5 \% \mathrm{CO}_{2}$, so it can be said that $\mathrm{CO}_{2}$ availability may have been the limiting factor for culture growth. Samples cultivated with $2.5 \%$ and $5 \% \mathrm{CO}_{2}$ gas supply showed similar growth patterns. 


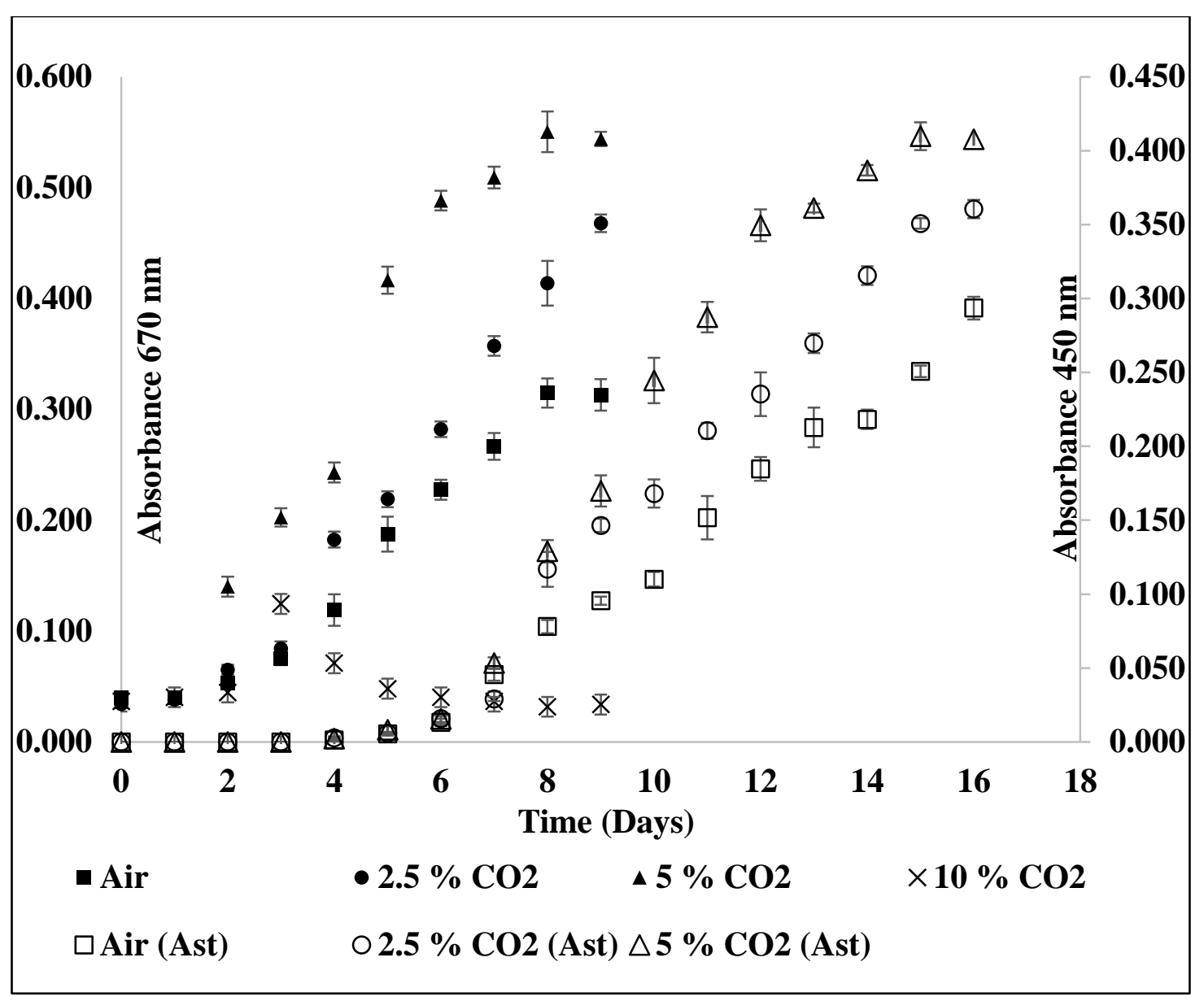

Figure 4.3: Growth and astaxanthin accumulation curve at different concentration of $\mathrm{CO}_{2}$ gas supply.

Figure 4.4 shows that the sample supplemented with $5 \% \mathrm{CO}_{2}$ gas supply reached the highest biomass production $(4.37 \pm 0.07 \mathrm{~g} / \mathrm{l})$ and the astaxanthin rich dried biomass is shown in Figure 4.5. The change in the $\mathrm{pH}$ of the GroAst media under the effect of different concentration of $\mathrm{CO}_{2}$ is summarized in Table 4.1, along with the specific growth rate. When only air is supplied, the $\mathrm{pH}$ increased from 7 to 9.64 by the end of the stationary phase and a biomass density of $2.028 \pm 0.09 \mathrm{~g} / \mathrm{l}$ was obtained. However, when the growth media was supplied with $5 \% \mathrm{CO}_{2}$, the $\mathrm{pH}$ changed to 6.32 at the end of the experimental 
run and the maximum biomass density was achieved on the $11^{\text {th }}$ day $\left(\mathrm{T}_{\max }\right)$ with a specific growth rate of 0.317 day $^{-1} .10 \% \mathrm{CO}_{2}$ supply resulted in an acidic media ( $\left.\mathrm{pH} 3.91\right)$ and a stunted algal growth.

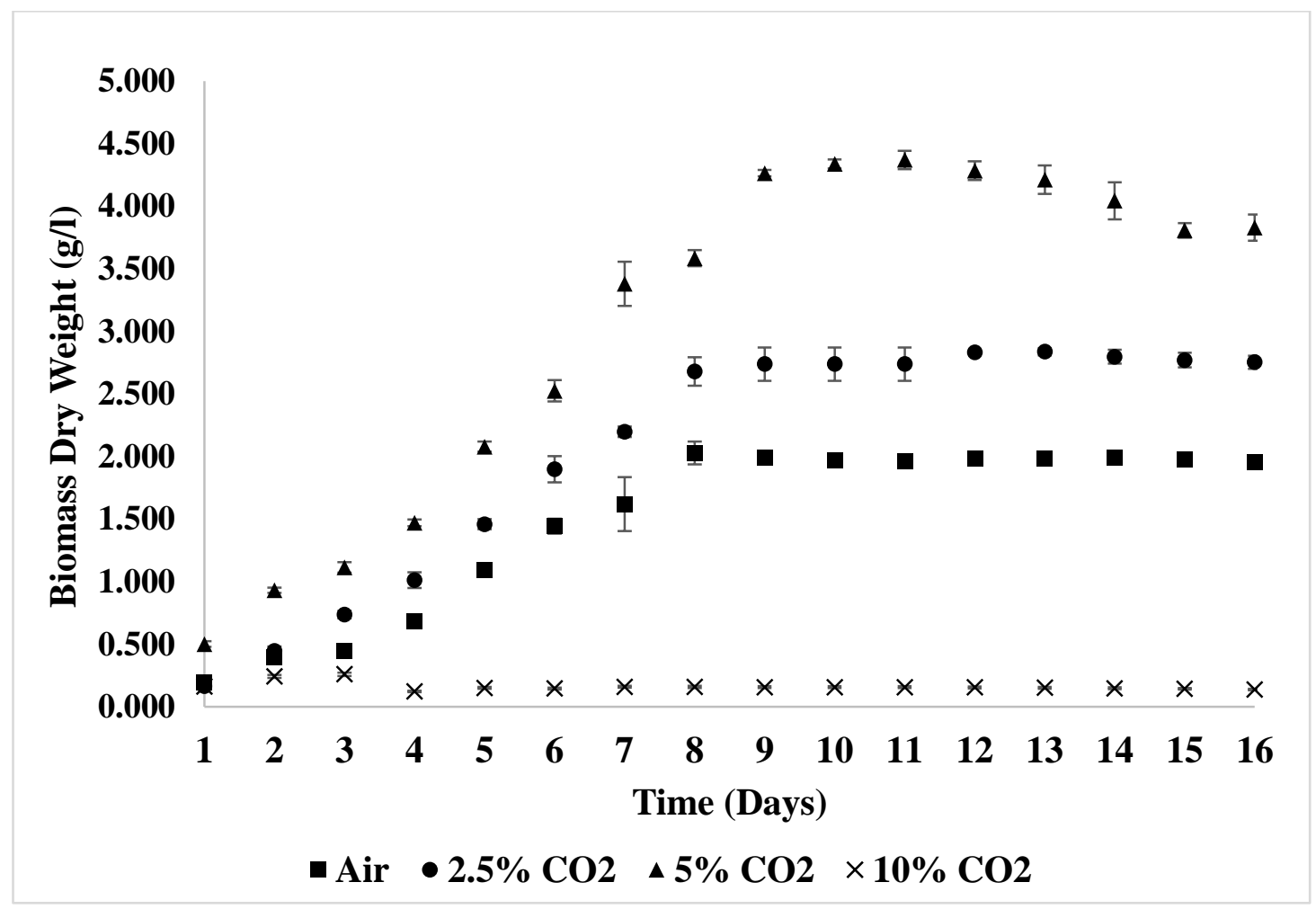

Figure 4.4: Biomass density at different $\mathrm{CO}_{2}$ gas supply.

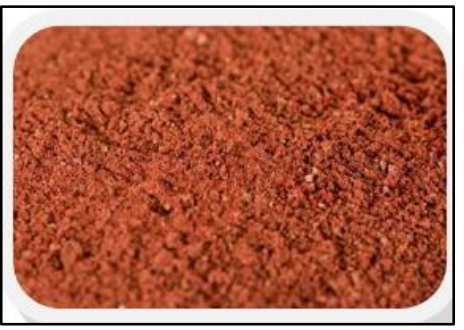

Figure 4.5: Dried astaxanthin rich $H$. pluvialis biomass. 
Table 4.1: $\mathrm{pH}$ change and specific growth rate at different $\mathrm{CO}_{2}$ concentrations.

\begin{tabular}{|c|c|c|c|c|c|c|c|}
\hline \multirow{2}{*}{$\begin{array}{l}\mathrm{CO}_{2} \\
\text { Concentration }\end{array}$} & \multirow{2}{*}{$\begin{array}{l}\text { Initial } \\
\text { pH }\end{array}$} & \multicolumn{3}{|c|}{ pH } & \multirow{2}{*}{$\begin{array}{l}\text { T } \\
\text { max } \\
\text { (day) }\end{array}$} & \multirow{2}{*}{$\begin{array}{l}\text { DW } \\
\max \\
(\mathrm{g} / \mathrm{l})\end{array}$} & \multirow{2}{*}{$\begin{array}{l}\text { Specific } \\
\text { Growth } \\
\text { Rate } \\
\left(\text { day }^{-1}\right)\end{array}$} \\
\hline & & $\begin{array}{l}\text { Lag } \\
\text { phase }\end{array}$ & $\begin{array}{l}\text { Exponential } \\
\text { phase }\end{array}$ & $\begin{array}{l}\text { Stationary } \\
\text { Phase }\end{array}$ & & & \\
\hline Air & 7.00 & 7.91 & 8.42 & 9.64 & 8 & $\begin{array}{l}2.028 \\
\pm \\
0.09\end{array}$ & 0.236 \\
\hline $2.5 \%$ & 7.00 & 7.33 & 7.93 & 8.22 & 13 & $\begin{array}{l}2.836 \\
\pm \\
0.03\end{array}$ & 0.280 \\
\hline $5 \%$ & 7.00 & 7.84 & 6.61 & 6.32 & 11 & $\begin{array}{l}4.37 \\
\pm \\
0.07\end{array}$ & 0.317 \\
\hline $10 \%$ & 7.00 & 4.13 & 4.09 & 3.91 & 3 & $\begin{array}{l}0.259 \\
\pm \\
0.02\end{array}$ & 0.013 \\
\hline
\end{tabular}

\subsubsection{Comparison of initial and final characteristics of the wastewater media}

Table 4.2 shows the nutrient composition of the wastewater samples (S1 and S3) and the GroAst media used for astaxanthin production, along with the amount of nutrient removal at the end of the experimental run. It can be seen that the modified S1 sample has the similar nutrient composition to that of the standard media, modified M1B5. The GroAst media contained $0.215 \mathrm{~g} / \mathrm{l}$ of acetic acid, which is devoid in the standard media, and hence additional supplement of acetic acid is not required. H. pluvialis culture resulted in $91.67 \%$ total nitrogen removal and $100 \%$ total phosphorus removal. $42.33 \%$ acetic acid was consumed for astaxanthin synthesis and the final media contained $32.99 \%$ of total organic carbon. 
Table 4.2: Wastewater characterization and percentage nutrient removal. $(\mathrm{S} 1=$ Thin Stillage, $\mathbf{S 2}=$ Process Condensate).

\begin{tabular}{|l|l|l|l|l|l|l|l|}
\hline Analysis & S1 & S3 & $\begin{array}{l}\text { Modified } \\
\text { S1 }\end{array}$ & $\begin{array}{l}\text { Modified } \\
\text { M1B5 }\end{array}$ & $\begin{array}{l}\text { GroAst } \\
\text { media }\end{array}$ & $\begin{array}{l}\text { Residual } \\
\text { media }\end{array}$ & $\begin{array}{l}\text { Nutrient } \\
\text { Removal } \\
(\%)\end{array}$ \\
\hline pH & 3.82 & 3.11 & 7 & 6.74 & 6.61 & 6.32 & NA \\
\hline TN $(\mathbf{g} / \mathbf{l})$ & 1.52 & 0.017 & 0.025 & 0.025 & 0.012 & 0.001 & 91.67 \\
\hline TOC (g/l) & 23.1 & 1.28 & 0.385 & 0.03 & 0.882 & 0.291 & 67.01 \\
\hline TP $(\mathbf{g} / \mathbf{l})$ & 1.79 & 0.0015 & 0.031 & 0.026 & 0.004 & 0 & 100 \\
\hline $\begin{array}{l}\text { Acetic } \text { Acid } \\
\text { (g/l) }\end{array}$ & 0.861 & 0.336 & 0.0144 & NA & 0.215 & 0.124 & 42.33 \\
\hline
\end{tabular}

\subsubsection{Microcystin Detection Test}

Figure 4.6 shows the calibration curve for microcystin. Using this curve, the concentration of microcystin in the H. pluvialis sample has been calculated and tabulated in Table 4.3, along with the $\% \mathrm{~B}_{\mathrm{o}}$ values. The Negative control has $100 \% \mathrm{~B}_{\mathrm{o}}$ because it does not contain any MC, so during the ELISA test, the maximum amount of MC-Enzyme conjugate binds to the antibody. Also, it can be seen that $H$. pluvialis samples show a $\% \mathrm{~B}_{\mathrm{o}}$ value in the range of $92.01-93.05 \%$, which is very close to that of the negative control (i.e., $100 \% \mathrm{~B}_{\mathrm{o}}$ ), and they also showed negative results for microcystin test. 


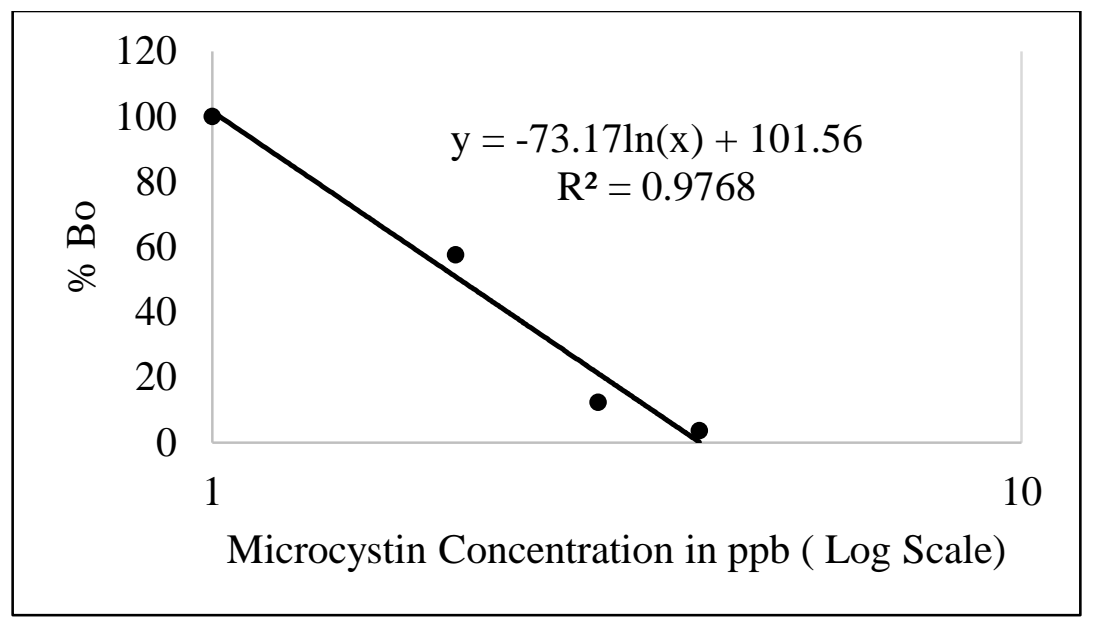

Figure 4.6: Microcystin calibration Curve. $\left(x=\% B_{o}\right.$ and $y=$ Microcystin concentration)

Table 4.3: Microcystin concentration in the $H$. pluvialis sample.

\begin{tabular}{|l|l|l|}
\hline Compound & $\mathbf{\%}_{\mathbf{o}}$ & $\begin{array}{l}\text { Microcystin Concentration } \\
\text { ppb }\end{array}$ \\
\hline Negative Control & 100 & NA \\
\hline Calibrator 0.16 ppb & 57.60 & NA \\
\hline Calibrator 0.6 ppb & 12.39 & NA \\
\hline Calibrator 2.5 ppb & 3.70 & NA \\
\hline H. pluvialis cultured in modified M1B5 media \\
\hline Green Cells & 93.05 & Negative \\
\hline Red Cells & 90.79 & Negative \\
\hline H. pluvialis cultured in GroAst media & \\
\hline Green Cells & 92.01 & Negative \\
\hline Red cells & 92.08 & Negative \\
\hline
\end{tabular}

\subsubsection{Characterization of residual $\mathrm{H}$. pluvialis biomass}

\subsubsection{Proximate and Ultimate Analysis}

The characterization of $H$. pluvialis biomass as a biofuel feedstock is itemized in Table 4.4. The ash content, volatile matter, moisture content and fixed carbon of the algal biomass is $5.43 \pm 0.25 \%, 71.28 \pm 0.27 \%, 7.93 \pm 0.12 \%$ and $15.36 \pm 0.56 \%$, respectively. 
The ultimate analysis shows that the residual biomass has $43.57 \%$ Carbon, $6.26 \%$ Hydrogen, 48.04\% Oxygen, $1.97 \%$ Nitrogen and very little Sulphur (0.47\%). This helps to understand the elemental composition of the sample and the empirical formula of the residual algal biomass is found to be $\mathrm{C}_{3.63} \mathrm{H}_{6.26} \mathrm{~N}_{0.14} \mathrm{~S}_{0.01} \mathrm{O}_{3}$. The $\mathrm{H} / \mathrm{C}$ an $\mathrm{O} / \mathrm{C}$ molar ratios (on the ash free dry basis) were calculated from the elemental composition as 1.72 and 0.83 , respectively. The HHV of the un-extracted algal biomass is measured to be 22.78 $\mathrm{MJ} / \mathrm{kg}$, whereas the HHV of the post extracted residual biomass is $11.31 \mathrm{MJ} / \mathrm{kg}$, which is almost half of that of the astaxanthin rich algal biomass.

Table 4.4: Characterization of residual Haematococcus Biomass.

\begin{tabular}{|c|c|c|}
\hline \multicolumn{2}{|l|}{ Properties } & \multirow{2}{*}{$\frac{\text { Haematococcus pluvialis }}{22.78 \pm 0.24}$} \\
\hline $\begin{array}{l}\mathrm{HHV} \quad(\mathrm{MJ} / \mathrm{kg}) \\
\begin{array}{l}\text { astaxanthin-rich } \\
\text { biomass }\end{array}\end{array}$ & & \\
\hline $\begin{array}{l}\mathrm{HHV}(\mathrm{MJ} / \mathrm{kg}) \text { of residual } \\
\text { biomass }\end{array}$ & & $11.31 \pm 0.01$ \\
\hline $\begin{array}{l}\text { Empirical formula (on ash } \\
\text { free basis) }\end{array}$ & & $\mathrm{C}_{3.63} \mathrm{H}_{6.26} \mathrm{~N}_{0.14} \mathrm{~S}_{0.01} \mathrm{O}_{3}$ \\
\hline $\begin{array}{l}\mathrm{H} / \mathrm{C} \text { molar ratio (on ash free } \\
\text { basis) }\end{array}$ & & 1.72 \\
\hline $\begin{array}{l}\mathrm{O} / \mathrm{C} \text { molar ratio (on ash free } \\
\text { basis) }\end{array}$ & & 0.83 \\
\hline \multirow[t]{5}{*}{ Elemental analysis (wt. \%) } & Carbon & $43.57 \pm 0.61$ \\
\hline & Hydrogen & $6.26 \pm 0.54$ \\
\hline & Nitrogen & $1.98 \pm 0.16$ \\
\hline & Sulphur & $0.47 \pm 0.03$ \\
\hline & Oxygen & $48.04 \pm 1.5$ \\
\hline \multirow[t]{4}{*}{ Proximate analysis (wt. \%) } & Moisture & $7.93 \pm 0.12$ \\
\hline & Volatile matter & $71.28 \pm 0.27$ \\
\hline & Fixed Carbon & $15.36 \pm 0.56$ \\
\hline & Ash & $5.43 \pm 0.25$ \\
\hline
\end{tabular}




\subsubsection{FTIR Spectra}

FTIR spectroscopy helps in the rapid analysis of algal biomass and offers a viable screening approach to determine the biofuel potential of algae. The FTIR spectrum of the H. pluvialis algal biomass and residual biomass is shown in Figure 4.7. The identification of the unknown components is derived by comparing the bands of the recorded FTIR spectrum with those available in the literature (Bi and He, 2013; Ceylan and Goldfarb, 2015; Serio et al.; Sudhakar and Premalatha, 2015), and has been summarized in Table 4.5. It reveals the presence of $-\mathrm{OH},-\mathrm{COOH}$ and $\mathrm{CO}$ organic functional groups:

- $900-1,400 \mathrm{~cm}^{-1}$ : Phenols and alcoholic groups;

- $\quad 1,500-1,800 \mathrm{~cm}^{-1}$ : Carboxyl group;

- 3,200-3,400 $\mathrm{cm}^{-1}$ : Hydroxyl group;

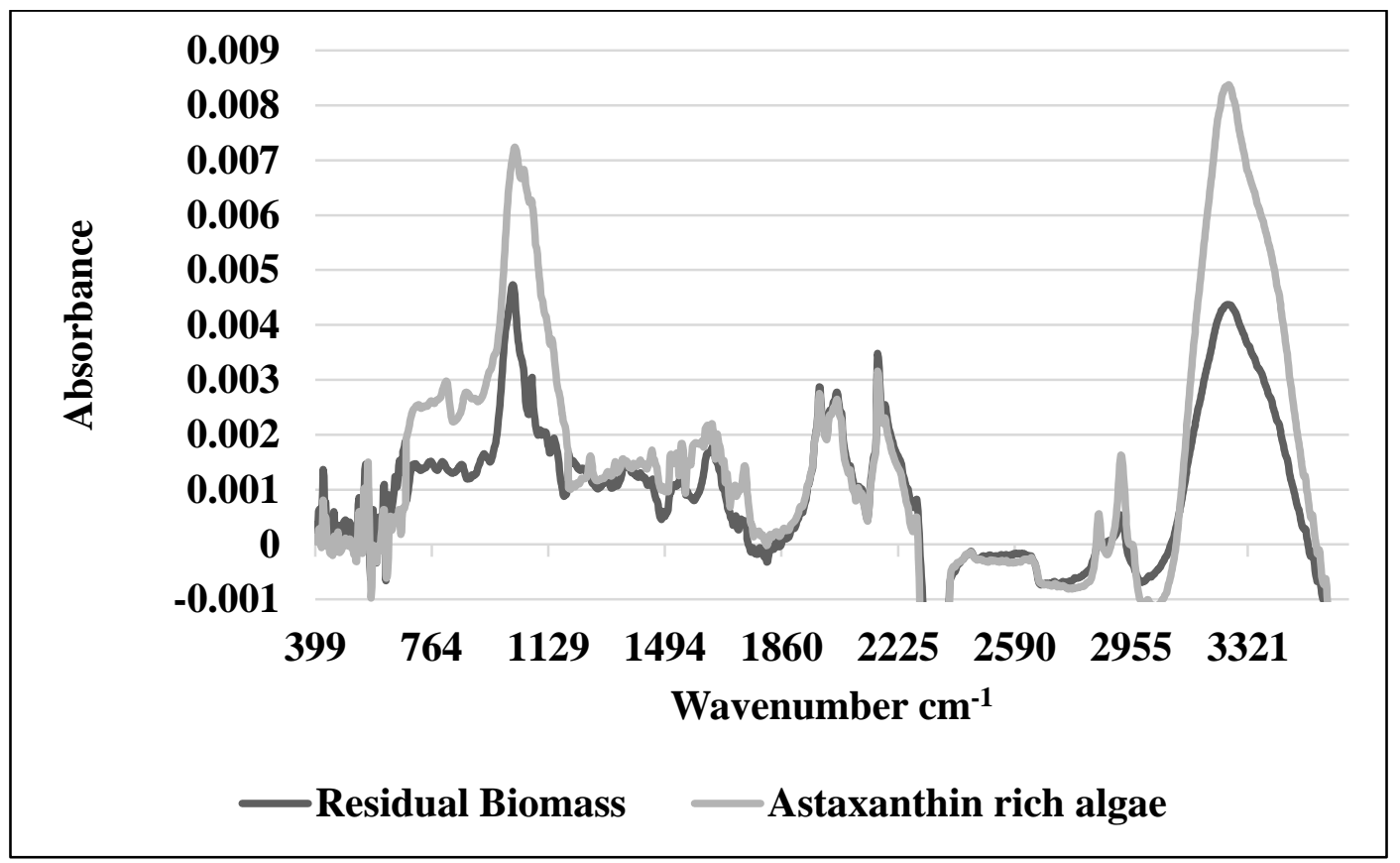

Figure 4.7: FTIR Spectrum of astaxanthin-rich algae and residual biomass. 
In the spectrum of the residual biomass, the band at $3,268 \mathrm{~cm}^{-1}$ is due to the $\mathrm{O}-\mathrm{H}$ stretching. The weak band centered at $2,933 \mathrm{~cm}^{-1}$ is due to the presence of asymmetric CH stretching vibrations, which is likely due to the lipid's methylene group. The increase in the peaks at $1,982 \mathrm{~cm}^{-1}$ is due to the carboxylic stretch, and this confirms a greater concentration of fatty acids. A sharp peak at $1,652 \mathrm{~cm}^{-1}$ corresponds to $\mathrm{C}=\mathrm{O}$ amide stretching from proteins present in the residual algal biomass. The peak spanning between $1,800-1,500 \mathrm{~cm}^{-1}$ is the characteristic bands for proteins and $1,456-1,402 \mathrm{~cm}^{-1}$ is likely due to $\mathrm{C}-\mathrm{H}$ stretching vibration in methyl, methylene and methyne groups. A twin absorbance peak at $1,078 \mathrm{~cm}^{-1}$ and $985 \mathrm{~cm}^{-1}$ are likely the $\mathrm{C}-\mathrm{O}$ and $\mathrm{C}-\mathrm{O}-\mathrm{H}$ deformation in the secondary and tertiary alcohol or aliphatic ethers. The C-O-H vibrational stretching suggests the presence of polysaccharides (Sudhakar and Premalatha, 2015).

It is clear that the intensity of the absorbance corresponding to polysaccharides (985 $\left.\mathrm{cm}^{-1}\right)$ is much higher than the one for the lipids $\left(2,933 \mathrm{~cm}^{-1}\right)$. Also, the intensity of the spectra of the residual biomass is lower than the un-extracted biomass. There is a general decrease in the lipid and protein content as can be seen in the $3,000-2,800 \mathrm{~cm}^{-1}$ region and $1,800-1,400 \mathrm{~cm}^{-1}$ region, respectively. It is evident from the FTIR spectrum of $H$. pluvialis residual biomass that distinct fingerprint regions for triglycerides, lipids and polysaccharides exist in the biomass. 
Table 4.5: Characteristic bands observed in the FTIR spectrum of the biomass (Bi and He, 2013; Ceylan and Goldfarb, 2015; Serio et al., 1996; Sudhakar and Premalatha, 2015).

\begin{tabular}{|l|l|l|}
\hline Wavenumber $\mathbf{~ c m}^{-\mathbf{1}}$ & Functional Group & $\begin{array}{l}\text { Species/ } \\
\text { compound/Element }\end{array}$ \\
\hline Functional groups assigned to peaks on solid H. pluvialis & residual biomass surface \\
\hline 3,268 & $-\mathrm{OH}, \mathrm{N}-\mathrm{H}$ & Alcohol, Amine \\
\hline 2,933 & $\mathrm{C}-\mathrm{H}$ & Methylene groups (Lipids) \\
\hline 1,982 & $\mathrm{C}=\mathrm{O}$ & $\begin{array}{l}\text { Aromatic conjugates, } \\
\text { Carboxylic group }\end{array}$ \\
\hline 1,371 & $\mathrm{C}-\mathrm{O}$ & Acid \\
\hline 1,151 & $\mathrm{C}-\mathrm{O}-\mathrm{H}$ & Phenols \\
\hline $1,078-985$ & $\mathrm{C}-\mathrm{O}, \mathrm{C}-\mathrm{O}-\mathrm{H}$ & $\begin{array}{l}\text { Alcohols, Esters, and } \\
\text { polysaccharides }\end{array}$ \\
\hline
\end{tabular}

\subsubsection{Thermal Analysis}

\subsection{TGA}

The weight loss of the biomass can be seen from the TGA curve at with the temperature increase with time, and Figure 4.8 shows the TGA - DTG curve of the residual algal biomass at a heating rate of $10^{\circ} \mathrm{C} / \mathrm{min}$. There are three distinct decomposition zones observed during the pyrolysis process of the microalgae:

- Dehydration Zone: This is the initial stage, at around $110^{\circ} \mathrm{C}$, where the weight loss occurs due to the loss of moisture from the biomass.

- Devolatilization Zone: This is the second stage where the biomass sample loses the volatile matter content. Three overlapped peaks indicate this zone at $250{ }^{\circ} \mathrm{C}, 320$ ${ }^{\circ} \mathrm{C}$ and $375^{\circ} \mathrm{C}$. After the peak obtained at $110^{\circ} \mathrm{C}$ for moisture loss, two more stages of weight loss occur at $300{ }^{\circ} \mathrm{C}$ and $420{ }^{\circ} \mathrm{C}$, in the vicinity of $350{ }^{\circ} \mathrm{C}$, which is believed to be lipid loss and some lignocellulosic polymer decomposition. Major 
volatile matter loss, $72 \%$, occurs at $300{ }^{\circ} \mathrm{C}$ and Sudhakar and Premalatha, 2015 suggests that cellulose decomposition usually occurs between $290{ }^{\circ} \mathrm{C}-390{ }^{\circ} \mathrm{C}$.

- Solid Residue Decomposition Zone: This is the last stage, where slow decomposition of the solid residue, formed in the above step, occurs. As seen from Figure 4.8 , beyond $450{ }^{\circ} \mathrm{C}$, slow loss of weight continues until $750{ }^{\circ} \mathrm{C}$. The final solid residue content obtained at the end of the process is $25.99 \%$. The nitrogen gas, used as the inert purge gas for the TGA process, eliminates unwanted oxidation of the sample by displacing the air in the pyrolytic zone, hence it can be said that only the volatile matter are loss during the devolatilization zone, and the fixed carbon and ash forms the solid residue in the last stage. The result obtained for the final solid residue $(25.99 \%)$ is similar to the results obtained for fixed carbon (15.36 \pm $0.56 \%)$ and ash content $(5.43 \pm 0.25 \%)$ using proximate analysis (Table 4.4). However, there is a small difference in these numbers, which can be due to the different conditions at which TGA was carried out. For proximate analysis, ash content was determined by burning the sample in a muffle furnace at $575^{\circ} \mathrm{C}$ for 5 hours, however, TGA was carried out using nitrogen gas at $10^{\circ} \mathrm{C} / \mathrm{min}$ for $75 \mathrm{~min}$.

The main pyrolysis reaction takes place in between $110{ }^{\circ} \mathrm{C}$ and $450{ }^{\circ} \mathrm{C}$, where the active pyrolysis zone is the region between $110^{\circ} \mathrm{C}-320^{\circ} \mathrm{C}$, and $320^{\circ} \mathrm{C}-420^{\circ} \mathrm{C}$ region is the zone of passive pyrolysis which terminates at $450{ }^{\circ} \mathrm{C}$. Along with the heating value of $10{ }^{\circ} \mathrm{C} / \mathrm{min}$, the thermogram of the residual biomass was also obtained at 20 ${ }^{\circ} \mathrm{C} / \mathrm{min}$ and $30^{\circ} \mathrm{C} / \mathrm{min}$ (data not shown) and no significant difference was observed at these different heating values. Hence, this degradation profile of the algal biomass 
suggests that it can be a potential biofuel feedstock and maybe suitable for thermochemical conversion (Phukan et al., 2011).

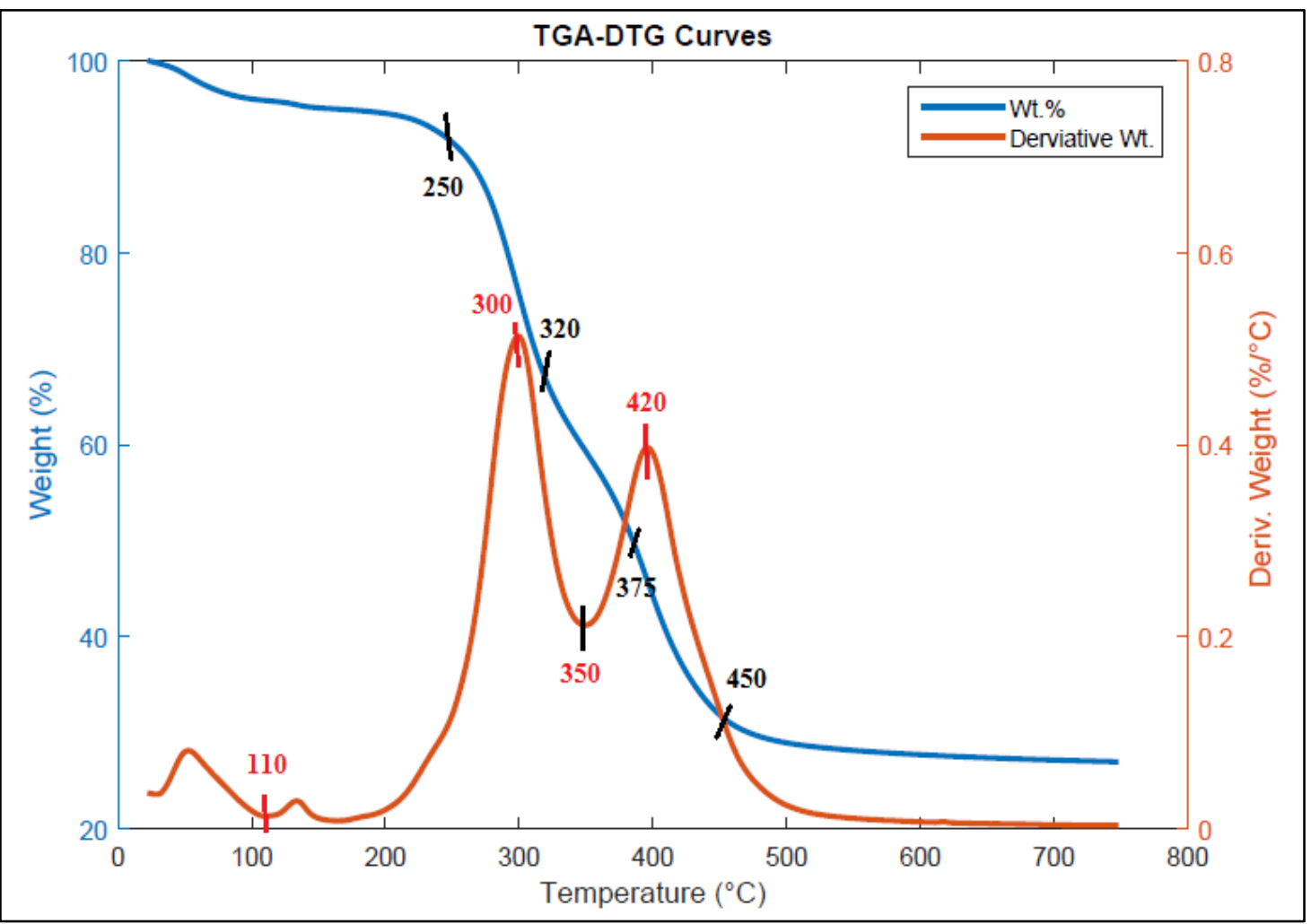

Figure 4.8: The TGA-DTG curve of residual biomass at $10{ }^{\circ} \mathrm{C} / \mathrm{min}$ heating flow rate.

\subsection{Analysis of the gas evolved during TGA process}

The volatile compounds evolved during the TGA process were analyzed using FTIR. Figure 4.9 presents the 3D IR spectrum with respect to wavenumber $\left(\mathrm{cm}^{-1}\right)$, time (min) and absorbance. In the region between 2,000-2,300 $\mathrm{cm}^{-1}$ some significant peaks for $\mathrm{C}=\mathrm{O}$ stretching of $\mathrm{CO}_{2}$ were obtained. The regions between $4,000-3,400 \mathrm{~cm}^{-1}$ give the characteristic signals for water (Sudhakar and Premalatha, 2015). 


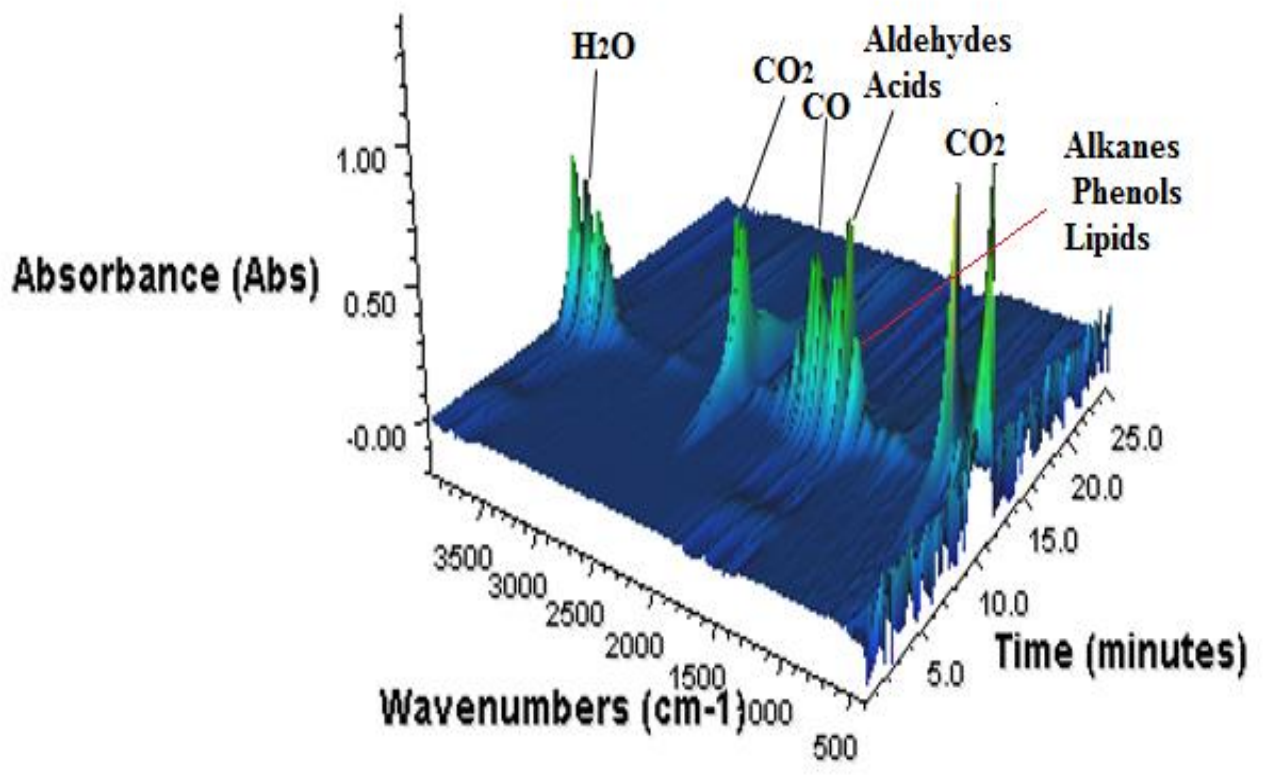

Figure 4.9: FTIR Spectrum of the gasses evolved during the TGA process.

Table 4.6 summarizes the peaks and their corresponding functional groups, based on the literature (Sudhakar and Premalatha, 2015). The main gaseous products from the pyrolysis were $\mathrm{CO}_{2}, \mathrm{CO}, \mathrm{H}_{2} \mathrm{O}$ and some organics (a mixture of acids, aldehydes, alkanes, and ethers).

Table 4.6: Characteristic bands observed in the evolved gas (Sudhakar and Premalatha, 2015).

\begin{tabular}{|l|l|l|}
\hline Wavenumber $\mathbf{c m}^{-1}$ & Functional Group & $\begin{array}{l}\text { Species/ } \\
\text { compound/Element }\end{array}$ \\
\hline Functional groups in devolatilized gasses from $H$. pluvialis residual biomass. \\
\hline $4,000-3,400$ & $\mathrm{O}-\mathrm{H}$ & $\mathrm{H}_{2} \mathrm{O}$ \\
\hline $2,400-2,300$ & $\mathrm{C}=\mathrm{O}$ & $\mathrm{CO}_{2}$ \\
\hline $2,300-2,000$ & $\mathrm{C}-\mathrm{O}$ & $\mathrm{CO}$ \\
\hline $1,900-1,650$ & $\mathrm{C}=\mathrm{O}$ & Aldehydes, Acids \\
\hline $1,700-1,450$ & $\mathrm{C}=\mathrm{C}$ & Aromatics \\
\hline $1,475-1,000$ & $\mathrm{C}-\mathrm{O}, \mathrm{C}-\mathrm{C}$ & $\begin{array}{l}\text { Alkanes, alcohols, phenols, } \\
\text { ethers, lipids, } \mathrm{CO}_{2}\end{array}$ \\
\hline
\end{tabular}




\subsection{Discussion}

A high-density $H$. pluvialis culture was obtained using bioethanol waste stream, in an air-lift photobioreactor supplemented with $5 \% \mathrm{CO}_{2}$. The specific growth rate $(0.317$ day-1) reported in this study is similar to the one reported by Kaewpintong et al., 2007 who achieved the maximum value of 0.45 day -1 for a continuous culture and 0.31 day- 1 for a semi-continuous culture of $\mathrm{H}$ pluvialis in an air-lift reactor. The highest biomass density obtained was $4.37 \pm 0.07 \mathrm{~g} / \mathrm{l}$, which is slightly lower than the one achieved by Ranjbar et al., 2008 who reported $5 \mathrm{~g} / \mathrm{l}$ cell concentration weight using modified basal media and $1 \mathrm{~L}$ bubble column reactor, but more than the $2.62 \mathrm{~g} / \mathrm{l}$ achieved by Jun et al., 2012, who cultivated $H$. pluvialis in a $6 \mathrm{~L}$ bag type reactor supplemented with $2 \% \mathrm{CO}_{2}$. Both air and $10 \% \mathrm{CO}_{2}$ supply resulted in a moderate growth, however, atmospheric $\mathrm{CO}_{2}$ supply resulted in a basic media ( $\mathrm{pH}$ of 9.64) and $10 \% \mathrm{CO}_{2}$ supply led to an acidic media ( $\mathrm{pH}$ of 3.91). The relation between $\mathrm{CO}_{2}$ supply and algal growth can be attributed to the $\mathrm{pH}$ change. When $\mathrm{CO}_{2}$ enriched air is bubbled into the culture media, the initial $\mathrm{CO}_{2}(\mathrm{~g})$ (gaseous) gets transferred to the $\mathrm{CO}_{2}(\mathrm{aq})$ (liquid phase), and this $\mathrm{CO}_{2}(\mathrm{aq})$ reacts with water and carbonic acid $\left(\mathrm{H}_{2} \mathrm{CO}_{3}\right)$ are formed, followed by the formation of bicarbonate $\left(\mathrm{pK}_{1} 6.35\right)$, and

carbonate $\left(\mathrm{pK}_{2}\right.$ 10.33) in the later stage (Stumm, 1996). Figure 4.10 shows the total concentration of dissolved carbonate species $\left(\mathrm{C}_{\mathrm{T}}\right)$, i.e., collective concentration of carbonic acid, bicarbonates and carbonates species, in water along with the predefined $\mathrm{pH}$ values. At $\mathrm{pH}$ less than $\mathrm{pK}_{1}$, carbonic acid species are the predominant species, and as the proton concentration is already very high at lower $\mathrm{pH}$, solubility of carbonic acid in water decreases and this results in lower $\mathrm{C}_{\mathrm{T}}$ value at acidic $\mathrm{pH}$. At $\mathrm{p} K_{1}<\mathrm{pH}<\mathrm{p} K_{2}$, bicarbonate $\left(\mathrm{HCO}_{3}{ }^{-}\right)$is the predominant species and at $\mathrm{pH}>\mathrm{pK} 2$, carbonate $\left(\mathrm{CO}_{3}{ }^{2-}\right)$ is the predominant 
species, and $\mathrm{C}_{\mathrm{T}}$ value further increases. Whereas $\mathrm{CO}_{2}$ supply reduces the $\mathrm{pH}$ of the culture medium, photosynthesis raised the $\mathrm{pH}$ of the medium as $\mathrm{CO}_{2}$ is consumed and this causes the carbonate species in the medium to be proportionately high. It is clear that $\mathrm{CO}_{2}$ supply/consumption ratio plays a major role in maintaining a suitable $\mathrm{pH}$ of the medium. At atmospheric $\mathrm{CO}_{2}$ condition, the $\mathrm{CO}_{2}$ consumption is higher than $\mathrm{CO}_{2}$ supply, hence the $\mathrm{pH}$ of the medium increases to 9.64 at the end of the stationary phase, where carbonate species dominates, and the $\mathrm{C}_{\mathrm{T}}$ value is higher. At $5 \% \mathrm{CO}_{2}$ gas supply the rate of $\mathrm{CO}_{2}$ supply is balanced by the photosynthetic $\mathrm{CO}_{2}$ consumption, thereby the $\mathrm{pH}$ of the medium is close to 6.32, where carbonic acid and bicarbonate species both co - exist. However, at $10 \% \mathrm{CO}_{2}$ gas supply, the $\mathrm{CO}_{2}$ supply exceeds the $\mathrm{CO}_{2}$ consumption rate, hence the $\mathrm{pH}$ drops to a greater extent (3.91) and this carbonic acid rich acidic medium, do not support algal growth. It has been reported that a $\mathrm{pH}$ more than 10 or less than 5.5 is detrimental to the algal growth (Kang et al., 2005; Ranga Rao, 2011). 


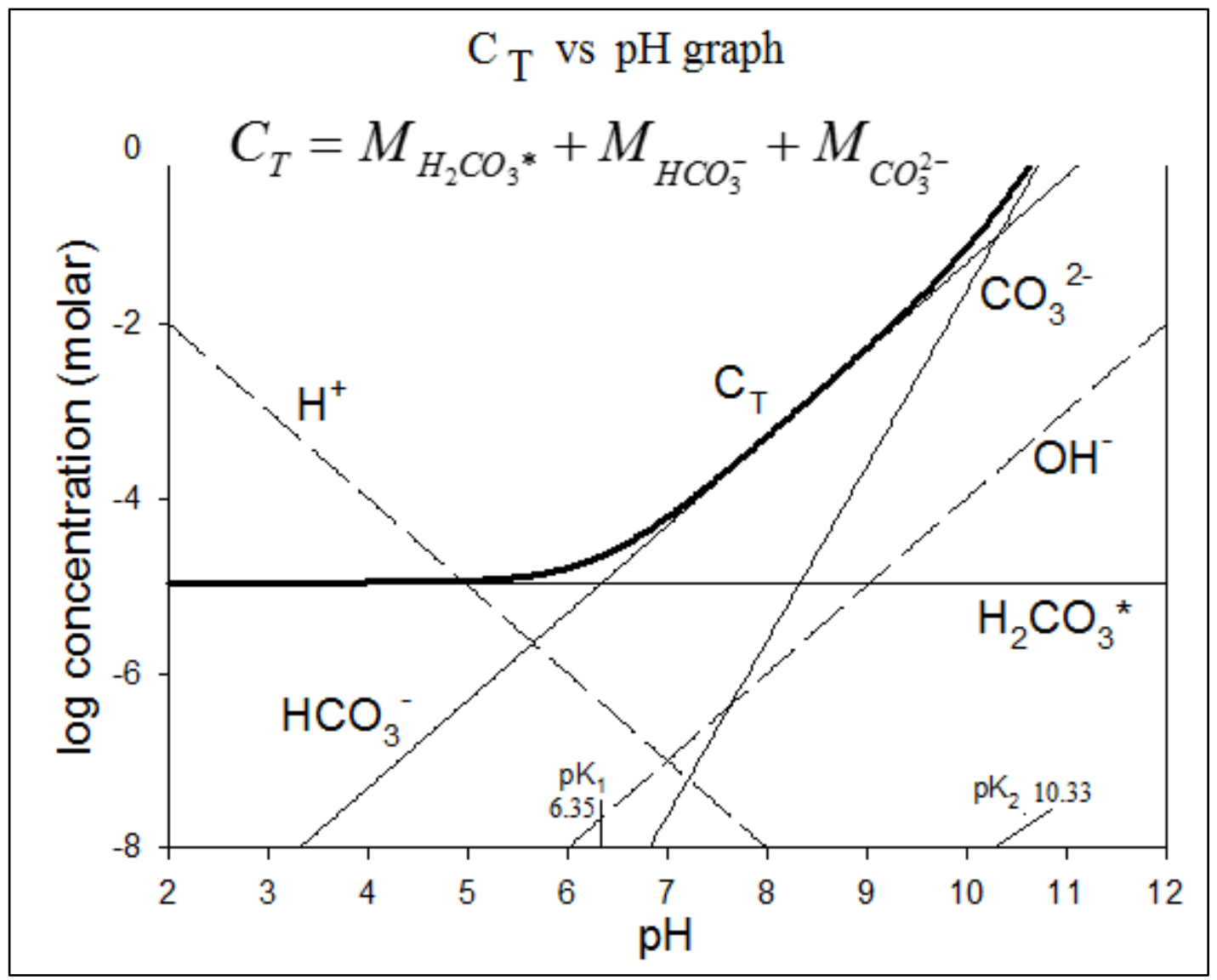

Figure 4.10: Variation of the Total dissolved carbonate concentration $\left(\mathrm{C}_{T}\right)$ relative to pH (Adapted from Stumm, 1996).

The ability of $\mathrm{H}$. pluvialis to utilize $\mathrm{CO}_{2}$ for their growth can help in $\mathrm{CO}_{2}(\mathrm{GHG})$ mitigation. Canada is responsible for approximately $1.6 \%$ of global GHG emissions, which is estimated by the Canadian Environment Protection Agency (CEPA) to be 283 megatons $\mathrm{CO}_{2}$ equivalent in 2014 (EC, 2014). In addition to $\mathrm{CO}_{2}$ uptake, $H$. pluvialis successfully utilized inorganic wastes, $91.67 \%$ total nitrogen and $100 \%$ total phosphorous, from the wastewater sample. These results are in accordance with $\mathrm{Wu}$ et al., 2013, who reported 93.8\% $\mathrm{N}$ removal and $97.8 \% \mathrm{P}$ removal when $H$. pluvialis were cultured in the domestic secondary effluent. Also, Kang et al., 2006 studied the biosynthesis of astaxanthin by cultivating $H$. pluvialis in primary treated sewage and primary treated piggery wastewater, 
and the author reported that 4-8 fold dilution of primary treated piggery wastewater resulted in $100 \% \mathrm{~N}$ and $\mathrm{P}$ removal at the end of the process.

The H. pluvialis samples showed negative results for microcystin test (detection limit $0.16 \mathrm{ppb}$ ). According to the $\mathrm{WHO}$ guidelines for drinking water quality, the guiding value for the total MC is $1 \mathrm{ppb}$ (WHO, 1998). Also, in 2014, EFSA (European Food and Safety Authority) published a report on the safety of their astaxanthin product, AstaREAL, which were produced from $\mathrm{H}$. pluvialis and were being marketed at powder or encapsulated oil. These AstaREAL products were intended to be used in fermented and non - fermented liquid dairy products, fermented soya products and fruit drinks for healthy adults. Their study showed that their product AstaREAL is safe with no genotoxicity related concern (EFSA, 2014). Hence, it can be seen that astaxanthin production from $H$. pluvialis does not pose any threat of microcystin presence.

The characterization of residual algal biomass helped to understand its physio chemical properties to decide which energy conversion technology will be suitable. The $\mathrm{HHV}$ of the astaxanthin rich biomass is measured to be $22.78 \mathrm{MJ} / \mathrm{kg}$, whereas the $\mathrm{HHV}$ of the residual biomass is $11.31 \mathrm{MJ} / \mathrm{kg}$, which is almost half of that of the astaxanthin rich algal biomass. This can be explained using the FTIR spectrum of the residual biomass and the astaxanthin rich biomass (Figure 4.7), which shows that the peak for polysaccharides, lipids, and proteins get lowers in case of residual biomass, thus resulting in a lower HHV value. The high volatile matter content $(71.28 \pm 0.27 \%)$, which is similar to that of the green microalgae Chlorella sp. as reported by Phukan et al., 2011, and the TGA thermogram suggests that the residual biomass can be a potential feedstock for thermochemical conversions (Phukan et al., 2011). The high moisture content (7.9 \pm 0.12 
$\%)$ is not desirable as it reduces the heating value of the biomass. Minimal ash content is desirable in the biomass as it has no heating value and it also affects both the handling and processing cost of the biomass energy conversion. (Ceylan and Goldfarb, 2015; Sudhakar and Premalatha, 2015). Since the residual biomass has low ash content and high volatile content, hence it can be a good source for gasification and pyrolysis technology, as the high volatile matter significantly influences the thermal decomposition, and hence, the formation of pyrolysis end products (Ceylan and Goldfarb, 2015). The ultimate analysis showed that the residual biomass possesses low $\mathrm{N}$ and $\mathrm{S}$ values $\left(\mathrm{C}_{3.63} \mathrm{H}_{6.26} \mathrm{~N}_{0.14} \mathrm{~S}_{0.01} \mathrm{O}_{3}\right)$, which is favorable as this limits the formation of NOx and SOx during the combustion process, and hence proves to be environmental friendly, similar to other biomass sources (Table 4.7). Residual Haematococcus biomass has an $\mathrm{H} / \mathrm{C}$ ratio (ash free basis of 1.72, which is lower than the $\mathrm{H} / \mathrm{C}$ ratio of rice husk (1.95), higher than that of Laminaria saccharina, a brown microalgae (1.42), and similar to the $\mathrm{H} / \mathrm{C}$ ratio of Chlorella, Nannochloropsis and Spirulina species (Chow et al., 2013; Phukan et al., 2011; Zhu et al., 2013). Hence, the residual Haematococcus biomass has an $\mathrm{H} / \mathrm{C}$ ratio similar to other microalgal biomass, thus indicating that this residue can be used as a biofuel feedstock. 
Table 4.7: Ultimate Analysis of different biomass sources.

\begin{tabular}{|c|c|c|c|c|c|c|c|c|}
\hline \multicolumn{7}{|c|}{ Weight percentage (\%) } \\
\hline Biomass & $\mathbf{C}$ & $\mathbf{H}$ & $\mathbf{O}$ & $\mathbf{N}$ & $\mathbf{S}$ & $\mathbf{A s h}$ & $\begin{array}{c}\text { H/C } \\
\text { molar } \\
\text { ratio }\end{array}$ & Reference \\
\hline Rice Husk & 34.48 & 5.59 & 43.36 & 0.63 & 0.041 & 15.87 & 1.95 & $\begin{array}{c}\text { (Olupot et } \\
\text { al., 2016) }\end{array}$ \\
\hline Wheat Straw & 39.99 & 5.15 & 38.99 & 0.29 & 0.104 & 2.69 & 1.55 & $\begin{array}{c}\text { (Zhang et } \\
\text { al., 2013) }\end{array}$ \\
\hline $\begin{array}{c}\text { Chlorella } \text { sp. } \\
\text { MP-1 }\end{array}$ & 47.54 & 7.1 & 38.63 & 6.73 & 0 & 5.93 & 1.79 & $\begin{array}{c}\text { (Phukan et } \\
\text { al., 2011) }\end{array}$ \\
\hline $\begin{array}{c}\text { Nannochloropsis } \\
\text { salina (Lipid } \\
\text { Extracted } \\
\text { biomass) }\end{array}$ & 49.0 & 6.96 & 26.3 & 5.76 & 0.94 & 11.0 & 1.70 & $\begin{array}{c}\text { (Zhu et al., } \\
2013)\end{array}$ \\
\hline $\begin{array}{c}\text { Laminaria } \\
\text { saccharina }\end{array}$ & 31.3 & 3.7 & 26.3 & 2.4 & 0.7 & 35.6 & 1.42 & $\begin{array}{c}\text { (Chow et } \\
\text { al., 2013) }\end{array}$ \\
\hline $\begin{array}{c}\text { Spirulina } \\
\text { platensis }\end{array}$ & 47.8 & 6.8 & 30.6 & 10.6 & 0.6 & 7.3 & 1.71 & $\begin{array}{c}\text { (Chow et } \\
\text { al., 2013) }\end{array}$ \\
\hline
\end{tabular}

Microalgal biomass can be converted to bioenergy by using thermochemical conversion, which produces oil and gas as the end products, or by using biochemical processes, where ethanol and biodiesel can be produced (Amin, 2009; Patil et al., 2008). Table 4.8 shows the comparison between these different conversion technologies in terms of the end product formed, operating conditions and requirements, and it can be seen that moisture content plays a key role in deciding which conversion technology can be used? Thermochemical conversion is best suited for biomass with low moisture content whereas biochemical conversion is preferred for biomass with high moisture content. Along with the moisture content, it is important to understand the main component of the residual biomass, if it is rich in carbohydrate then it can be used in bioethanol production and if it is rich in fatty acids, then biodiesel can be produced. (Bi and He, 2013). FTIR spectrum of the residual Haematococcus biomass showed high peaks for carbohydrates and lipids. So, 
based on these characteristics, a selection matrix (Table 4.8) is created, which will help to decide which conversion technology will be suitable.

Table 4.8: Selection of a suitable biofuel conversion technology (Amaro et al., 2011; Amin, 2009; Boer and Moheimani, 2012; Patil et al., 2008).

("--"= Not favorable, "+" = Favorable)

\begin{tabular}{|c|c|c|c|c|}
\hline Process & $\begin{array}{l}\text { Operating } \\
\text { conditions }\end{array}$ & $\begin{array}{l}\text { Drying } \\
\text { Required? }\end{array}$ & Remarks & $\begin{array}{l}\text { Decision } \\
\text { Preference }\end{array}$ \\
\hline Liquefaction & $\begin{array}{lll}250-330 & { }^{\circ} \mathrm{C}, & 5-20 \\
\mathrm{MPa}\end{array}$ & No & $\begin{array}{l}\text { High Pressure } \\
\text { is undesirable }\end{array}$ & - \\
\hline Pyrolysis & $\begin{array}{l}300-600{ }^{\circ} \mathrm{C}, 0.1-0.5 \\
\mathrm{MPa}\end{array}$ & Yes & High VM & + \\
\hline Combustion & $\begin{array}{l}700-1400^{\circ} \mathrm{C},>0.1 \\
\mathrm{MPa}\end{array}$ & $\begin{array}{l}\text { Not } \\
\text { essential }\end{array}$ & $\begin{array}{l}\text { High } \\
\text { Temperature }\end{array}$ & + \\
\hline Gasification & $\begin{array}{l}500-1300^{\circ} \mathrm{C},>0.1 \\
\mathrm{MPa}\end{array}$ & Yes & High VM & + \\
\hline Fermentation & $25-30{ }^{\circ} \mathrm{C}$ & No & $\begin{array}{l}\text { Integration } \\
\text { with } \\
\text { Bioethanol } \\
\text { plant possible. } \\
\text { Carbohydrates } \\
\text { present }\end{array}$ & +++ \\
\hline Transesterification & $60-120^{\circ} \mathrm{C}$ & No & Lipids Present & ++ \\
\hline $\begin{array}{l}\text { Hydrothermal } \\
\text { liquefaction }\end{array}$ & $\begin{array}{l}280-370{ }^{\circ} \mathrm{C}, 10- \\
25 \mathrm{MPa}\end{array}$ & No & Lipids Present & ++ \\
\hline
\end{tabular}

Hence, according to the selection matrix, it can be seen that the fermentation process is the most suitable option to convert the residual biomass to biofuel (bioethanol, for this process). The reasons which favor this conversion technology includes:

- The biomass has a high moisture content, but drying is not a necessary step for fermentation.

- In the FTIR spectrum, it was seen that the carbohydrate showed a higher peak compared to lipids, thus indicating that the biomass is a good source of 
carbohydrates. The fermentation process requires a carbohydrate-rich raw material, and the Haematococcus biomass fits in this requirement.

- H. pluvialis was cultured in wastewater obtained from the bioethanol production plant, which uses fermentation technology to produce ethanol. So, the residual Haematococcus biomass can be fed into the saccharification unit, which will be an additional feedstock, hence this biomass will not go to waste.

\subsection{Cost Analysis of astaxanthin production}

The major manufacturers of synthetic astaxanthin are DSM (Dutch-based multinational life sciences and materials sciences) in Netherlands, BASF (Badische Anilin und Soda Fabrik) in France, and NHU in China. The estimated cost of production of synthetic astaxanthin is about $\$ 1000 / \mathrm{kg}$ and the total market value being more that $\$ 200$ million per year (Olaizola, 2003). Due to the food safety concerns related to the petrochemical-derived synthetic astaxanthin, the high production cost of synthetic astaxanthin, and a high market demand for natural astaxanthin, the biological sources of astaxanthin are being exploited for a long time (Zhu et al., 2011). Extensive research has been done to develop bioprocesses to produce astaxanthin and even many plants have been established, for example, Cyanotech in Hawaii. But, it is still uncertain if natural astaxanthin can be produced at lower cost than synthetic astaxanthin, and there are not many reports available on cost analysis of natural astaxanthin. Many researchers suggest that natural astaxanthin production in PBR and raceway ponds can compete with the cost of production of synthetic astaxanthin (Guerin et al., 2003). Zhu et al., 2011 gave a comprehensive cost analysis of astaxanthin production from $H$. pluvialis in Shenzhen, 
China, for a hypothetically scaled up plant having a production capacity of about $900 \mathrm{~kg}$ astaxanthin per year.

The total production cost includes two parts: total fixed capital cost and total operation cost. To estimate the cost of production of astaxanthin produced using bioethanol waste stream in photobioreactors, the total fixed cost of the various components of the manufacturing unit and the cost of the operating parameters has to be estimated. The major components of the manufacturing unit would include a laboratory, PBR for inoculum, PBR for the green phase of $H$. pluvialis, PBR for reddening (astaxanthin accumulation stage), sedimentation tanks, centrifuges, a pulverizer, pressurized air supply, $\mathrm{CO}_{2}$ tank, and extraction unit. The operational cost of production would include raw materials, utilities, and labor. The power consumption arises from bioreactor heating, low-pressure air supply, compressed air supply and wastewater pumping. These parameters and costs have been itemized in Table 4.9, and the economic estimates have been provided for the H.pluvialis cultivation, harvesting, and extraction units of a process, for the scaled up production of $1000 \mathrm{~kg}$ of astaxanthin per year. The quantity of PBRs, sedimentations or centrifugation unit required has been roughly calculated for $1000 \mathrm{~kg}$ of astaxanthin production. The cost estimates were extrapolated from National Alliance for Advanced Biofuels and Bioproducts (NAABB) report, National Renewable Energy Laboratory (NREL) database, Aspen Plus databank and literature studies (Olaizola, 2003; Zhu et al., 2011). Energy cost were based on an average US cost of $\$ 0.15 / \mathrm{kWh}$.

Since this process is proposed to be integrated into an established bioethanol production plant, with an existing infrastructure, this eliminates the need to invest in some facilities required for astaxanthin production. Investments on land procurement, 
wastewater (medium) supply station, and pulverizer will be eliminated. Since algae are being grown in wastewater generated during bioethanol production process, there will be no need for a separate supply station. Also, this plant uses pulverizer to grind the corn kernels (the raw material used for bioethanol production), so the same pulverizer can be used for grinding the algal biomass. From Table 4.9, it can be seen that, for wastewater and disinfection/ sterilization, total cost estimated is zero. This is because the wastewater generated by the bioethanol plant is being reused. At present, the bioethanol plant makes use of ozonation as the wastewater disinfection method, before disposing of the wastewater. So sterilization of wastewater is not an additional step, and this further reduces the operation cost.

The total annual fixed capital cost and total annual operation cost of production of $1000 \mathrm{~kg}$ astaxanthin are estimated to be $\$ 1,054,000$ and $\$ 326,850$, respectively. If a 10 year depreciation of fixed cost is adopted, then the unit total fixed production cost of astaxanthin will be $\$ 105,400$. This means, the unit fixed production cost and the unit operation production cost will be $\$ 105.40 / \mathrm{kg}$ astaxanthin and $\$ 326.85 / \mathrm{kg}$ astaxanthin, respectively. Therefore, the total unit production cost will be about $\$ 432 / \mathrm{kg}$ astaxanthin. The production cost of synthetic astaxanthin by DSM, BASF and NHU is estimated to be $\$ 1000 / \mathrm{kg}$ astaxanthin, and (Zhu et al., 2011) estimated a production cost of $\$ 718 / \mathrm{kg}$ astaxanthin. Therefore, the greener and intensified process proposed in this study would be able to produce natural astaxanthin at a lower cost of $\$ 432 / \mathrm{kg}$. The main reason for this lowered cost is due to integrating microalgal culture in a bioethanol plant and utilizing the waste product generated in the plant itself. The cost might be able to be further reduced with the advances of technologies and optimization of processes. 
Table 4.9: Cost analysis of astaxanthin production in bioethanol waste stream.

\begin{tabular}{|c|c|c|c|c|c|}
\hline \multicolumn{3}{|c|}{ Total Fixed Capital Cost } & \multicolumn{3}{|c|}{ Total Operation Cost } \\
\hline Items and Qty. & $\begin{array}{l}\text { Unit cost } \\
\text { (\$) }\end{array}$ & \begin{tabular}{|l} 
Total cost \\
(\$)
\end{tabular} & Items and Qty. & $\begin{array}{l}\text { Unit } \\
\text { cost }(\$)\end{array}$ & $\begin{array}{l}\text { Total } \\
\text { cost }(\$)\end{array}$ \\
\hline Land $\left(30,000 \mathrm{~m}^{2}\right)$ & 10 & $-300,000$ & $\begin{array}{l}\text { Wastewater } \\
\text { (3000 ton) }\end{array}$ & NA & 0 \\
\hline $\begin{array}{l}\text { Building area (250 } \\
\mathrm{m}^{2}\end{array}$ & 500 & 125,000 & $\begin{array}{l}\text { Chemicals } \\
\text { (NaOH/ } \\
\text { Methanol) } \\
\text { ton) }\end{array}$ & 250 & 37,500 \\
\hline $\begin{array}{l}\text { Laboratory } \\
\text { Instruments }\end{array}$ & 40,000 & 40,000 & $\begin{array}{l}\text { Disinfection/ } \\
\text { Sterilization }\end{array}$ & NA & 0 \\
\hline PBR (22) & 20,723 & 456,000 & $\begin{array}{l}\text { Other } \\
\text { consumables }\end{array}$ & 10,000 & 10,000 \\
\hline $\begin{array}{l}\text { Wastewater supply } \\
\text { station }\end{array}$ & 20,000 & $-20,000$ & $\begin{array}{l}\text { Power for PBR } \\
\text { heating. }(300,000 \\
k W h)\end{array}$ & 0.15 & 45,000 \\
\hline $\begin{array}{l}\text { Low pressure air } \\
\text { supply (2) }\end{array}$ & 4,000 & 8,000 & $\begin{array}{l}\text { Power for low air } \\
\text { pressure. }(60,000 \\
\text { kWh) }\end{array}$ & 0.15 & 9,000 \\
\hline $\begin{array}{l}\text { Sedimentation } \\
\operatorname{tank}(3)\end{array}$ & 5000 & 15,000 & $\begin{array}{ll}\text { Power } & \text { for } \\
\text { compressed } & \text { air. } \\
(5,000 \mathrm{kWh}) & \\
\end{array}$ & 0.15 & 750 \\
\hline $\mathrm{CO}_{2}$ storage tank & 35,000 & 35,000 & $\begin{array}{l}\text { Power for } \\
\text { ultrasonication. } \\
(4,000 \mathrm{kWh})\end{array}$ & 0.15 & 600 \\
\hline Centrifuge & 10,000 & 10,000 & $\begin{array}{l}\text { Power for } \\
\text { pulverization. } \\
(20,000 \mathrm{kWh})\end{array}$ & 0.15 & 3,000 \\
\hline Pulverizer & 50,000 & $-50,000$ & $\begin{array}{l}\text { Power for } \\
\text { pumping. } \\
(50,000 \mathrm{kWh})\end{array}$ & 0.15 & 7,500 \\
\hline $\begin{array}{l}\text { Extraction } \\
\text { (Ultrasonicator) }\end{array}$ & 240,000 & 240,000 & Labor (10) & 10,350 & 103,500 \\
\hline $\begin{array}{lr}\text { Pumps, } & \text { valves, } \\
\text { pipings } & \text { and } \\
\text { Electrical. } & \\
\end{array}$ & 35,000 & 35,000 & Supervision (4) & 15,000 & 60,000 \\
\hline $\begin{array}{l}\text { Engineering } \\
\text { supervision for } \\
\text { process control }\end{array}$ & 50,000 & 50,000 & $\begin{array}{ll}\text { General } & \text { plant } \\
\text { overheads }\end{array}$ & 50,000 & 50,000 \\
\hline $\begin{array}{l}\text { Construction } \\
\text { expenses }\end{array}$ & 40,000 & 40,000 & $\begin{array}{l}\text { Total } \\
\text { Operational } \\
\text { Cost }\end{array}$ & US \$326 & \\
\hline Total Fixed Cost & US \$1,054 & ,000 & & & \\
\hline
\end{tabular}




\subsection{Conclusion}

A high density $(4.37 \pm 0.07 \mathrm{~g} / \mathrm{l}) H$. pluvialis culture was obtained using the bioethanol production waste stream as the growth media, in an air-lift bioreactor supplemented with $5 \% \mathrm{CO}_{2}$. Total astaxanthin extracted was $38 \pm 2.55 \mathrm{mg} / \mathrm{g}$ and the residual Haematococcus biomass showed a potential to be used as a future biofuel feedstock. This microalga can make use of a simple and inexpensive nutrient medium, wastewater, to grow, at a growth rate faster than the land crops and trees. Also, not only did H. pluvialis resulted in $91.67 \%$ total nitrogen and $100 \%$ total phosphorous removal, but also showed a negative result for microcystin test, hence eliminating the safety concern regarding the final product. The proximate and ultimate analysis showed that the biomass has a very good biochemical profile, with very little nitrogen and negligible Sulfur, hence it will limit the problems of NOx and SOx formations, and proves to be an environmentally

friendly source. The FTIR analysis confirms the presence of carbohydrates and lipids, and the thermal analysis presents a good decomposition profile of the biomass. Hence, the characterization of the biomass, with respect to bioenergy production, proves to be a potential feedstock, and the production of biofuel from $H$. pluvialis can also be coupled with $\mathrm{CO}_{2}$ uptake from the effluent produced during the bioethanol production, wastewater reutilization, and production of high-value astaxanthin. 


\section{CHAPTER V - OVERALL CONCLUSIONS AND RECOMMENDATIONS}

\subsection{Conclusions}

Wastewater, thin stillage, and process condensate, generated from the bioethanol production plant were characterized and evaluated to formulate a growth media to support H. pluvialis growth as well as astaxanthin accumulation. This procedure was also examined using an air-lift photobioreactor, using carbon dioxide supplementation, for sufficient agitation, as well as $H$. pluvialis growth. For an intensified extraction of astaxanthin, ultrasonication technique was examined, and the residual biomass hence obtained after extraction was characterized to evaluate its potential as a biofuel feedstock. In this chapter, a summary of the conclusion of the previous chapter has been presented, which are as below.

\subsubsection{H. pluvialis growth and astaxanthin accumulation in wastewater}

Culturing Haematococcus pluvialis in bioethanol wastewater streams can be a greener alternative to conventional media, as it not only puts the readily available wastewaters to better use but also eliminates the dependency on industrialized chemicals for culture media preparation. The maximal growth of $H$. pluvialis (vegetative cells) was obtained in 60x diluted thin stillage, and maximal astaxanthin accumulation was obtained in GroAst media (60\% 60x thin stillage, and 40\% acetate-rich process condensate), coupled with continuous illumination (to induce astaxanthin production). The GroAst media is not only a cheaper media, compared to the chemically synthesized media, but it is also a "greener" sustainable alternative to conventional growth media. 


\subsubsection{High-density cultivation of $\boldsymbol{H}$. pluvialis in Air - Lift Photobioreactor}

A high density $(4.37 \pm 0.07 \mathrm{~g} / \mathrm{l}) \mathrm{H}$. pluvialis culture was obtained using GroAst media, in an air-lift photobioreactor, supplemented with $5 \% \mathrm{CO}_{2}$. The air-lift bioreactor has carbon dioxide bubbles being dispersed without mechanical agitation, so cells with low mechanical strength do not suffer high shear rates due to the motion of the impellers in a stirred reactor. During the cultivation of photosynthetic cells, oxygen acts as an inhibitor, so carbon dioxide bubbles ensure the removal of oxygen and enhances the mass transfer rate, prevents settling of cells and keeps then floating. So, $\mathrm{CO}_{2}$ supplementation helps in keeping the microalgal cells in a suspended state, while $H$. pluvialis simultaneously can help in $\mathrm{CO}_{2}$ uptake from the effluent produced during the bioethanol production.

\subsubsection{Intensified Recovery of Astaxanthin using ultrasonication}

Ultrasonication with sodium hydroxide pretreatment, followed by methanol extraction (US w/ $\mathrm{NaOH}$ w/ methanol) resulted in best extraction efficiency. Astaxanthin extraction using ultrasonication proved advantageous in terms of short extraction time (25 min), less chemical consumption ( $2 \mathrm{M} \mathrm{NaOH})$, GRAS solvent usage (methanol), high efficiency in cell disruption, high extraction yield $(80.6 \pm 0.005 \%)$ and suitability to extract thermolabile astaxanthin. The ultrasonication treatment with sodium hydroxide leads to the formation of cavitation in solution, whereby the adjacent microalgal cells undergo cell disruption due to the localized high temperatures and pressures, in the presence of sodium hydroxide. Since the high temperature is localized, the astaxanthin in the cell and in the solution is minimally exposed to degrading temperatures. Hence, the use of ultrasonication does not lead to noticeable loss of astaxanthin caused by thermal degradation. 


\subsubsection{Nutrient removal from the wastewater}

Haematococcus pluvialis uses the nutrients (mainly nitrogen and phosphorous) present in the wastewater for their growth and hence results in $91.67 \%$ total nitrogen and $100 \%$ total phosphorous removal. Even though the astaxanthin was produced using wastewater, it showed a negative result for microcystin test.

\subsubsection{Residual Haematococcus biomass is a potential biofuel feedstock}

The residual Haematococcus biomass has the characteristics to be used as a potential biofuel feedstock. The proximate and ultimate analysis showed that the biomass has a very good biochemical profile, with very little nitrogen and negligible sulfur. The FTIR analysis of the biomass confirms the presence of carbohydrates and lipids, and the thermal analysis presents a good decomposition profile of the biomass. With moderate moisture content, high volatile matter, and high carbohydrate content, this residual biomass can utilize the fermentation process as a conversion technology. Since H. pluvialis was cultured in wastewater obtained from the bioethanol production plant, which uses fermentation technology to produce ethanol, so, the residual Haematococcus biomass can be fed into the saccharification unit, which will be an additional feedstock, hence this biomass will not go to waste. 


\subsection{Recommendations for Future work}

- Pilot-scale study: This experimental study was performed on a laboratory scale. A pilot scale up of this procedure will help in understanding the applicability of this proposed work in industries.

- Fermentation kinetics study: It has been suggested in this study that fermentation is a desirable option to convert the residual Haematococcus biomass to biofuel, as a future work, fermentation process for converting $H$. pluvialis biomass to biofuels and the kinetics can be tested.

- Alternative uses of residual Haematococcus biomass: In this study, the residual biomass was characterized on the basis of biofuel feedstock parameters only. Future study can be done to analyze alternative uses of the residual biomass, such as animal or aquatic feed.

- Limitation of Ultrasonication: The use of ultrasound at industrial scale, however, still needs to be verified, as high energy consumption and scalability limitations may not make it the economically optimal technique for astaxanthin extraction.

- Techno-economic assessment: A techno - economic evaluation study in terms of process parameters, such as energy input, raw materials, product output, of a pilot scale will help to understand the cost benefit of this procedure, and its applicability on an industrial scale. A detailed analysis of the fixed capital cost and the operation cost will help to perform a sensitivity analysis on astaxanthin production and marketing. 


\section{References:}

Algatech, Accessed 15 June 2016, < http://www.algatech.com/>

Abou-Shanab, R.A.I., Ji, M.K., Kim, H.C., Paeng, K.J., Jeon, B.H., 2013. Microalgal species growing on piggery wastewater as a valuable candidate for nutrient removal and biodiesel production. J. Environ. Manage. 115, 257-264. doi:10.1016/j.jenvman.2012.11.022

Amaro, H.M., Guedes, A.C., Malcata, F.X., 2011. Advances and perspectives in using microalgae to produce biodiesel. Appl. Energy 88, 3402-3410. doi:10.1016/j.apenergy.2010.12.014

Ambati, R.R., Moi, P.S., Ravi, S., Aswathanarayana, R.G., 2014. Astaxanthin: Sources, extraction, stability, biological activities and its commercial applications - A review. Mar. Drugs 12, 128-152. doi:10.3390/md12010128

Amin, S., 2009. Review on biofuel oil and gas production processes from microalgae. Energy Conversion and Management 50, 1834-1840. doi:10.1016/j.enconman.2009.03.001

AstaFactor, Accessed 15 June 2016, < http://www.astafactor.com> AstaReal, Accessed 15 June 2016, < http://www.astareal.com> AstaSupreme, Accessed 15 June 2016, < http://www.astasupreme.co.nz> AstaVantage, Accessed 15 June 2016, < http://www.algaecan.com>

B. Santhose, I., Elumalai, S., Kanna G, R., 2014. Airlift Photobioreactor Cultivation of a New Strain of Haematococcus pluvialis Collected from High Altitude Regions of Himalayas. International journal on Science and Research 3, 2289-2292.

Banerjee, K., Ghosh, R., Homechaudhuri, S., Mitra, A., 2009. Biochemical Composition of Marine Macroalgae from Gangetic Delta at the Apex of Bay of Bengal. African J. Basic Appl. Sci. 1, 96-104.

Bi, Z., He, B.B., 2013. Characterization of microalgae for the purpose of biofuel production. American Society of Agricultural and Biological Engineers, Annual meeting 56, 1529-1539.

BioAstin, Accessed 15 June 2016, < http://www.cyanotech.com>

Boer, K. De, Moheimani, N.R., 2012. Extraction and conversion pathways for microalgae to biodiesel : a review focused on energy consumption. Journal of Applied Phycology 24, 1681-1698. doi:10.1007/s10811-012-9835-z

Bonnie, T., Choo, Y., 1999. Oxidation and thermal degradation of carotenoids. J. oil palm Res. 2, 62-78.

Boon, C.S., McClements, D.J., Weiss, J., Decker, E. a, 2010. Factors influencing the chemical stability of carotenoids in foods. Crit. Rev. Food Sci. Nutr. 50, 515-532. doi:10.1080/10408390802565889

Borowitzka, M.A., Huisman, J.M., Osborn, A., 1991. Culture of the astaxanthinproducing green alga Haematococcus pluvialis 1 . Effects of nutrients on growth and cell type. J. Appl. Phycol. 295-304. 
Boussiba, S., Vonshak, A., 1991. Astaxanthin Accumulation in the Green Alga Haematococcus pluvialis1. Plant Cell Physiol. 32, 1077-1082. doi:10.1111/j.17447909.2007.00468.x

Bradley, M.S., Ph, D., Scientific, T.F., n.d. TGA-IR Analysis Using the OMNIC Mercury TGA Software. Accessed 14 June 2016, <www.thermofisher.com/content/dam/tfs/ATG/CAD/CAD\%20Documents/Applicat ion\%20\&\%20Technical\%20Notes/Molecular\%20Spectroscopy/FTIR/FTIR\%20Spe ctrometers/D20952 .pdf>

Canada's Emissions Trends, Environment, EC 2014, Accesed 14 August 2016, < https://ec.gc.ca/ges-ghg/E0533893-A985-4640-B3A2008D8083D17D/ETR_E\%202014.pdf>

Ceylan, S., Goldfarb, J.L., 2015. Green tide to green fuels : TG - FTIR analysis and kinetic study of Ulva prolifera pyrolysis. Energy Convers. Manag. 101, 263-270. doi:10.1016/j.enconman.2015.05.029

Chisti, Y., 2007. Biodiesel from microalgae. Biotechnol. Adv. 25, 294-306. doi:10.1016/j.biotechadv.2007.02.001

Chow, M.C., Jackson, W.R., Cha, A.L., Marshall, M., 2013. Thermal Treatment of Algae for Production of Biofuel. Energy Fuels, Am. Chem. Soc. 27, 1926-1950. doi:dx.doi.org/10.1021/ef3020298

Conk, M., Imamoglu, E., Demirel, Z., 2007. Agricultural Fertilizers as Economical Alternative for Cultivation of Haematococcus pluvialis. J. Microbiol. Biotechnol 17, 393-397.

Csiktusnádi Kiss, G. a., Forgács, E., Cserháti, T., Mota, T., Morais, H., Ramos, A., 2000. Optimisation of the microwave-assisted extraction of pigments from paprika (Capsicum annuum L.) powders. J. Chromatogr. A 889, 41-49. doi:10.1016/S00219673(00)00440-4

Damiani, M.C., Popovich, C.A., Constenla, D., Leonardi, P.I., 2010. Bioresource Technology Lipid analysis in Haematococcus pluvialis to assess its potential use as a biodiesel feedstock. Bioresour. Technol. 101, 3801-3807. doi:10.1016/j.biortech.2009.12.136

Dong, S., Huang, Y., Zhang, R., Wang, S., Liu, Y., 2014. Four different methods comparison for extraction of astaxanthin from green alga Haematococcus pluvialis. ScientificWorldJournal. 2014, 694305. doi:10.1155/2014/694305

EFSA, 2014. Scientific Opinion on the safety of astaxanthin-rich ingredients ( AstaREAL A1010 and AstaREAL L10 ) as novel food ingredients 1. EFSA J. 12, 1-35. doi:10.2903/j.efsa.2014.3757

Ehimen, E.A.., Connaughton, S., Zhifa, S., Carrington, G.C., 2009. Energy recovery from lipid extracted, transesterified and glycerol codigested microalgae biomass. Bioenergy 1, 371-381. doi:10.1111/j.1757-1707.2009.01029.x

Fillaudeau, L., Blanpain-Avet, P., Daufin, G., 2006. Water, wastewater and waste management in brewing industries. J. Clean. Prod. 14, 463-471. 
doi:10.1016/j.jclepro.2005.01.002

García-Malea, M.C., Gabriel Acién, F., Río, E. Del, Fernández, J.M., Cerón, M.C., Guerrero, M.G., Molina-Grima, E., 2009. Production of astaxanthin by haematococcus Pluvialis: Taking the one-step system outdoors. Biotechnol. Bioeng. 102, 651-657. doi:10.1002/bit.22076

Giannelli, L., Yamada, H., Katsuda, T., Yamaji, H., 2015. Effects of temperature on the astaxanthin productivity and light harvesting characteristics of the green alga Haematococcus pluvialis. J. Biosci. Bioeng. 119, 345-350. doi:10.1016/j.jbiosc.2014.09.002

Gogate, P.R., Nadar, S.G., 2015. Ultrasound-assisted Intensification of Extraction of Astaxanthin from Phaffia rhodozyma. Indian Chem. Eng. 1-16. doi:10.1080/00194506.2015.1026947

Goksan, T., Ak, I., 2006. Vegetative growth of the green alga Haematococcus pluvialis cultivated in different light-path lengths. Asian J. Plant Sci. doi:10.3923/ajps.2006.455.460

González, L.E., Cañizares, R.O., Baena, S., 1997. Efficiency of ammonia and phosphorus removal from a Colombian agroindustrial wastewater by the microalgae Chlorella vulgaris and Scenedesmus dimorphus. Bioresour. Technol. 60, 259-262. doi:10.1016/S0960-8524(97)00029-1

Guerin, M., Huntley, M.E., Olaizola, M., 2003. Haematococcus astaxanthin: Applications for human health and nutrition. Trends Biotechnol. 21, 210-216. doi:10.1016/S0167-7799(03)00078-7

Gugała, M., Zarzecka, K., Sikorska, A., 2015. Wastewater management in food processing enterprises - A case study of the ciechanów dairy cooperative. J. Ecol. Eng. 16, 178-183. doi:10.12911/22998993/605

Hagen, C., Siegmund, S., Braune, W., 2016. Ultrastructural and chemical changes in the cell wall of Haematococcus pluvialis ( Volvocales , Chlorophyta ) during aplanospore formation 0262. doi:10.1017/S0967026202003669

Hagen, C., Siegmund, S., Braune, W., 2002. Ultrastructural and chemical changes in the cell wall of Haematococcus pluvialis (Volvocales, Chlorophyta) during aplanospore formation. Eur. J. Phycol. 37, 217-226. doi:10.1017/S0967026202003669

Hanan, N., Al-Shorgani, N., Shukor, H., Rahman, N., Kalil, M., 2013. Pre-optimization conditions for Haematococcus pluvialis growth. Int. J. Adv. Sci. Eng. Inf. Technol. $3,70-73$.

Haque, F., Dutta, A., Thimmanagari, M., Wai, Y., 2016. Intensified green production of astaxanthin from Haematococcus pluvialis. Food Bioprod. Process. 99, 1-11. doi:10.1016/j.fbp.2016.03.002

Higuera-Ciapara, I., Félix-Valenzuela, L., Goycoolea, F.M., 2006. Astaxanthin: a review of its chemistry and applications. Crit. Rev. Food Sci. Nutr. 46, 185-96. doi:10.1080/10408690590957188

Jeon, Y.C., Cho, C.W., Yun, Y.S., 2006. Combined effects of light intensity and acetate 
concentration on the growth of unicellular microalga Haematococcus pluvialis. Enzyme Microb. Technol. 39, 490-495. doi:10.1016/j.enzmictec.2005.12.021

Jiang, L., Luo, S., Fan, X., Yang, Z., Guo, R., 2011. Biomass and lipid production of marine microalgae using municipal wastewater and high concentration of $\mathrm{CO}_{2}$. Appl. Energy 88, 3336-3341. doi:10.1016/j.apenergy.2011.03.043

Jiao, G., Hui, J.P.M., Burton, I.W., Thibault, M.-H., Pelletier, C., Boudreau, J., Tchoukanova, N., Subramanian, B., Djaoued, Y., Ewart, S., Gagnon, J., Ewart, K.V., Zhang, J., 2015. Characterization of Shrimp Oil from Pandalus borealis by High Performance Liquid Chromatography and High Resolution Mass Spectrometry. Mar. Drugs 13, 3849-76. doi:10.3390/md13063849

Jun, J., Seung, Y., Choi, P., Woo, B., 2012. Optimal design of scalable photo-bioreactor for phototropic culturing of Haematococcus pluvialis. Bioprocess Biosyst. Eng. 309-315. doi:10.1007/s00449-011-0616-x

Kaewpintong, K., Shotipruk, A., Powtongsook, S., Pavasant, P., 2007. Photoautotrophic high-density cultivation of vegetative cells of Haematococcus pluvialis in airlift bioreactor. Bioresour. Technol. 98, 288-295. doi:10.1016/j.biortech.2006.01.011

Kang, C.D., An, J.Y., Park, T.H., Sim, S.J., 2006. Astaxanthin biosynthesis from simultaneous $\mathrm{N}$ and $\mathrm{P}$ uptake by the green alga Haematococcus pluvialis in primarytreated wastewater. Biochem. Eng. J. 31, 234-238. doi:10.1016/j.bej.2006.08.002

Kang, C.D., Lee, J.S., H., P.T., Sim, S.J., 2005. Comparison of heterotrophic and photoautotrophic induction on astaxanthin production by Haematococcus pluvialis 237-241. doi:10.1007/s00253-005-1889-2

Kang, C.D., Lee, J.S., Park, T.H., Sim, S.J., 2007. Complementary limiting factors of astaxanthin synthesis during photoautotrophic induction of Haematococcus pluvialis : C / N ratio and light intensity. Biotechnol. Prod. Process Eng. 987-994. doi:10.1007/s00253-006-0759-x

Kang, C.D., Sim, S.J., 2007. Selective Extraction of Free Astaxanthin from Haematococcus Culture Using a Tandem Organic Solvent System. Biotechnol. Prog. 23, 866-871. doi:10.1021/bp0700354

Katsuda, T., Shimahara, K., Shiraishi, H., Yamagami, K., Ranjbar, R., Katoh, S., 2006. Effect of flashing light from blue light emitting diodes on cell growth and astaxanthin production of Haematococcus pluvialis. J. Biosci. Bioeng. 102, 442446. doi:10.1263/jbb.102.442

Kim, S., Cho, E., Yoo, J., In, M.J., Chae, H.J., 2008. Extraction and analysis of astaxanthin from Haematococcus pluvialis using sonication. J. Korean Soc. Food Sci. Nutr. 37, 1363-1368. doi:10.3746/jkfn.2008.37.10.1363

Kobayashi, M., Kakizono, T., Nagai, S., 1993. Enhanced carotenoid biosynthesis by oxidative stress in acetate-induced cyst cells of a green unicellular alga, Haematococcus pluvialis. Appl. Environ. Microbiol. 59, 867-873.

Kobayashi, M., Kakizono, T., Nishio, N., Nagai, S., Kurimura, Y., Tsuji, Y., 1997. Antioxidant role of astaxanthin in the green alga Haematococcus pluvialis. Appl. 
Microbiol. Biotechnol. 48, 351-356. doi:10.1007/s002530051061

Kobayashi, M., Kakizono, T., Yamaguchi, K., 1992. Growth and Astaxanthin Formation of Haematococcus pluvialis in Heterotrophic and Mixotrophic Conditions. J. Ferment. Bioeng. 74, 17-20.

Krichnavaruk, S., Shotipruk, A., Goto, M., Pavasant, P., 2008. Supercritical carbon dioxide extraction of astaxanthin from Haematococcus pluvialis with vegetable oils as co-solvent. Bioresour. Technol. 99, 5556-5560.

doi:10.1016/j.biortech.2007.10.049

L. Shuler, M., Kargi, F., 2002. Bioprocess Engineering Basic Concepts.

Lee, J.H., Kim, Y.S., Choi, T.J., Lee, W.J., Kim, Y.T., 2004. Paracoccus haeundaensis sp. nov., a Gram-negative, halophilic, astaxanthin-producing bacterium. Int. J. Syst. Evol. Microbiol. 54, 1699-1702. doi:10.1099/ijs.0.63146-0

Lorenz, R.T., Cysewski, G.R., 2000. Commercial potential for Haematococcus microalgae as a natural source of astaxanthin. Trends Biotechnol. 18, 160-167. doi:10.1016/S0167-7799(00)01433-5

Machado, F.R.S., Reis, D.F., Boschetto, D.L., Burkert, J.F.M., Ferreira, S.R.S., Oliveira, J.V., Burkert, C.A. V, 2014. Encapsulation of astaxanthin from Haematococcus pluvialis in PHBV by means of SEDS technique using supercritical CO2. Ind. Crops Prod. 54, 17-21. doi:10.1016/j.indcrop.2014.01.007

Mendes-Pinto, M.M., Raposo, M.F.J., Bowen, J., Young, a. J., Morais, R., 2001. Evaluation of different cell disruption processes on encysted cells of Haematococcus pluvialis: Effects on astaxanthin recovery and implications for bio-availability. J. Appl. Phycol. 13, 19-24. doi:10.1023/A:1008183429747

Meyer, P.S., Du Preez, J.C., 1994. Effect of culture conditions on astaxanthin production by a mutant of Phaffia rhodozyma in batch and chemostat culture. Appl. Microbiol. Biotechnol. 40, 780-785. doi:10.1007/BF00173974

Olaizola, M., 2003. Commercial development of microalgal biotechnology: From the test tube to the marketplace. Biomol. Eng. 20, 459-466. doi:10.1016/S13890344(03)00076-5

Olupot, P.W., Candia, A., Menya, E., Walozi, R., 2016. Characterization of rice husk varieties in Uganda for biofuels and their techno-economic feasibility in gasification. Chem. Eng. Res. Des. 107, 63-72. doi:10.1016/j.cherd.2015.11.010

Orosa, M., Torres, E., Fidalgo, P., Abalde, J., 2000. Production and analysis of secondary carotenoids in green algae. J. Appl. Phycol. 12, 553-556. doi:10.1023/a:1008173807143

Pasquet, V., Chérouvrier, J.R., Farhat, F., Thiéry, V., Piot, J.M., Bérard, J.B., Kaas, R., Serive, B., Patrice, T., Cadoret, J.P., Picot, L., 2011. Study on the microalgal pigments extraction process: Performance of microwave assisted extraction. Process Biochem. 46, 59-67. doi:10.1016/j.procbio.2010.07.009

Patil, V., Tran, K., Giselrød, H.R., 2008. Towards Sustainable Production of Biofuels from Microalgae 1188-1195. doi:10.3390/ijms9071188 
Pérez-Gálvez, A., Negro-Balmaseda, J.J., Mínguez-Mosquera, M.I., Cascajo-Almenara, M. V., Garrido-Fernández, J., 2008. Astaxanthin from Crayfish (Procambarus clarkii) as a Pigmentary Ingredient in the Feed of Laying Hens. Grasas y Aceites 59, 139-145. doi:10.3989/gya.2008.v59.i2.502

Phukan, M.M., Chutia, R.S., Konwar, B.K., Kataki, R., 2011. Microalgae Chlorella as a potential bio-energy feedstock. Appl. Energy 88, 3307-3312.

doi:10.1016/j.apenergy.2010.11.026

Querques, N., Cesta, M., Santos, R.M., Chiang, Y.W., 2015. Microalgal phycocyanin productivity: Strategies for phyco-valorization. J. Chem. Technol. Biotechnol. 90, 1968-1982. doi:10.1002/jctb.4796

Ranga Rao, a, 2011. Production of astaxanthin from cultured green alga Haematococcus pluvialis and its biological activities. PhD thesis, University of Mysore.

Ranjan, A., Patil, C., Moholkar, V.S., 2010. Mechanistic assessment of microalgal lipid extraction. Ind. Eng. Chem. Res. 49, 2979-2985. doi:10.1021/ie9016557

Ranjbar, R., Inoue, R., Shiraishi, H., Katsuda, T., Katoh, S., 2008. High efficiency production of astaxanthin by autotrophic cultivation of Haematococcus pluvialis in a bubble column photobioreactor. Biochem. Eng. J. 39, 575-580.

doi:10.1016/j.bej.2007.11.010

Razzak, S. a., Hossain, M.M., Lucky, R. a., Bassi, A.S., De Lasa, H., 2013. Integrated $\mathrm{CO} 2$ capture, wastewater treatment and biofuel production by microalgae culturing A review. Renew. Sustain. Energy Rev. 27, 622-653.

doi:10.1016/j.rser.2013.05.063

Reyes, F.A., Mendiola, J.A., Iba??ez, E., Del Valle, J.M., 2014. Astaxanthin extraction from Haematococcus pluvialis using CO 2-expanded ethanol. J. Supercrit. Fluids 92, 75-83. doi:10.1016/j.supflu.2014.05.013

Rosana, G., Tarlen, S., H., F.C., Sales, E.A., 2013. Modeling of Biomass Production of Haematococcus pluvialis 2013, 50-56.

Ruen-ngam, D., Shotipruk, A., Pavasant, P., 2010. Comparison of Extraction Methods for Recovery of Astaxanthin from Haematococcus pluvialis. Sep. Sci. Technol. 46, 6470. doi:10.1080/01496395.2010.493546

Safety and efficacy of Panaferd-AX (red carotenoid rich bacterium Paracoccus carotinifaciens) as feed additive for salmon and trout. EFSA Journal 2007. 546, 119.

Sarada, R., Vidhyavathi, R., Usha, D., Ravishankar, G.A., 2006. An Efficient Method for Extraction of Astaxanthin from Green Alga Haematococcus pluvialis 7585-7588.

Satyawali, Y., Balakrishnan, M., 2008. Wastewater treatment in molasses-based alcohol distilleries for COD and color removal: A review. J. Environ. Manage. 86, 481-497. doi:10.1016/j.jenvman.2006.12.024

Schmidt, I., Schewe, H., Gassel, S., Jin, C., Buckingham, J., Hambelin, M., Sandmann, G., Schrader, J., 2011. Biotechnological production of astaxanthin with Phaffia rhodozyma/Xanthophyllomyces dendrorhous. Appl. Microbiol. Biotechnol. 89, 555- 
571. doi:10.1007/s00253-010-2976-6

Schroeder, W. a., Johnson, E. a., 1995. Singlet oxygen and peroxyl radicals regulate carotenoid biosynthesis in Phaffia rhodozyma. J. Biol. Chem.

doi:10.1074/jbc.270.31.18374

Serio, M.A., Bassilakis, R., Solomon, P.R., 1996. Use of TG-FTIR analysis for the characterization of fuels and resources. Advanced Fuel Research Incl 1, 43-50.

Singh, K., Zondlo, J., 2011. Tga-ftir analysis of woody biomass and coal for energy production.

Solovchenko, A., 2014. Accumulation of Astaxanthin by a New Haematococcus pluvialis Strain BM1 from the White Sea Coastal Rocks (Russia). Marine drugs 12, 45044520. doi:10.3390/md12084504

Sudhakar, K., Premalatha, M., 2015. Environmental Effects Characterization of Micro Algal Biomass Through FTIR / TGA / CHN Analysis : Application to Scenedesmus sp . TGA / CHN Analysis : Application to Scenedesmus sp . Energy sources part A 1, 7036. doi:10.1080/15567036.2013.825661

Suh, I.S., Joo, H.N., Lee, C.G., 2006. A novel double-layered photobioreactor for simultaneous Haematococcus pluvialis cell growth and astaxanthin accumulation. J. Biotechnol. 125, 540-546. doi:10.1016/j.jbiotec.2006.03.027

Thana, P., Machmudah, S., Goto, M., Sasaki, M., Pavasant, P., Shotipruk, A., 2008. Response surface methodology to supercritical carbon dioxide extraction of astaxanthin from Haematococcus pluvialis. Bioresour. Technol. 99, 3110-3115. doi:10.1016/j.biortech.2007.05.062

Tocquin, P., Fratamico, A., Franck, F., 2012. Screening for a low-cost Haematococcus pluvialis medium reveals an unexpected impact of a low N/P ratio on vegetative growth. J. Appl. Phycol. 24, 365-373. doi:10.1007/s10811-011-9771-3

Vustin, M.M., Belykh, E.N., Kishilova, S.A., 2004. Relationship between astaxanthin production and the intensity of anabolic processes in the yeast Phaffia rhodozyma. Microbiology 73, 643-649. doi:10.1007/s11021-005-0004-0

Wan, M., Zhang, J., Hou, D., Fan, J., Li, Y., Huang, J., Wang, J., 2014. The effect of temperature on cell growth and astaxanthin accumulation of Haematococcus pluvialis during a light-dark cyclic cultivation. Bioresour. Technol. 167, 276-283. doi:10.1016/j.biortech.2014.06.030

Wang, M., Kuo-Dahab, W.C., Dolan, S., Park, C., 2014. Kinetics of nutrient removal and expression of extracellular polymeric substances of the microalgae, Chlorella sp. and Micractinium sp., in wastewater treatment. Bioresour. Technol. 154, 131-137. doi:10.1016/j.biortech.2013.12.047

Wang, W., Yu, L., Zhou, P., 2006. Effects of different fungal elicitors on growth, total carotenoids and astaxanthin formation by Xanthophyllomyces dendrorhous. Bioresour. Technol. 97, 26-31. doi:10.1016/j.biortech.2005.02.012

Wang, Y., Peng, J., 2008. Growth-associated biosynthesis of astaxanthin in heterotrophic Chlorella zofingiensis (Chlorophyta). World J. Microbiol. Biotechnol. 24, 1915- 
1922. doi:10.1007/s11274-008-9692-8

WHO, 1998. Cyanobacterial toxins : Microcystin-LR in Drinking-water Background document for development of WHO Guidelines for Drinking-water Quality. Environ. Heal. 2, 1-14. doi:10.1016/j.kjms.2011.05.002

Wilkie, A.C., Riedesel, K.J., Owens, J.M., 2000. Stillage characterization and anaerobic treatment of ethanol stillage from conventional and cellulosic feedstocks. Biomass and Bioenergy 19, 63-102. doi:10.1016/S0961-9534(00)00017-9

Willington, I.P., Marten, G.G., 1982. Options for handling stillage waste from sugarbased fuel ethanol production. Resour. Conserv. 8, 111-129. doi:10.1016/01663097(82)90036-0

Woertz, I., Feffer, a., Lundquist, T., Nelson, Y., 2009. Algae Grown on Dairy and Municipal Wastewater for Simultaneous Nutrient Removal and Lipid Production for Biofuel Feedstock. J. Environ. Eng. 135, 1115-1122. doi:10.1061/(ASCE)EE.19437870.0000129

Wu, W., Lu, M., Yu, L., 2011. A new environmentally friendly method for astaxanthin extraction from Xanthophyllomyces dendrorhous. Eur. Food Res. Technol. 232, 463-467. doi:10.1007/s00217-010-1414-4

Wu, Y.H., Yang, J., Hu, H.Y., Yu, Y., 2013. Lipid-rich microalgal biomass production and nutrient removal by Haematococcus pluvialis in domestic secondary effluent. Ecol. Eng. 60, 155-159. doi:10.1016/j.ecoleng.2013.07.066

Xiao, A.F., Ni, H., Cai, H.N., Li, L.J., Su, W.J., Yang, Q.M., 2009. An improved process for cell disruption and astaxanthin extraction from Phaffia rhodozyma. World J. Microbiol. Biotechnol. 25, 2029-2034. doi:10.1007/s11274-009-0104-5

Yang, Y., Kim, B., Lee, J., 2013. Astaxanthin Structure, Metabolism , and Health Benefits. Marine Drugs 2, 1-11.

Yao, H., Du, X., Yang, L., Wang, W., Yang, F., Zhao, C., Meng, X., Zhang, L., Zu, Y., 2012. Microwave-assisted method for simultaneous extraction and hydrolysis for determination of flavonol glycosides in Ginkgo foliage using brönsted acidic ionicliquid aqueous solutions. Int. J. Mol. Sci. 13, 8775-8788. doi:10.3390/ijms13078775

Zhang, D.H., Lee, Y.K., 1997. Enhanced accumulation of secondary carotenoids in a mutant of the green alga, Chlorococcum sp. J. Appl. Phycol. 9, 459-463. doi:10.1023/A:1007902103419

Zhang, Y., Ghaly, A.E., Li, B., 2013. Determination of the exergy of four wheat straws. Am. J. Biochem. Biotechnol. 9, 338-347. doi:10.3844/ajbbsp.2013.338.347

Zhu, D., Shen, S., Wang, G., 2011. An economic assessment of astaxanthin production by large scale cultivation of Haematococcus pluvialis.

doi:10.1016/j.biotechadv.2011.04.001

Zhu, Y., Albrecht, K.O., Elliott, D.C., Hallen, R.T., Jones, S.B., 2013. Development of hydrothermal liquefaction and upgrading technologies for lipid-extracted algae conversion to liquid fuels. Algal Res. 2, 455-464. doi:10.1016/j.algal.2013.07.003 
Zou, T. Bin, Jia, Q., Li, H.W., Wang, C.X., Wu, H.F., 2013. Response surface methodology for ultrasound-assisted extraction of astaxanthin from Haematococcus pluvialis. Mar. Drugs 11, 1644-1655. doi:10.3390/md11051644 